NBER WORKING PAPER SERIES

\title{
CHILDREN'S SCHOOLING AND PARENTS' INVESTMENT IN CHILDREN: EVIDENCE FROM THE HEAD START IMPACT STUDY
}

\author{
Alexander M. Gelber \\ Adam Isen \\ Working Paper 17704 \\ http://www.nber.org/papers/w17704 \\ NATIONAL BUREAU OF ECONOMIC RESEARCH \\ 1050 Massachusetts Avenue \\ Cambridge, MA 02138 \\ December 2011
}

We thank Jay Bhattacharya, Hanley Chiang, David Cutler, David Deming, Mark Duggan, Olivia Mitchell, Michael Puma, Dan Sacks, Todd Sinai, Danny Yagan, and seminar participants at Wharton for suggestions. Gelber acknowledges financial support from the Center for Human Resources, the Risk and Decision Processes Center, and the Zicklin Center for Business Ethics, all at Wharton. Isen acknowledges financial support from the Institute of Education Sciences, U.S. Department of Education, through Grant \#R305B090015 of the U.S. Department of Education. All errors are our own. The views expressed herein are those of the authors and do not necessarily reflect the views of the National Bureau of Economic Research.

NBER working papers are circulated for discussion and comment purposes. They have not been peerreviewed or been subject to the review by the NBER Board of Directors that accompanies official NBER publications.

(C) 2011 by Alexander M. Gelber and Adam Isen. All rights reserved. Short sections of text, not to exceed two paragraphs, may be quoted without explicit permission provided that full credit, including (C) notice, is given to the source. 
Children's Schooling and Parents' Investment in Children: Evidence from the Head Start Impact Study

Alexander M. Gelber and Adam Isen

NBER Working Paper No. 17704

December 2011

JEL No. H31,H52,I21,I28,J13

\begin{abstract}
Parents may have important effects on their children, but little work in economics explores whether children's schooling opportunities crowd out or encourage parents' investment in children. We analyze data from the Head Start Impact Study, which granted randomly-chosen preschool-aged children the opportunity to attend Head Start. We find that Head Start causes a substantial increase in parents' involvement with their children — such as time spent reading to children, math activities, or days spent with children by fathers who do not live with their children - both during and after the period when their children are potentially enrolled in Head Start. We discuss a variety of mechanisms that are consistent with our findings, including a simple model we present in which Head Start impacts parent involvement in part because parents perceive their involvement to be complementary with child schooling in the production of child qualities.
\end{abstract}

\author{
Alexander M. Gelber \\ The Wharton School \\ University of Pennsylvania \\ 1403 Steinberg-Dietrich Hall \\ 3620 Locust Walk \\ Philadelphia, PA 19104 \\ and NBER \\ agelber@nber.org \\ Adam Isen \\ University of Pennsylvania \\ Steinberg-Dietrich Hall \#1400 \\ 3620 Locust Walk \\ Philadelphia, PA 19104-6372 \\ isen@wharton.upenn.edu
}

An online appendix is available at:

http://www.nber.org/data-appendix/w17704 
Parent inputs may have important effects on child outcomes (e.g. Gary Becker and Nigel Tomes 1976; Becker 1981; Becker and Tomes 1986; Petra Todd and Kenneth Wolpin 2003; Bruce Sacerdote 2007). ${ }^{2}$ In analyzing the return to schooling, it is possible to distinguish the direct impact that schooling programs have on children from the indirect impact that is mediated through the effect that schooling has on parent investment in children. If parents have large impacts on their children, these indirect effects may be important. A priori, we do not know the sign of these indirect effects: schooling inputs could crowd out or encourage parent inputs. Furthermore, the degree to which government inputs cause parent inputs to increase or decrease helps to determine the efficiency of government expenditure on schooling: many believe that government-provided schooling may supplant parents' role to some extent. As Becker and Tomes (1986) write in their theoretical analysis of crowdout of parent investment by public expenditure: "Compensatory responses of parents apparently greatly weaken the effects of...some Head Start programs." ${ }^{3}$ Moreover, if investment in children is costly to parents, then estimating the impact of schooling programs on parents' investment is relevant to a full welfare analysis of the programs. These questions are important for understanding the effect of schooling programs on children and the mechanisms through which these effects operate, but there is little empirical work in economics on how schooling programs impact parents' investment in children. ${ }^{4}$

The Head Start Impact Study (HSIS) represents a promising setting for investigating these issues in the context of Head Start (HS). HS is a government program that provides

\footnotetext{
${ }^{2}$ Indeed, parenting is often thought to play an important role in explaining differences in child outcomes across racial and socioeconomic status groups (e.g. Jeanne Brooks-Gunn, Greg Duncan, and Pamela Klebanov 1996), as well as by gender (Marianne Bertrand and Jessica Pan 2011). Randomized control trials of efforts to involve parents in children's lives have often found positive impacts on children, including on children's cognitive scores (Chad Nye, Herb Turner, and Jamie Schwartz 2006).

${ }^{3}$ Becker and Tomes also write that "Government programs may have effects [on parent behavior] by changing rates of return on parent investments in children...However, we have emphasized the redistribution effects of many programs - including Head Start programs...because the redistribution effects are clear, while effects [due to changing the marginal rate of return] are not clear, even in direction...." By "redistribution effects," Becker and Tomes are referring to the compensatory responses of parents that could cause a decrease in parent investment in response to an increase in child schooling. See also Becker and Tomes (1976).

${ }^{4}$ In the education field, concern about the importance of parents has spawned a literature on how to increase parent involvement (e.g. Joyce Epstein 2011). Perry Preschool, the Abecedarian Project, and the Chicago Child-Parent Center Program all sought to involve parents and appear to have achieved large gains for lowincome youth (e.g. Flavio Cunha and James Heckman 2010 or Frances Campbell and Craig Ramey 1994). On the empirical relationship between parent inputs and child endowments, see Anna Aizer and Flavio Cunha (2011), Christina Paxson and Norbert Schady (2007), Sandra Black, Paul Devereux, and Kjell Salvanes (forthcoming), or Mark Rosenzweig and Junsen Zhang (2009).
} 
preschool to low-income children. Like many schooling programs, one specific goal of HS is to increase parent involvement with their children. First-time applicants to HS for the fall of 2002 were randomly selected by HSIS for access to HS. ${ }^{5}$ HSIS followed the children and their parents for several subsequent years, collecting information on a variety of child and parent outcomes both during and after the period when children were potentially enrolled in HS (U.S. Department of Health and Human Services 2010, henceforth HHS 2010). A wide range of measures of parent involvement in children's lives are available, including parents' responses to questions on time spent with children and various parent-child activities, as well as teachers' and HSIS interviewers' reports of parent involvement. By "parent involvement" we mean activities that parents undertake that require time or effort and directly involve their children.

We find that in response to children's HS access, parents are substantially and statistically significantly more involved with their children along a wide variety of dimensions, particularly along those dimensions that appear to be investments in child human capital. For example, parents read to their children more often, and for a longer amount of time at each sitting, when their children have access to HS than when they do not. Even after children are no longer attending HS, their parents appear to invest more in them. For example, fathers not living in the home with their children spend more days visiting their children when their children had been in HS, even after these children are no longer enrolled in HS. When we use access to HS as an instrument for HS enrollment, we find that the point estimates of the mean increase in parent investment in children is $15 \%$ of a standard deviation while children are potentially enrolled in Head Start and 6\% of a standard deviation after they are potentially enrolled. We show that these results are robust to a wide variety of alternative empirical choices. Teachers and interviewers also report greater parent involvement in the HS group than in the control group, suggesting that the increase in measured parent involvement is not simply due to self-reporting by parents. These findings

\footnotetext{
${ }^{5}$ HSIS randomly assigned a sample of 3- and 4-year-old HS applicants either to the "HS group" or to the control group. The HS group was allowed to enroll in HS at the HS center to which they applied, while the control group was not granted access to HS at that center (but may have received similar services through other available programs chosen by their parents-in occasional cases through other HS centers). Even though a minority of the control group still managed to attend other HS centers, we often refer to those in the treatment group as those who had "HS access" or "HS eligibility." A "program" is a contractor with the government that runs one or more "centers." A "center" refers to a specific location containing a number of HS classrooms.
} 
on parent involvement during and after the experiment constitute the core of the paper. Our results show that HS is successful in its goal of increasing parent involvement with children. Intriguingly, we find that across HS programs, those programs that raised children's cognitive test scores more also tended to raise parents' involvement with their children more. We discuss a variety of mechanisms that are consistent with our findings, including a simple model we present in which Head Start impacts parent involvement in part because parents perceive their involvement to be complementary with child schooling in the production of child qualities.

While there is little attention to the relationship between parent and schooling inputs in the economics literature, our analysis builds on many important studies that have empirically examined aspects of HS and its impact on children. ${ }^{6}$ HHS (2010) investigates data from the HSIS, focusing primarily on the impact of HS on children's cognitive and noncognitive test scores. As we describe later, HHS (2010) also investigates certain measures of parent involvement with their children but finds very limited evidence that parent involvement was impacted. HSIS collected a rich set of data that are not analyzed in HHS (2010) but that we analyze in this study; these data show a strong impact of Head Start on a wide variety of parent involvement outcomes. Relative to HHS (2010), we investigate the impact of HS on an order of magnitude more parent outcomes; we use several new methods to analyze the data, including new econometric approaches; we explore the mechanisms through which the effect on parent involvement may operate; and we place our results in a possible theoretical context. ${ }^{7}$

HHS (2010) follows previous work by Janet Currie and Duncan Thomas (1995), who find that HS improves children's cognitive scores while they are enrolled in HS but that these gains fade over time for blacks. Eliana Garces, Thomas, and Currie (2002) find evidence of long-run impacts of HS on school attainment, earnings, and criminal behavior. Jens Ludwig

\footnotetext{
${ }^{6}$ Jishnu Das, Stefan Dercon, James Habyarimana, Pramila Krishnan, Karthik Muralidharan, and Venkatesh Sundararaman (2011) examine the relationship between schooling and parent expenditures in the context of India. Andrew Houtenville and Karen Conway (2008) estimate a production function that includes both schooling and parent inputs. Fuhua Zhai, Jane Waldfogel, and Jeanne Brooks-Gunn (2011) use nonexperimental variation to examine the effect of HS on the maltreatment of children by parents. Randomized evaluations of the Even Start family literacy program have found little evidence that it impacted parent involvement with children (e.g. St. Pierre et al. 1995). HHS (2010) provides an extensive review of literature on the impact of HS on children.

${ }^{7}$ Appendix B describes in detail the differences and small number of similarities between our paper and HHS (2010).
} 
and Douglas Miller (2007) find that HS has persistent positive impacts on children's future schooling and mortality. David Deming (2009) also finds long-run effects of HS on children's skills. ${ }^{8}$ It is difficult to reconcile the combination of fade-out of test score gains with long-run impacts of HS, though similar results have been found in other contexts $(e . g$. James J. Heckman, Lena Malofeeva, Rodrigo Pinto, and Peter Savelyev 2010; Raj Chetty et al. 2011; Susan Dynarski, Joshua Hyman, and Diane Whitmore Schanzenbach 2011); persistent parent investment could be one mechanism through which the long-run impacts are mediated.

The paper proceeds as follows. Section I describes the Head Start Impact Study. Section II lays out the basic empirical approach of the paper. Section III presents our basic results and various robustness checks. Section IV discusses the results and suggests several mechanisms that may underlie them. Section V concludes.

\section{HS and the Head Start Impact Study}

Head Start is a program of the U.S. Department of Health and Human Services that provides education, health, nutrition, and parent involvement services to low-income children and their families. In 2009, HS provided services to 904,153 children, $54 \%$ of whom were four years old or older, and $46 \%$ of whom were three years old or younger. Services were provided by 1,591 programs operating 49,200 classrooms. The average per-child expenditure was $\$ 7,600$. Eligibility is largely income-based-families typically must earn less than $130 \%$ of the federal poverty level in order to be eligible — though each local program includes other eligibility criteria, such as child disability status.

During the spring and summer of 2002, eligible first-time 3- and 4-year-old applicants to HS for the Fall of 2002 were randomly selected by HSIS for access to HS. We refer to HHS (2010) for a much more detailed description of the experiment, but we briefly describe several of its main features here. The study selected children from 84 nationally representative HS programs, corresponding to 353 HS centers. HSIS collected information on a variety of child and parent outcomes for several subsequent years in both groups. The "HS group" was allowed to enroll in HS, while the "control group" was not granted access to HS (but may have received similar services through other available programs chosen by their

\footnotetext{
${ }^{8}$ Others such as Katherine Magnuson, Christopher Ruhm, and Jane Waldfogel (2004) have studied the effect of prekindergarten on school performance. HHS (2002) studies Early Head Start for infants and toddlers. Chloe Gibbs, Ludwig, and Miller (2011) also discuss the long-run impact of Head Start on children.
} 
parents-in occasional cases through other HS centers). ${ }^{9}$ The treatment group contains at least some non-missing observations on 2,479 children, and the control group contains at least some non-missing observations on 1,582 children. ${ }^{10}$

HSIS collected information on these children and on a wide variety of measures of their parents' activities in the Fall of 2002 (subsequent to their enrollment in HS) and in the Spring of 2003, 2004, 2005, and 2006. HSIS interviewed parents-almost always mothers-in an in-home interview. The questions asked of parents in the HSIS in-home interview, listed in Appendix Table 1 (available as an Electronic Appendix), vary somewhat across survey years but also contain many questions that overlap across years. The children were grouped in two cohorts, the "3-year-old cohort" (2,449 children) and the "4-year-old cohort" (1,993 children). The 3-year-old HS cohort could first attend HS in the Fall of 2002, but both treatment and control group members from this cohort were allowed to enroll in HS in the Fall of 2003. ${ }^{11}$ In the 3-year-old cohort, the fraction of the treatment group that enrolled in HS was $88 \%$ in the Fall of 2002 and $63 \%$ in the Fall of 2003 . The fraction of the control group that enrolled in HS was 19\% in the Fall of 2002 and $49 \%$ in the Fall of 2003. Subsequent to the end of the 2003-4 school year, children in the 3-year-old cohort could no longer be enrolled in HS. The 4-year-old HS cohort could first attend HS in the Fall of 2002. Subsequent to the 2002-3 school year, the 4-year-old cohort could no longer be enrolled in HS. In the 4-year-old cohort, the fraction of the treatment group that enrolled in HS was $83 \%$ in the Fall of 2002, and the fraction of the control group that enrolled in HS was $16 \%$ in the Fall of $2002 .^{12}$

Table 1 displays summary statistics for the main demographic variables in the experiment. The means of these variables are balanced between the treatment and control groups: in no case is the mean in the treatment group statistically significantly different from the mean in the control group at the $10 \%$ level. ${ }^{13}$ The experiment's randomization therefore

\footnotetext{
${ }^{9}$ We often refer to the HS group as the "treatment group."

${ }^{10}$ Data are missing for part of the sample; we discuss this issue in greater detail below.

${ }^{11}$ The study follows each cohort through the first grade, so the 4-year-old cohort is followed through Spring 2005, while the 3-year-old cohort is followed through Spring 2006.

$129 \%$ of the treatment group and $23 \%$ of the control group is in non-Head Start center-based care (such as a child care center, preschool, or pre-kindergarten program), while those not in any center-based care are typically in daycare homes or cared for by their parents or other relatives.

${ }^{13}$ This holds true whether comparing the raw means of the treatment and control group or comparing the means when the observations are weighted by their sample weights. HHS (2010) only examines balance after weighting by parent weights that adjust for non-response and other factors.
} 
appears valid. Nearly half of the sample of children is male. Just over a third is Hispanic; just under a third is black; and slightly under a third is white or another race. Just under $70 \%$ speak English at home, and just over 30\% speak Spanish. Almost 70\% have a mother who was born in the U.S. Children are 3.92 years old on average, mothers are 28.9 years old on average, and fathers are 29.11 years old on average. Appendix Table 1 shows the means and standard deviations of the full set of dependent variables on parent involvement used in the paper. While a full discussion of these 87 variables is beyond the scope of the paper, it is worth noting that these summary statistics show that parents on average report being quite involved with their children's lives along a wide variety of dimensions. For example, the summary statistics show that in the "During" ("After") period, parents spent a mean of 91.81 (108.53) minutes per week reading to their children; fathers living outside the home spent a mean of 6.10 (5.02) days per month with their children; 19\% (23\%) of parents visited an art gallery or museum with their children; and $45 \%$ of parents track the learning and development of their children using stars or stickers to chart their progress in the "During" period. $^{14}$

\section{Basic Empirical Approach}

In our main specification, we use an instrumental variables (IV) procedure:

$$
\begin{aligned}
& \text { HeadStart }_{i p}=\alpha_{0}+\alpha_{1} T_{i p}+\mathbf{X}_{\mathbf{i p}} \boldsymbol{\alpha}+v_{i p} \\
& Y_{i p}=\beta_{0}+\beta_{1} \text { HeadStart }_{i p}+\mathbf{X}_{\mathbf{i p}} \boldsymbol{\beta}+u_{i p}
\end{aligned}
$$

(1) is the first stage equation, and (2) is the second stage. In (1), HeadStart ip is a dummy that equals 1 if the child is enrolled in HS and 0 otherwise; $T_{i p}$ is a dummy variable measuring whether individual $i$ in program $p$ is part of the treatment or control group in the experiment; $\alpha_{0}$ is a constant; $\alpha_{1}$ is the first stage coefficient on treatment; and $\boldsymbol{\alpha}$ is a vector of coefficients on the control variables. The two-stage least squares estimate of $\beta_{1}$ identifies a local average treatment effect: the causal impact of Head Start among the subset of individuals who would enroll in Head Start on winning the lottery and would not enroll in Head Start without winning the lottery (i.e. the compliers). The first stage of this IV procedure yields a

\footnotetext{
${ }^{14}$ We define the "During" period as the period while children are still potentially eligible for HS (Fall 2002 and Spring 2003), and we define the "After" period as the period after children are potentially eligible for HS (Spring 2004-2006). We exclude data from the 3-year-old cohort observed in Spring 2004 from both the During and After periods because some of the 3-year-olds were still enrolled in HS during this period, as described above. When we include these data alternatively in the "During" period or the "After" period, we obtain similar results to those shown (slightly smaller than those shown in the former case, and slightly larger than those shown in the latter case).
} 
coefficient of 0.68 on the dummy representing HS access. The first-stage F-statistic is typically near 500. In (2), $Y_{i p}$ is an outcome variable for individual $i$ in HS program $p$. These outcomes could represent a measure of parent involvement with their children (such as reading or math activities with children), a dummy variable for the mother's labor force participation, or other relevant outcomes. In some cases, we also run the following reduced form regression:

$$
Y_{i p}=\beta_{0}+\beta_{1} T_{i p}+\mathbf{X}_{\mathbf{i p}} \boldsymbol{\beta}+u_{i p},
$$

in which we regress the outcome directly on the treatment dummy. $\mathbf{X}_{\mathbf{i p}}$ is a vector of controls for demographic variables; $\beta_{0}$ is a constant; $\beta_{l}$ is the coefficient of interest on the treatment dummy; $\beta$ is a vector of coefficients on $X$; and $\varepsilon$ is an error. Except where otherwise noted, we cluster the standard errors at the level of the HS program.

In the regressions in the main tables in the paper, we typically use two-stage least squares to estimate (1) and (2). In Appendix Table 2, we report the reduced form regression for each outcome, in which we regress the outcome directly on the treatment dummy, using the technique appropriate to the form that the dependent variable takes (ordinary least squares (OLS) for continuous outcomes, probit for binary outcomes, or ordered probit for multiple ordered outcomes). In order to form the IV estimates in Appendix Table 2, the simplest approach is simply to compute the Wald estimate by dividing the estimated effect of treatment by 0.68 (i.e. multiplying by 1.47 ); as we show, the results of the reduced form and first stage are extremely similar with and without covariates. The results of the two-stage least squares regressions with covariates are always nearly identical to this Wald estimate reported in Appendix Table 2. Since the first stage is so strong, it is unsurprising that the significance levels on the coefficients are always the same when we run the reduced form as when we run the IV.

Missing data represents a potential challenge in this setting. In $17.48 \%$ of the sample, data are always missing on the dependent variable due to non-response by an individual. ${ }^{15}$ HHS (2010) weights the data so that it is nationally representative of the HS student population. Our basic results, reported in the main tables, use their final sample weights. We

\footnotetext{
${ }^{15} 22.10 \%$ of all observations are missing in the control group, and $14.24 \%$ are missing in the treatment group. Note, however, that the fact that the treatment is uncorrelated with demographics for non-missing observations (as shown in Table 1) is suggestive of the possibility that treatment is uncorrelated with unobservables for nonmissing observations.
} 
additionally address the presence of missing data in three ways. First, we perform a slightly different imputation procedure. We match non-missing individuals to their nearest missing neighbor using a propensity score calculated using all of the demographics in Table 1 collected in the initial HS application and their interactions, plus dummies for HS Centers. We then replace missing data with data on the nearest non-missing neighbor. These results, which we show in Table 4, are almost always similar to the results we obtain from using the sample weights developed by HHS (2010); in those cases in which they diverge, the alternative results almost always show slightly larger effects of treatment on parent involvement than the results based on the weights in HHS (2010). Second, in Table 4 and Appendix Table 2, we calculate the bounds on the treatment effect proposed by David S. Lee (2009), which bound the effect of treatment when data are missing in an experimental design. In many cases, the Lee lower bounds on the treatment effects we estimate also indicate positive effects of treatment on parent involvement. Third, we show regressions in Table 4 that do not use weights.

\section{Effect of HS Enrollment on Parent Inputs}

\section{a. Effect of HS Access on Parent Inputs}

Appendix Table 2 shows the effect of treatment on each dependent variable relating to parent involvement with children. ${ }^{16}$ The regression results in Appendix Table 2A show a strong positive and significant impact of treatment on most measures of parent involvement with children while the experiment was in progress, in Fall 2002 and Spring 2003. Broadly speaking, categories of activities that are typically positively affected include reading/writing-/vocabulary-related activities (such as "practice writing the alphabet"), math-related activities (such as "play math-related games"), tracking the learning and development of the child (such as "by keeping notes about (his/her) behavior or progress"), undertaking cultural activities with the child (such as "visited an art gallery, museum, or historical site"), setting rules for children (such as "rules or routines about how many hours of TV allowed to

\footnotetext{
${ }^{16}$ We put these results in the appendix for convenience, not because we wish to suggest that they are much less important to the paper than the results we show below in Table 2 and elsewhere. Indeed, we consider the results in Table 2 to be convenient elaborations on the results in Appendix Table 2. Since the number of dependent variables in question is very large, it is less unwieldy to present these results in an appendix than in the main text. In Table 3 of the main text, we discuss selected outcomes of interest from Appendix Table 2.
} 
watch"), and qualitative features of parenting practices (such as "I encourage my child to be curious, to explore, and to question things"). ${ }^{17}$

Appendix Table 2B shows the results of regression (1) when the dependent variables are instead measured after the experiment occurred, in Spring 2004 and Spring 2005 for the 4-year-old-cohort, and in Spring 2005 and Spring 2006 for the 3-year-old cohort. The set of dependent variables is different than those measured in the During period, because certain variables were measured only during the period of the experiment (such as certain math activities or activities relating to tracking the learning and development of the child), and other variables (such as days the mother spent volunteering in the child's school) are measured only after the experiment occurred. The results show that most parent inputs are estimated to have increased in response to the treatment. ${ }^{18}$ However, the point estimates are usually smaller than the estimates in the During period (for those variables that are observed in both periods), and fewer estimates are statistically significantly different from zero.

Several categories of variables are often positively and statistically significantly impacted by treatment in the After period: math activities, father inputs, rules set by parents, and qualitative features of parenting practices.

\section{b. Aggregating the results}

It is additionally of interest to assess whether treatment "usually" had a positive impact on parent involvement with children. We do so in three ways, described in greater detail below. Each of these approaches is of interest, but each one also has limitations. By providing a compilation of evidence that all supports the same conclusion, we attempt to address concerns that might arise about any of these approaches considered on its own. All of these analyses point to the same conclusion: that parent involvement with children generally increased in response to treatment.

First, we assess how many of the estimated impacts of treatment on parent involvement are positive and significant. Of the 65 effects estimated in the During period, 24 are positive and significant at the $1 \%$ level, 8 are positive and significant at the $5 \%$ level, 12

\footnotetext{
${ }^{17}$ HHS (2010) finds that HS eligibility increases a "cultural enrichment" scale, specifically for the 3-year-old cohort in Spring 2003 (significant at the 5\% level after correcting for multiple comparisons), and that parents were more likely to read to children (specifically for the 3-year-old cohort in Spring 2003, significant at $10 \%$ after correcting for multiple comparisons). It finds insignificant impacts on several other outcomes.

${ }^{18}$ When we limit the set of dependent variables in Fall 2002 and Spring 2003 only to those that are only observed in Spring 2004, Spring 2005, and Spring 2006 (or vice versa), the results show positive and extremely similar and significant impacts of treatment.
} 
are positive and significant at the $10 \%$ level, and 20 are positive and insignificant. One is negative and insignificant ( $\mathrm{p}>.40),{ }^{19}$ and none is negative and significant. Of the 62 effects estimated in the After period, 8 are positive and significant at the $1 \%$ level, 6 at the 5\% level, 5 at the $10 \%$ level, and 34 are positive and insignificant. 9 are negative and insignificant, and none is negative and significant. ${ }^{20}$

Second, in order to make the outcome variables comparable with each other, we follow the method of Jeffrey Kling, Jeffrey Liebman, and Lawrence Katz (2007). ${ }^{21} \mathrm{We}$ normalize each of the dependent variables by subtracting its mean and dividing by its standard deviation in the control group. We calculate the coefficient estimates reported in Table 2 by averaging the coefficient estimates across the regressions for all parent involvement outcomes:

$$
\Sigma_{j}(1 / J)\left(\beta_{j} / \sigma_{j}\right)
$$

where $j$ indexes outcomes, $J$ is the total number of outcomes, $\beta_{\mathrm{j}}$ represents the coefficient on treatment for the $j$-th outcome, and $\sigma_{j}$ represents the standard deviation of the $j$-th outcome in the control group. Following Kling, Liebman, and Katz, we calculate the standard error by running an IV regression pooling all of the data from all of the different outcomes. ${ }^{22}$ In particular, we pool the normalized data across all outcome variables and then regress these pooled outcomes on a dummy variable for treatment. ${ }^{23}$ We refer to this procedure as "normalized IV." The normalized analysis is useful because it allows us to form an aggregate measure of the magnitude of the effect of treatment on parent outcomes. Nonetheless, this analysis has limitations: it implicitly weights each outcome equally and uses a functional form that is not appropriate for ordered categorical outcomes.

\footnotetext{
19 "Has your family received any child support payments from (his/her) father?"

${ }^{20}$ We exclude the parent medical involvement outcomes in Appendix Table 2 (such as taking the child to a vision screening) from this aggregation and the two other aggregation methods we discuss below, since medical outcomes are arguably less closely related to parent involvement. We include medical outcomes in a robustness check. Note that 3 of 4 medical outcomes are significantly positively affected by treatment in the During period, and 1 of 4 is marginally significantly positively affected in the After period.

${ }^{21}$ Some of the variables are binary; others are represented as multiple ordered outcomes; and still others can take on any positive value.

${ }^{22}$ We obtain similarly significant results when we do not first normalize the dependent variable for continuous outcomes in this way.

${ }^{23}$ We pool all outcomes, leading to a large sample size, and cluster the standard errors at the program level. When we instead take the mean of normalized parent inputs for each individual and run a regression of mean normalized parent inputs on the treatment dummy (with as many observations as individuals), the results are very similar, with very similar significance levels.
} 
Row A of Table 2 shows these results, which demonstrate a strong positive and significant mean effect of treatment on the outcomes. The point estimates suggest that pooling across all measures of parent outcomes, treatment raises parent involvement with their children by an average of $15 \%$ of a standard deviation in the During period and $6 \%$ in the After period, both of which are significant at the $1 \%$ level. ${ }^{24}$ These results are essentially unchanged by adding controls in Columns 2 and 5. In Figure 1, for each individual, we calculate the mean of the normalized parent involvement measures and plot the distribution of this variable in the treatment group (upper line) and control group (lower line). This figure shows that Head Start appears to have had the biggest impact on parent involvement in the lowest quantiles, and that it had a bigger impact in the During period than the After period. $^{25}$

The other rows of Table 2 show this analysis aggregated by category of parent involvement (created using the variables in each category listed in Appendix Table 2). In the During period, reading activities, math activities, tracking the learning and development of the child, and parent use of rules or routines are each significantly positively affected at the $1 \%$ level. Qualitative features of parenting effort and other (often cultural) activities are each significantly positively affected at the $5 \%$ level. It is notable that some of the impacts that are quantitatively largest are found for those categories of involvement that seem most likely to impact child human capital directly (e.g. reading activities, math activities, and tracking the child's development). In the After period, math activities and rules or routines are each significantly positively impacted at the $1 \%$ level, and teacher and interviewer reports of parent involvement and qualitative features of parenting effort at the $5 \%$ level. ${ }^{26}$

\footnotetext{
${ }^{24}$ We obtain results with similar significance levels throughout the pooled analysis in the paper when we remove certain dependent variables from the analysis that arguably may not reflect greater parent involvement with their children, including when we remove all of the variables relating to rules set by parents, or when we remove all of the variables relating to "qualitative parent practices" such as "I encourage my child to be curious, to explore, and to question things."

${ }^{25}$ The Kolmogorov-Smirnov test shows that the treatment and control distributions are significantly different in the During period $(\mathrm{p}<.001)$ and in the After period $(\mathrm{p}<.05)$.

${ }^{26}$ Note that since some questions were asked in the After period that were not asked in the During period and vice versa, each category of involvement sometimes refers to a different set of questions in each period. For example, there are no uniform teacher reports of parent involvement in the During period (since many children, especially in the control group, did not have teachers before kindergarten), whereas they reported three measures of parent behavior in the After period; the interviewer-reported variable "A variety of learning materials are available" was asked in both periods. Please see Appendix Tables 1 and 2 for a list of all of the variables included in each category and period.
} 
Third, we examine whether across all regressions, the estimated impact of treatment on the outcomes is jointly significant and different from zero, by performing a generalized Hausman test for joint significance of the coefficients across all of the reduced form regressions considered in Appendix Table 2, which include probit regressions (for the binary dependent variables), ordered probit regressions (for the 3-, 4-, 5-, and 6-category outcomes), and ordinary least squares regressions (for the continuous outcomes). These results in Table 2 again show that across all specifications, the coefficients are jointly significant at the $1 \%$ level, in both the During and After periods. One limitation of this analysis is that the generalized Hausman test examines joint significance with respect to the null that all of the coefficients are equal to zero. If a coefficient is negative, this would (at an intuitive level) "contribute" to the joint significance level of the coefficients. However, as noted above, the estimated coefficient is negative in only one case in the During period (and is insignificant in this case). Despite this limitation, we show the generalized Hausman test because it allows us to cumulate results while running the specifications that are most appropriate to ordered or binary dependent variables. $^{27}$

When we examine the dynamics of the effect on parent involvement, we find no evidence that the impact of HS enrollment on parent involvement fades over the course of the period after children are potentially enrolled in HS. When we estimate the IV treatment effect using data only on children in 2004, 2005, or 2006, we estimate coefficients (standard errors) on the HS enrollment dummy of .06 (.03), .05 (.02), and .06 (.03), respectively, all significantly different from zero at the 5\% level. The time trend over 2004-6 interacted with treatment is insignificantly different from zero $(\mathrm{p}>0.40)$. When we estimate the IV treatment effect in the After period using data only on children currently in kindergarten or in first

\footnotetext{
${ }^{27}$ Factor analysis represents a different approach to aggregating the dependent variables, which we explore in Appendix Table 3. One benefit of factor analysis is that it recovers a number of latent parent input variables, rather than implicitly weighting each outcome equally. We ran a factor analysis by first pooling all of the dependent variables together and extracting their common variability, and then using the Kaiser criterion to keep factors whose eigenvalues are greater than 1 . We then regressed each of the factors on HS attendance and instrument for HS attendance with treatment status. The results show a strong positive and significant impact of treatment on most of the factors considered individually in the During period: the estimated impact of treatment is positive and significant at the $1 \%$ level for two of the factors; positive and significant at the $5 \%$ level for one of the factors; and positive and insignificant for two of the factors. In the After period, the outcomes are grouped into nine factors. The estimated impact of treatment is positive and significant at the $5 \%$ level for three of the factors; positive and significant at the $10 \%$ level for two of the factors; positive and insignificant for three of the factors; and negative and insignificant ( $p>.40)$ for one of the factors. In both the During and After periods, when we pooled the factors together, we found larger and more significant mean effects of HS on the factors than the effects we found in the other analyses.
} 
grade, we estimate coefficients (standard errors) on HS enrollment of .05 (.02) and .06 (.02), respectively, both significantly different from zero at the $5 \%$ level. The time trend interacted with treatment is again insignificantly different from zero for these groups $(\mathrm{p}>0.40){ }^{28}$

\section{c. Particular outcomes}

In Table 3, we examine particular outcomes of interest. We do so not because we believe that these are always more important than other outcomes listed in Appendix Table 2, but rather in order to highlight some outcomes of particular interest, and to give show more specific examples in the main text of the sorts of outcomes that respond to treatment. As noted above, parents tend to increase their reading-related activities with their children. Column 1 shows that the number of times parents read to children increases significantly in response to HS enrollment in the During period, and Column 2 shows that the amount of time a parent reads to a child per sitting increases significantly, as well. By multiplying together the number of times a parent read to a child by the amount of time spent reading per sitting, we can form a measure of the amount of time a parent spent reading to their child. ${ }^{29}$ More broadly, we could consider this to be an imperfect proxy for parent-child teaching time. We find a positive, large, and highly significant effect of treatment on the estimated amount of time spent reading with children in the During period: the increase in amount of time spent reading in response to treatment is 18.71 minutes ( $20.4 \%$ of the mean of this variable), with a standard error of 4.79 minutes.

Days spent with the father, asked among children whose fathers do not live in the home, represents a second measure of the time parents spend with children. Interestingly, in Column 4 of Table 3, days spent by the father with the child increases a striking amount after the experiment is over, with a point estimate of the effect of treatment of .94 days (18.7\% of the mean, with a standard error of .45 days); in the During period, days spent by the father with the child increases insignificantly, with a point estimate of the effect of treatment of 62 days (10.2\% of the mean, with a standard error of .58 days).

\footnotetext{
${ }^{28}$ When we estimate the impact of HS enrollment on parent involvement just in Fall 2002, the coefficient (standard error) on HS enrollment is .12 (.02), and in Spring 2003, it is .19 (.03), both significantly different from zero at the $1 \%$ level, and significantly different from each other at the 5\% level. It therefore appears that parents increase their involvement over the course of the During period.

${ }^{29}$ How many times per week a parent read to a child is "topcoded" at "every day." In the results reported here, we assume that "every day" indicates that a parent read to a child exactly 7 times in the past week. The results are not sensitive to alternative assumptions.
} 
In Column 5, we show an example of the finding that parent involvement in children's math activities rises in response to Head Start enrollment (in this case "practicing math concepts using dance or acting out stories"). Column 6 shows an example of the finding that culturally enriching activities parents undertake with their children tend to rise in response to Head Start enrollment (in this case "taking a child to an art gallery, museum, or historical site"). Column 7 shows an example of the finding that parents track child development more in response to Head Start enrollment (in this case "by keeping notes about the child's behavior or progress"). Throughout these regressions, it is typical that the estimated positive effects on parent involvement are larger and more significant in the During period than in the After period.

Most of the results are based on parents' self-reports of their activities, but it is possible that they incorrectly self-report greater levels of involvement in response to HS access. For example, parents could have felt more pressure to report investing in their children or perceive greater involvement purely as a result of HS access. If not only parents but teachers and interviewers report greater parent involvement, we can have more confidence that parents are correct in reporting greater involvement. Column 8 of Table 2 shows that in the During and After periods considered separately, the interviewer's response to the question "A variety of learning materials are available" responds positively but insignificantly to treatment. However, when we pool results from the During and After periods, this coefficient increases to .072 (with a standard error of .032, implying that the coefficient is significantly different from zero at the $5 \%$ level). We also find some evidence that reports of parent involvement by children's kindergarten and first-grade teachers increased as a result of HS access, contained in the section of Appendix Table 2 entitled “Teacher and Interviewer-Reported Parent Involvement." Two of the estimates are insignificant, but a third estimate, of the effect of treatment on a dummy measuring parents' responses to the question "Have parents met with teacher and special needs team for special needs children," is large, positive, and significant at the 5\% level.

\section{d. Other econometric approaches}

In Appendix Table 2, we report each regression separately for many outcome variables and calculate standard errors separately for each of these regressions. One concern about this approach is that we consider multiple outcome variables but do not correct the 
standard errors for multiple comparisons. While we have aggregated results across regressions in a number of ways that are not subject to this criticism, we additionally address this issue by applying the Holm-Bonferroni procedure to our estimates. In Appendix Table 2, for each estimate, we report the p-value associated with the Holm adjustment in Column 4, which we view as a conservative-if anything overly conservative-approach to estimating the standard errors. Even after performing the Holm adjustment, 13 of the outcomes in the During period are estimated to have been significantly increased by the treatment at the $1 \%$ level, 3 at the $5 \%$ level, and 6 at the $10 \%$ level.

As noted above, data are always missing for $17.48 \%$ of the sample due to nonresponse. In addition to the alternative imputation procedure for missing data discussed above, we address missing data by calculating for each variable the lower bound on the treatment effect implied by the Lee (2009) trimming procedure and report it in Column 5 of Appendix Table 2. These lower bounds are positive for 22 out of 63 outcome variables in the During period, indicating that the effect of treatment on these measures of parent involvement is positive even in the Lee (2009) "worst case" scenario. ${ }^{30}$

Table 4 shows various robustness checks. Column 1 shows the results of reduced form OLS regressions (3) for the pooled analysis analogous to Column 1 of Table 2. Column 1 of Table 4 verifies the claim that the results of the IV regressions in Table 2 are extremely similar to the analogous results in Table 4 multiplied by $1 / 0.68=1.47$ (where 0.68 is the firststage coefficient in the IV regressions). Moreover, the significance levels in the OLS regressions are very similar to the significance levels in the IV regressions. Column 2 shows that "jackknife weights," which account for the uncertainty in the sampling of programs included in the analysis in order to make the sample ostensibly nationally representative, yield results extremely similar to the basic results. Column 3 shows the Lee lower bound on

\footnotetext{
${ }^{30}$ Note that only 20 out of 63 of the outcomes in the Appendix are listed as having a positive Lee lower bound, but that in fact 22 are positive because we round two numbers to zero. In counting these 22 outcomes, we exclude medical variables since we exclude these from the main analysis (but note that the coefficients on HS have a positive Lee lower bound for all of these medical variables, so that they would increase the total number of positives to 26 if included in the analysis). These Lee bound results suggest that missing data in fact is an important issue in interpreting the results, but they further suggest that the main result-that there is strong evidence that many parent inputs rise when children are eligible for HS - ultimately survives a correction for missing data. The top portion of the distribution trimmed from the sample varies across outcomes, and therefore examining the bounds on each individual outcome separately understates the degree to which we can bound the results across all outcomes. Consistent with this, when we pool all outcomes together and run the trimming procedure, the Lee lower bound is statistically significantly greater than zero in the During period (see Table 4 Column 3).
} 
the reduced form estimates in the main specification in Table 2 Row A. The lower bound on the treatment effect in the During period is 0.04 and is significantly different from zero at the $5 \%$ level (though the lower bound on the treatment effect in the After period is -0.01 and is insignificantly different from zero). ${ }^{31}$

In Column 4 of Table 4, we show the results when we run the main specification from Table 2 but instrument for whether a child enrolled in any center-based care, which includes HS enrollment as well as preschool, pre-kindergarten programs, or other child care centers. Doing so decreases the coefficient on the treatment dummy in the first stage regression (1) but does not affect the coefficient on the treatment dummy in the reduced form (3), and thus the estimated coefficient on HS enrollment increases slightly relative to the baseline specification. In Column 5, we include four medical outcomes in the analysis, such as whether the parent took the child to a routine doctor's appointment, which have been otherwise excluded from the analysis. Column 6 shows the results from the main specification without weights, as most other field experiments do. Column 7 shows the results from the main specification when we use our alternative weighting procedure to address missing data, as we describe more fully above and in Appendix A. The results are again extremely similar to the basic results.

We analyzed whether the impacts of HS on parent involvement were different across demographic groups and found no evidence of significantly different impacts across any of the different subsamples of children that we examined: whether or not the father was at home; male or female children; Fall 2002 income level of the parents; number of siblings; ${ }^{32}$ or the 3- or 4-year-old cohorts. The separate analysis of the 3- and 4-year-old cohorts is important because in the 3-year-old cohort, children in the treatment group on average spent 0.83 years more in HS than children in the control group, whereas the 4-year-old cohort, children in the treatment group on average spent 0.67 years more in HS than children in the control group. Thus, it is unsurprising that we find relatively similar impacts of treatment on these cohorts. When we examine each of the outcomes in Appendix Table 1 separately, we find only one out of 65 outcomes for which the effect of treatment is significantly different at the 5\% level in the 3-year-old and 4-year-old cohorts in the During period and none of 62

\footnotetext{
${ }^{31}$ The Lee lower bound in the After period is positive when we include medical variables in the analysis.

${ }^{32}$ Becker and Tomes (1976) raise the possibility that parents could respond to an education program for a given child by spending more time or money on other children in the family.
} 
outcomes that is significantly different at the $5 \%$ level in the two cohorts in the After period. ${ }^{33}$ These considerations all suggest that pooling data from the 3 -year-old and 4-yearold cohorts is appropriate.

In order to address this issue further, in Column 8 of Table 4 we additionally run a regression in which we regress parent inputs on a variable measuring the total amount of time over which a child was exposed to HS, and we instrument for this variable using the treatment dummy interacted with dummies for the 3- and 4-year-old cohorts. This specification implicitly recognizes that the treatment occurs on average for a slightly different total period of time for children in these different cohorts. The results are essentially identical to the basic results.

\section{e. Other outcomes}

Appendix Table 4 shows the estimated impact of HS on other relevant outcomes. It shows that HS had a positive and significant effect on child cognitive and non-cognitive scores in the During period ( $\mathrm{p}<.01$ and $\mathrm{p}<.10$, respectively), which is in the same vein as the results in HHS (2010). HS had a small and insignificant impact on cognitive and noncognitive scores in the After period, though the point estimates are still positive. HS had an insignificant impact on the probability that the father is in the home and the probability that a child is special needs in both the During and After periods, which are relevant in interpreting the results relating to father involvement and special needs children.

\section{Discussion}

This section states and explores several exclusive hypotheses that could account for the impact of Head Start on parent involvement. ${ }^{34}$ First, specific features of Head Start programs, such as the extent to which Head Start centers encourage parents to volunteer in the centers, could in turn encourage parents to be more involved with their children. Second (third), parents could perceive their involvement with their children as complementary to observed (unobserved) changes in child characteristics, such as cognitive or non-cognitive

\footnotetext{
${ }^{33}$ When we normalize all outcomes and examine all outcomes pooled (as in Column 1 of Table 2) and for all years of the data pooled together, we find that treatment had a 0.012 larger impact in the 4-year-old cohort than in the 3-year-old cohort, with a standard error of 0.025 , implying an insignificant difference between the groups. When we run these regressions in the During period, we find that treatment had a 0.016 larger impact in the 3year-old cohort than in the 4-year-old cohort, with a standard error of 0.036 . When we run these regressions in the After period, we find that treatment had a 0.018 larger impact in the 4-year-old cohort than in the 3-year-old cohort, with a standard error of 0.030 .

${ }^{34}$ These hypotheses are not mutually exclusive.
} 
scores, that result from Head Start enrollment. Fourth, parents could spend more time with their children because they are more pleasant to be with. ${ }^{35}$ Fifth, peer effects among parents could lead parents to change their behavior: those parents whose children are in Head Start could be exposed to high-involvement parents and therefore raise their involvement. Sixth, it is possible that parents perceive their children to have "won a lottery" and therefore invest more in them simply for this reason, for example because they would perceive their child to "be a winner" if they won any lottery. Seventh, Head Start could lead to changes in parent time with children through impacts on parents' time budget constraints (for example because the effectively free childcare given by Head Start influences parents' effective wage).

\section{a. Cross-Program Correlation of Effects on Cognitive Scores and Parent Inputs}

We demonstrate the intriguing finding that the parents of children randomly assigned to treatment in programs that boosted cognitive scores the most in Spring 2003 were more likely to show greater involvement with their children as a result of treatment. A positive correlation would be consistent with the claim that parents increase their involvement with their children due to the impact that HS has on their children's cognitive scores (consistent with Explanation 2 above). It is also possible that children's cognitive scores proxy for unobserved changes in children's characteristics (Explanation 3). However, this correlation would not be immediately predicted by Explanation 5 (peer effects among parents) or Explanation 6 (the "winning the lottery effect"), since there is no immediate reason why peer effects or the "winning the lottery effect" should be larger in programs that raise child cognitive scores the most. It also would not be immediately predicted by Explanation 1 (specific features of Head Start programs), but it would be consistent with Explanation 1 under the arguably reasonable presumption that those Head Start programs that are most effective in one dimension (raising cognitive scores) may also be most effective in another dimension (raising parent involvement). Finally, a positive cross-program correlation would be consistent with the possibility that parent involvement is responsible for the increase in child cognitive scores, rather than the reverse.

\footnotetext{
${ }^{35}$ We distinguish Explanation 4 from Explanations 2 and 3 because in Explanations 2 and 3, parents perceive HS as complementary with parent investment in producing child characteristics, whereas Explanation 4 posits that parents directly derive more utility from parent-child teaching time due to changes in child characteristics. See the framework in Appendix E.
} 
As a first step in estimating this correlation across Head Start programs, we estimate the effect of treatment in each Head Start program on both cognitive scores and parent involvement and then correlate these effects across programs. ${ }^{36}$ In particular, we run the following regressions:

$$
\begin{gathered}
\text { Cognitive }_{i p}=\alpha_{p}\left(T_{i p} * \boldsymbol{\delta}_{p}\right)+\boldsymbol{\delta}_{p}+\varepsilon_{i p} \\
\text { Involvement }_{i p}=\boldsymbol{\beta}_{p}\left(T_{i p} * \boldsymbol{\delta}_{p}\right)+\boldsymbol{\delta}_{p}+\varepsilon_{i p}
\end{gathered}
$$

In (5), Cognitive $e_{i p}$ represents a normalized cognitive score of individual $i$ in $\operatorname{program} p ; \boldsymbol{\delta}_{p}$ represents a vector of fixed effects for each HS program that equal 1 when individual $i$ is in program $p$ and 0 otherwise; $T_{i p}$ is the treatment dummy measured for individual $i$ in program $p$; and $\alpha_{p}$ is a vector of coefficients on the vector of interactions of the treatment dummy and the program fixed effects. In (6), the notation is the same and Involvement ${ }_{i p}$ represents the normalized involvement measures of parents of child $i$ in program $p$. Figure 2 shows that the correlation across programs of the $\alpha_{p}$ and $\boldsymbol{\beta}_{p}$ is positive and easily visible (with a correlation of 0.42 , which is significantly different from zero at the $1 \%$ level). ${ }^{37}$

Nonetheless, the estimated cross-program correlation between $\alpha_{\mathrm{p}}$ and $\beta_{\mathrm{p}}$ in (5) and (6) may be biased, among other reasons because parent involvement and cognitive scores are positively correlated in a cross section of students (even absent the effects of HS). With finite program size and a positive cross-sectional correlation between cognitive scores and parent involvement, we would estimate an upward-biased cross-program correlation between impacts of HS on parent involvement and impacts of HS on cognitive scores, absent a jackknife procedure. ${ }^{38}$ To address this issue, we implement a jackknife by omitting each individual $i$ 's scores when calculating program quality. Appendix Table 5 shows that there is a strong positive and statistically significant estimated association between cognitive scores

\footnotetext{
${ }^{36}$ In both the treatment and control groups, we consider a child to be in a given program if they applied to a center in that program.

${ }^{37}$ We run reduced-form regressions in (5) and (6), but the results of the IV regression (i.e. instrumenting for Head Start enrollment interacted with program fixed effects using Head Start eligibility interacted with program fixed effects) show an even higher correlation of program effects on cognitive scores and program effects on parent inputs $(0.73$, significant at $1 \%)$. When we calculate this correlation at the level of the HS center, rather than the HS program, we find a correlation of 0.35 (significantly different from zero at the $1 \%$ level). The results in Appendix Table 5 are also similar when the variation is at the level of the HS center (rather than program).

${ }^{38}$ Note, however, that programs on average have 42 students in the treatment and control groups, so the potential scope for bias is small. Moreover, error in measuring program impacts is likely to bias this estimated correlation in Figure 1 downward; following the method in Chetty et al. (2011), we calculate that this downward bias should be $30.2 \%$.
} 
and parent inputs in the During period. ${ }^{39}$ By contrast, Appendix Table 5 shows that 58 detailed HS center characteristics reported by center directors-which arguably comprise a list of the main plausible mechanisms by which HS (or other centers) may be directly promoting increased parent involvement (such as the utilization of parent teacher conferences, having parents volunteer in the center, or home visits by center staff) — together have little correlation with the impact of HS on parent inputs. ${ }^{40}$ This constitutes suggestive evidence that makes Explanation 1 appear less likely (though still possible). ${ }^{41}$ Appendix Table 5 also shows that the effect of programs on non-cognitive scores has a weaker relationship with the effect on parent involvement in the During period. ${ }^{42}$ Appendix C describes the jackknife procedure in detail and contains a further discussion of Appendix Table 5.

\section{b. Changes in parents' child care responsibilities and illustrative conceptual framework}

To examine the role the changes in parents' child care responsibilities may play in accounting for changes in parent investment in children (Explanation 7), consider how these

\footnotetext{
${ }^{39}$ The cross-program correlation of the effect of HS on parent involvement and cognitive scores is also notable because it again suggests that parents are not simply self-reporting higher levels of involvement in the treatment group. If the only reason that we see a correlation between treatment and parent involvement is that parents are self-reporting greater involvement with their children in response, even though they do not actually increase their involvement, then we would expect to see no correlation across programs of the effect on parent involvement with the effect on cognitive score.

${ }^{40}$ Center directors at both HS centers and at other childcare centers reported these 58 center characteristics. Appendix C describes how we construct these measures of HS and non-HS center characteristics. These reports by directors appear to contain useful information since they are highly correlated $(p<0.001)$ with reports by parents of their involvement in the centers.

${ }^{41}$ Another piece of evidence is consistent with the spirit of these results, which document an association of parent involvement with cognitive scores but not with Head Start center characteristics. When we instrument for own cognitive scores using the cognitive scores of peers in Column 4 of Appendix Table 5, the coefficient on the HS dummy is greatly affected-decreasing from 0.16 when we implement the specification in Appendix Table 5 without including cognitive scores as a regressor, to 0.08 when we do include cognitive scores ( $\mathrm{p}<.01)$ - but when we control for HS center characteristics in Column 5, the coefficient on the HS dummy stays at 0.08 ( $p>0.40)$. Similarly, when we run the regression from Table 2 Row A and control for cognitive scores, the coefficient on the HS dummy is greatly affected (going down by $56 \%, \mathrm{p}<.01$ for the test of equal coefficients to Table 2 Column 1), but when we instead control for HS center characteristics, the coefficient on the HS dummy is insignificantly affected ( $>>0.40)$ and the point estimate changes negligibly. In addition, when we run the regression from Table 2 Row A and control for non-cognitive scores, the coefficient on the HS dummy is little affected ( $>0.40$ ), again suggesting that changes non-cognitive scores have little association with changes in parent inputs. However, it is worth stressing the important caveats that unobserved features of Head Start programs could cause the positive cross-program correlation of impacts on parent involvement and cognitive scores that we observe; that cognitive and non-cognitive scores are endogenous outcomes that are affected by treatment along with parent involvement; and that center characteristics are not exogenously assigned across centers.

${ }^{42}$ If non-cognitive characteristics proxy for how enjoyable parent-child teaching time is, this constitutes suggestive (though far from definitive) evidence that parents are not investing more in children primarily due to observable ways that HS makes children more pleasant to spend time with (Explanation 4).
} 
results relate to the changes in child and parent time allocation associated with Head Start enrollment. Appendix Table 6 Panel B shows that HS enrollment raises children's weekly hours in childcare including HS (other than childcare by parents) by 11.71 hours per week, and the effect is significantly different from zero at the $1 \%$ level. ${ }^{43}$ Assuming that children must either be with their parents or in non-parent childcare-a reasonable approximation for 3- and 4-year-olds - this implies that total time with parents must have decreased during the experiment. ${ }^{44}$ This is due to the child time budget constraint: children who are enrolled in HS mechanically have less time to spend with their parents, since a large fraction of their day is now spent in HS rather than with their parents.

In order to provide an illustrative conceptual framework to organize ideas about children's and parents' time allocation as it relates to the results we obtain in the During period, in Appendix E we sketch a framework in which parent-child time has multiple dimensions. In this framework, children's time is divided into 4 categories: time spent in HS, time spent in non-HS non-parent childcare, time spent with parents in which parents teach or otherwise invest in them, and non-teaching time with parents. If time in non-parent childcare rises, then total parent time must fall. Parents' time is devoted to teaching or otherwise investing in children, spending non-teaching time with children, or non-child time. The first goal of this framework is to illustrate a very simple point: parent-child teaching time can increase even if total parent-child time decreases in response to child enrollment in HS.

In the framework, designed specifically to capture Explanation 2 (or 3) above, parents derive utility both directly from their own time allocation and from their children's characteristics, which are in turn a function of Head Start hours, non-Head Start non-parent childcare, parent teaching time, and parent non-teaching time. A key point illustrated by the framework is that if parent teaching time is perceived as sufficiently complementary with

\footnotetext{
${ }^{43}$ A similar finding is documented in HHS (2010). Appendices C and D discuss further results that we develop on children's time allocation from Appendix Table 6. As we discuss further in these appendices, Appendix Table 6 also shows that there is little evidence that parents' probability of labor force participation responded to child Head Start enrollment, which constitutes suggestive evidence that this factor does not drive changes in parent investment in children.

${ }^{44}$ It is possible that preschool-aged children also spend time with friends. However, this factor seems extremely unlikely to reverse the conclusion that Head Start caused a decrease in overall parent time with children. In order to reverse this conclusion, it would have to be the case that children spent at least 11.71 fewer hours with friends as a result of Head Start, which seems extremely unlikely. Nonetheless, in the framework in Appendix E, we accommodate the possibility that children could in principle be spending some time not with parents or in other childcare.
} 
Head Start inputs in producing valued child characteristics, then teaching time can increase in response to an increase in child Head Start hours. ${ }^{45}$ Appendix E contains a more detailed discussion of the framework and its relationship to our empirical results. In this framework and elsewhere in the paper, we interpret the measures of parent involvement from the empirical work as "investment" in children; by "investment," strictly speaking we mean simply that parent "investment" activities have both a direct impact on parents' utility and an indirect effect through child characteristics (whose value to parents and children may in part be realized later in life, for example through child earnings outcomes). We focus on Explanation 2 since it is arguably the most directly consistent with the data, and since it is helpful to clarify a formal framework that underlies the complementarity postulated in this explanation. However, it is worth emphasizing that the data certainly do not rule out other explanations discussed above.

\section{c. Parent involvement in the After period}

We noted above that the cross-program correlation of impacts on parent investment and child cognitive scores is consistent inter alia with the possibility that child cognitive scores impact parent investment, or with the possibility that parent investment impacts child cognitive scores. In light of the fact that the effect of HS on several parent inputs persists even after the experiment ends, it is perhaps surprising that the cognitive and non-cognitive gains from HS fade over time. This combination of findings suggests either that these parent inputs do not raise cognitive and non-cognitive measures, or that the effect on these scores is not large enough to be detected as statistically significant in our sample. ${ }^{46}$

Assuming that changes in child characteristics impact parent involvement, rather than the reverse, it is possible that increased parent involvement may persist in the HS group in the After period because it responds to unmeasured cognitive or non-cognitive characteristics of children that change due to HS. ${ }^{47}$ Alternatively, parents could increase their involvement

\footnotetext{
${ }^{45}$ A second key point illustrated by the framework is that the welfare impact of Head Start depends in part on the direct impact of parents' effort on their utility, as discussed below.

${ }^{46}$ It is also possible that the effect of these parent inputs is not apparent in these measures of cognitive and noncognitive ability but would appear in other measures.

${ }^{47}$ It could also be that parent involvement persists because parents falsely expect the measured test score gains from the During period to persist and thus continue their increased involvement in the After period.
} 
in the During period (for example in reaction to increases in child cognitive scores) and form habits of greater involvement that persist into the After period. ${ }^{48}$

\section{Conclusion}

We investigate the effect of HS enrollment on parents' involvement with their children. We find that when children enroll in HS, their parents are more involved with them along a wide variety of dimensions, both during and after the period when children are enrolled in the program. This finding is robust across a variety of analyses. We also find evidence that this impact on parent involvement does not fade over the course of the period after children are potentially enrolled in HS. Several hypotheses could account for the impact of Head Start on parent involvement; our data point toward parents' reaction to the impact of Head Start on child characteristics, or unobserved features of Head Start programs that directly induce parent involvement, as potential explanations for the increase in parent involvement, but several other explanations are possible.

Our findings are notable for a number of reasons. First, the results suggest that a welfare analysis of Head Start or other schooling programs must include an estimate of their effect on parents' effort, since effort is typically modeled as costly at the margin. ${ }^{49}$ Second, studies of the effect of schooling inputs on children have typically estimated the overall effect of schooling programs on child outcomes, without disaggregating these effects into direct effects of the programs on child outcomes and indirect effects of the programs that operate through their effect on parent investment. If these parent inputs positively affect children's outcomes, our results suggest that in previous studies that have measured the overall effect of HS on child outcomes, the direct effect on child outcomes is smaller than the estimates of the overall effect on child outcomes. ${ }^{50}$

Third, our findings are interesting in part because one of the goals of HS is to increase parent involvement with their children. Our results show that HS succeeds in that goal.

\footnotetext{
${ }^{48}$ In this light, it is interesting to note that as described in Section IV.c, parent involvement drops off sharply from the During to the After period, whereas parent involvement is persistently at a similar level throughout the After period: the estimated coefficient is 0.12, 0.19, 0.06, 0.05, and 0.06 in Fall 2002, Spring 2003, Spring 2004, Spring 2005, and Spring 2006, respectively. This time pattern appears inconsistent with a model in which parents form a habit of involvement with their children and (as we might expect) these habits slowly fade. ${ }^{49}$ Of course, the potential positive impacts of parent effort on children must be considered in any welfare analysis along with effort costs to parents. See the discussion of social welfare in the framework in Appendix E. ${ }^{50}$ Relatedly, the results suggest that in a fully specified model of the production of child human capital, parent inputs may be affected by government policy or other factors that affect child schooling.
} 
Interestingly, however, we find little evidence in support of the hypothesis that this effect operates through the measures that HS takes to involve parents, such as parent-teacher meetings. If the effect of HS on parents is mediated through the impact that HS has on children's cognitive ability-which appears consistent with the data-this suggests in turn that if schooling in other contexts has positive impacts on child test scores, it will also have positive impacts on parent investment. ${ }^{51}$

Despite the fact that test score gains fade out after HS ends, there is evidence that HS does have impacts on long-run child outcomes (Garces, Thomas, and Currie 2002; Deming 2009; Ludwig and Miller 2007). The re-emergence of schooling impacts on children in later life, despite no measurable medium-run impact on test scores, has also been noted in other contexts (e.g. Heckman, Malofeeva, Pinto, and Savelyev 2010; Chetty et al. 2011; Dynarski, Hyman, and Schanzenbach 2011). It is possible that persistent increases in parent investment constitute a channel through which the long-run impact on child outcomes is mediated.

This paper has a number of limitations and suggests several directions for future study. First, we typically do not directly observe time spent by parents on parent-child activities. These outcomes could be explored in a dataset in which measures of parent time with children is collected. Second, many educational institutions seek to increase parent involvement with their children, as parent involvement is often seen as a crucial factor in the success of educational programs. It would be of interest to see whether schooling has a similar impact on parents' involvement with their children in settings outside of HS. Third, we do not observe some important elements of parents' investment in children, including expenditures on many goods for children. A dataset with information on expenditures would be very helpful in completing this picture. Finally, it is difficult to know which, if any, of the parent involvement outcomes we investigated have positive impacts on their children. If we knew how different parent inputs affected child outcomes, we could use this paper's estimates of the impact of HS on each separate parent outcome to predict how changes in these inputs induced by Head Start should impact child outcomes. ${ }^{52}$ The effect of parent involvement on children's outcomes remains an important outstanding question.

\footnotetext{
${ }^{51}$ The estimated impacts are also similar across demographic groups. This is also suggestive that the findings may generalize in some other contexts.

${ }^{52}$ Some work has investigated how different parent inputs affect child outcomes in other contexts (e.g. Paxson and Schady 2007 on Ecuador), but this work has not examined the Head Start population.
} 


\section{References}

Aizer, Anna, and Flavio Cunha. 2011. "Child Endowments, Parent Investments and the Development of Human Capital." Brown University Working Paper.

Becker, Gary. 1981. A Treatise on the Family. Cambridge, MA: Harvard University Press.

Becker, Gary, and Nigel Tomes. 1976. "Child Endowments and the Quantity and Quality of Children." Journal of Political Economy 84(4): S143-S162.

Becker, Gary, and Nigel Tomes. 1986. "Human Capital and the Rise and Fall of Families." Journal of Labor Economics 4(3): S1-S39.

Bertrand, Marianne, and Jessica Pan. "The Trouble with Boys: Social Influences and the Gender Gap in Disruptive Behavior.” NBER Working Paper 17541.

Black, Sandra, Devereaux, Paul and Kjell Salvanes. 2007. "Small Family, Smart Family? Family Size and the IQ Scores of Young Men.” Forthcoming, Journal of Human Resources.

Brooks-Gunn, Jeanne, Greg Duncan, and Pamela Klebanov. 1996. "Ethnic Differences in Children's Intelligence Test Scores: The Role of Economic Deprivation, Home Environment and Maternal Characteristics," Child Development 67: 396-408.

Campbell, Frances, and Craig Ramey. 1994. "Effects of Early Intervention on Intellectual and Academic Achievement: A Follow-Up Study of Children from Low-Income Families." Child Development 65(2): 684-698.

Chetty, Raj, John Friedman, Nathaniel Hilger, Emmanuel Saez, Diane Schanzenbach, and Danny Yagan. Forthcoming. "How Does Your Kindergarten Classroom Affect Your Earnings? Evidence from Project STAR." Quarterly Journal of Economics.

Cunha, Flavio, and James J. Heckman. 2010. "Investing in our Young People.” NBER Working Paper 16201.

Currie, Janet, and Duncan Thomas. 1995. "Does Head Start Make a Difference?" American Economic Review 85(3): 341.

Dynarski, Susan, Joshua Hyman, and Diane Whitmore Schanzenbach. 2011 "Experimental Evidence on the Effect of Childhood Investments on Postsecondary Attainment and Degree Completion." NBER Working Paper 17533.

Das, Jishnu, Stefan Dercon, James Habyarimana, Pramila Krishnan, Karthik Muralidharan, and Venkatesh Sundararaman. 2007. "School Inputs, Household Substitution, and Test Scores.” University of San Diego Working Paper.

Deming, David. 2009. "Early Childhood Intervention and Life-Cycle Skill Development: Evidence from Head Start." American Economic Journal: Applied Economics 1(3): 111-134.

Epstein, Joyce. 2011. School, Family, and Community Partnerships: Preparing Educators and Improving Schools, 2nd edition. Boulder, CO: Westview Press.

Garces, Eliana, Duncan Thomas, and Janet Currie. 2002. "Longer-Term Effects of Head Start." American Economic Review 92(4): 999-1012.

Gelbach, Jonah B. 2002. "Public schooling for young children and maternal labor supply." American Economic Review 92: 307-322.

Gibbs, Chloe, Jens Ludwig, and Douglas Miller. 2011. "Does Head Start do any Lasting Good?" NBER Working Paper 17452.

Heckman, James J., Lena Malofeeva, Rodrigo Pinto and Peter Savelyev. 2008. "The Effect of the Perry Preschool Program on Cognitive and Noncognitive Skills: Beyond Treatment Effects." Unpublished manuscript, University of Chicago. 
Houtenville, Andrew, and Karen Conway. 2008. "Parental Effort, School Resources, and Student Achievement." Journal of Human Resources 43: 437-453.

Kling, Jeffrey, Jeffrey Liebman, and Lawrence Katz. 2007. "Experimental Analysis of Neighborhood Effects." Econometrica 75(1): 83-119.

Lee, David S. 2009. "Training, Wages, and Sample Selection: Estimating Sharp Bounds on Treatment Effects.” Review of Economic Studies 76: 1071-1102.

Ludwig, Jens, and Douglas Miller. 2007. "Does Head Start Improve Children's Life Chances? Evidence from a Regression Discontinuity Design." The Quarterly Journal of Economics 122(1): 159-208.

Magnuson, Katherine, Christopher Ruhm, and Jane Waldfogel. "Does Prekindergarten Improve School Preparation and Performance?” NBER Working Paper 10452.

Nye, Chad, Herb Turner, and Jamie Schwartz. 2006. "Approaches to parent involvement for improving the academic performance of elementary school age children." Campbell Systematic Reviews 4. doi: 10.4073/csr.2006.4.

Paxson, Christina, and Norbert Schady. 2007. "Cognitive Development among Young Children in Ecuador: The Roles of Wealth, Health, and Parenting," Journal of Human Resources 42(1): 49-84.

Rosenzweig, Mark and Junsen Zhang. 2009. "Do Population Control Policies Induce More Human Capital Investment? Twins, Birth Weight and China's "One-Child" Policy." Review of Economic Studies 76(3): 1149-1174.

Sacerdote, Bruce. 2007. "How Large are the Effects from Changes in Family Environment? A Study of Korean American Adoptees." Quarterly Journal of Economics 122(1): 119-157.

St. Pierre, Robert, G., Janet Swartz, Beth Gamse, Stephen Murray, Dennis Deck, and Phil Nickel. 1995. National evaluation of the Even Start family literacy program: Final report. Cambridge, MA: Abt Associates, Inc.

Todd, Petra, and Kenneth I. Wolpin. 2003. "On the Specification and Estimation of the Production Function for Cognitive Achievement.” Economic Journal 113: F3-F33.

U.S. Department of Health and Human Services, Administration for Children and Families. 2002. "Final Report on the Early Head Start Evaluation."

U.S. Department of Health and Human Services, Administration for Children and Families. 2010. "Head Start Impact Study, Final Report."

Zhai, Fuhai, Jane Waldfogel, and Jeanne Brooks-Gunn. "Estimating the effects of Head Start on parenting and child maltreatment." Child and Youth Services Review doi:10.1016/j.childyouth.2011.03.008. 
Figure 1a and 1b. Distribution of parent involvement in the treatment and control groups in the During period (1a) and After period (1b)
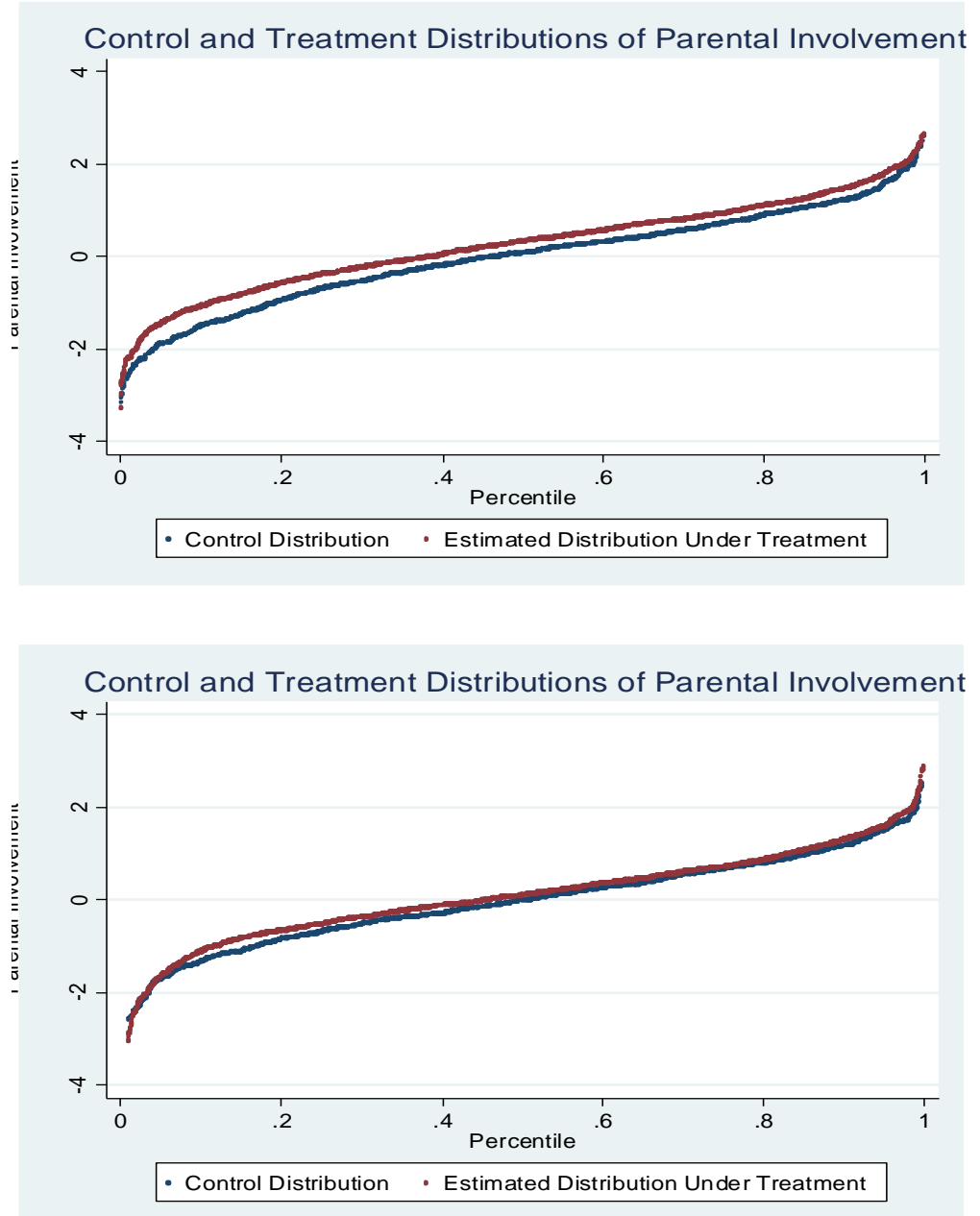

Notes: Figure 1a (Figure 1b) shows the distribution of parent involvement in the treatment and control groups in the During (After) period. The darker (blue) line (lower in each figure) shows the percentiles of the distribution in the control group, and the lighter (red) line (higher in each figure) shows the percentiles of the distribution in the treatment group. The Kolmogorov-Smirnov test shows that the treatment and control distributions are significantly different in the During period $(\mathrm{p}<.001)$ and the After period $(\mathrm{p}<.05)$. The index of parent involvement is calculated by first normalizing the parent involvement measures by subtracting the mean of each of the measures of parent involvement listed in Appendix Table 2, dividing by the standard deviation in the control group, and then averaging the normalized measures for each child. The figure shows that in the During period, the impact of treatment on parent involvement appears to have been largest at the lowest quantiles of parent involvement. The difference between the treatment and control distributions is much smaller in the After period than in the During period, but the differences between the treatment and control distributions also appear to be largest in the lower quantiles of the distribution in the After period. The size of the first stage does not vary appreciably across the distribution. Data are from the sample of survey responders $(\mathrm{N}=2,285$ in the treatment group; $\mathrm{N}=1,410$ in the control group). All observations are weighted by the final parent weights. 
Figure 2. Correlation across HS programs of effect of treatment on child cognitive scores (xaxis) and effect of treatment on parent involvement (y-axis)

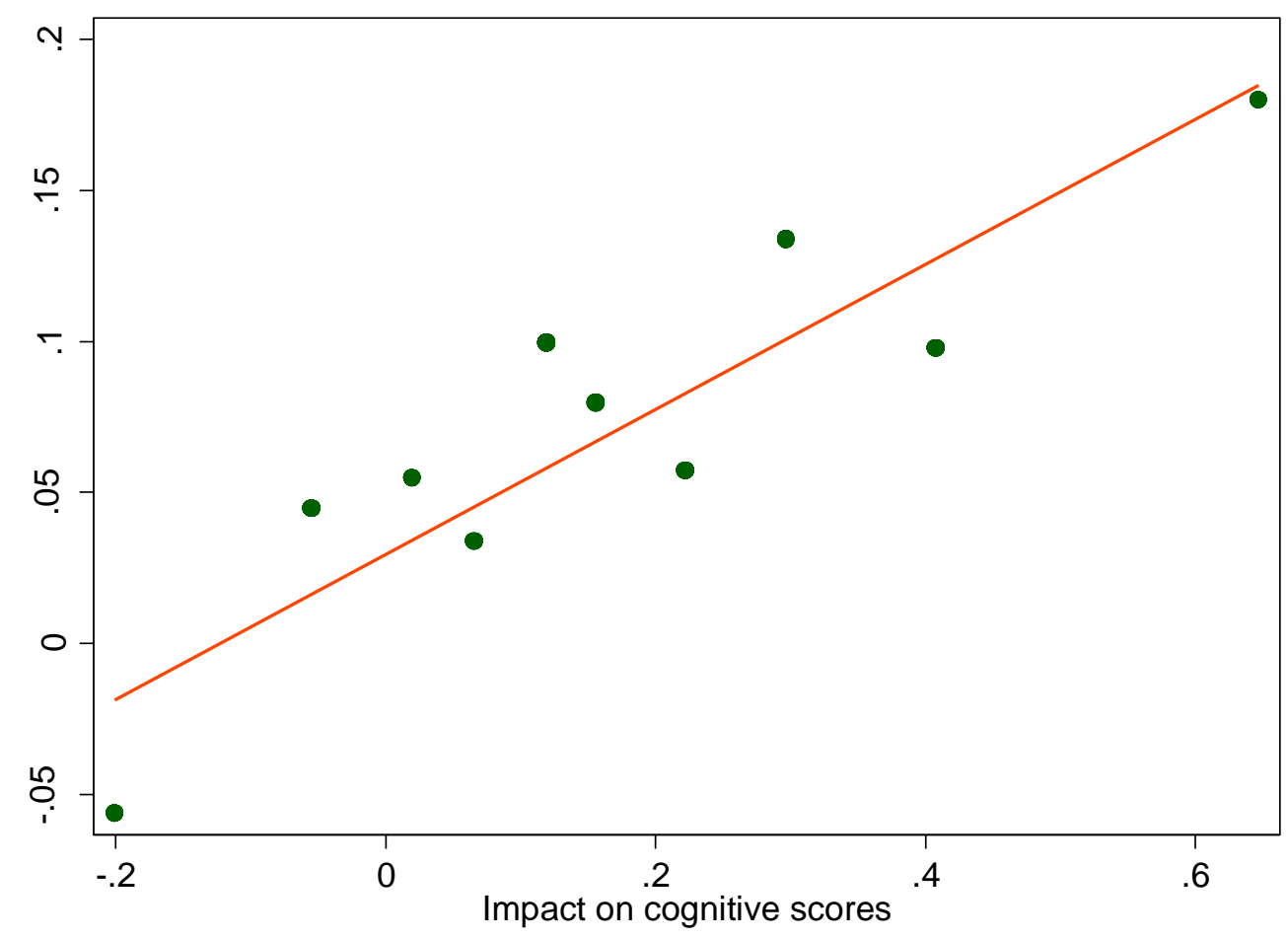

Notes: Figure 2 shows that there is a positive correlation across HS programs of the programs' estimated impact on children's cognitive scores (depicted on the X-axis) and the programs' estimated impact on parent involvement (depicted on the y-axis). The estimated correlation of these effects across programs is 0.42 , which is significantly different from zero at the $1 \%$ level. "Cognitive scores" refers to the 11 measures of cognitive scores of the child listed in Appendix A. We pool the measures of cognitive scores and run regression (5) in which we regress cognitive scores on treatment interacted with program dummies, plus the main effects of the program dummies. We pool the measures of parent inputs and run regression (6) in which we regress parent inputs on treatment interacted with program dummies, plus the main effects of the program dummies. We bin impacts on cognitive scores into 10 equal-sized bins (of 10 percentiles each) and plot the mean of the outcome variable within each bin. 
Table 1. Experiment Balance on Demographics. Weighted and unweighted means of demographic variables in the treatment and control groups, and p-values of t-tests for differences in means.

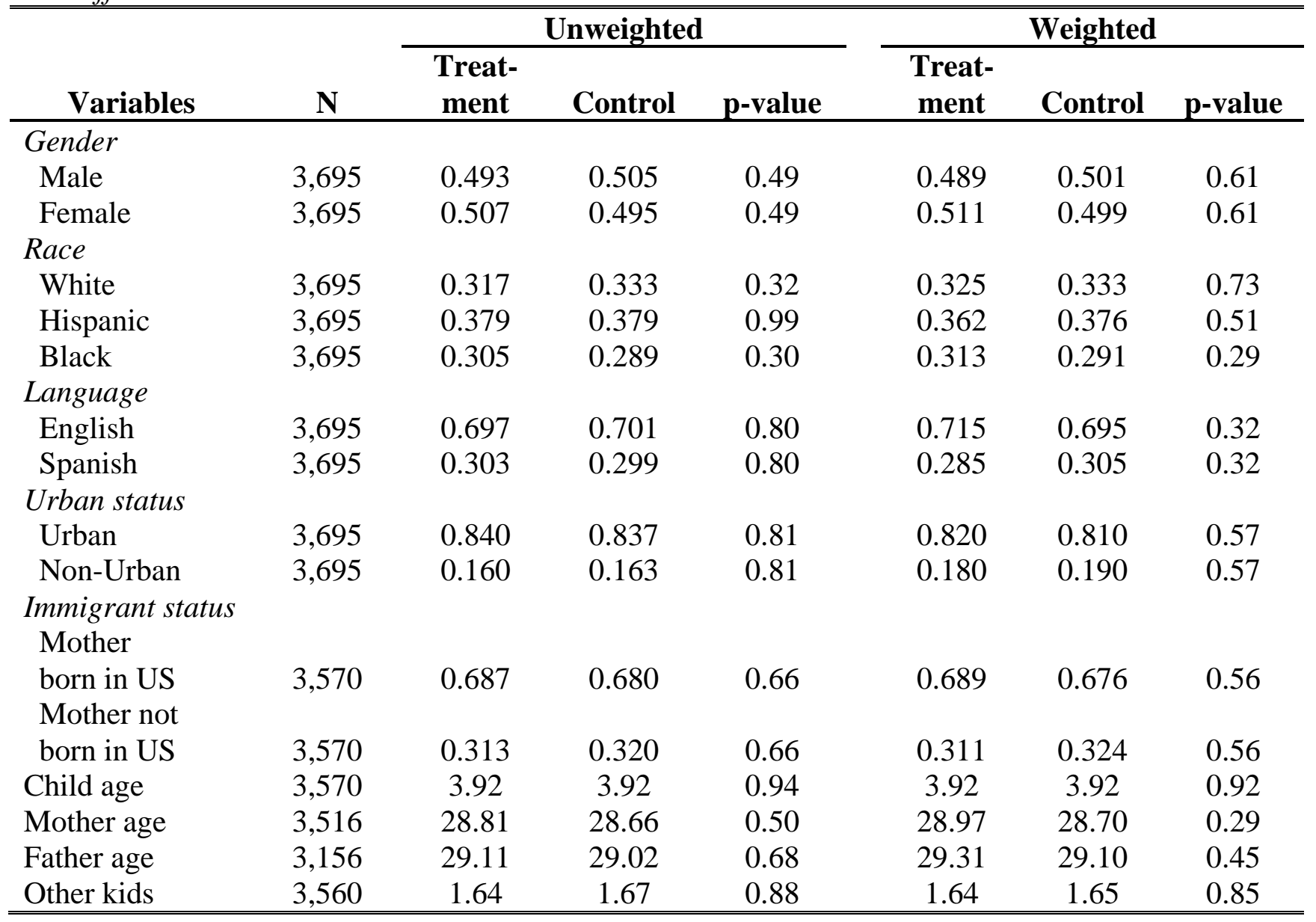

Notes: The table shows that there are no significant differences in demographics across the treatment and control groups. Gender, race, language spoken, and urban status refer to the characteristics of the child. "White" includes "other" (non-hispanic, non-black) races, which are aggregated together in the HSIS data. "Other kids" refers to the number of children in the household other than the child under study. In the "weighted" columns all observations for parents are weighted by the appropriate Fall 2002 final weights. In the "unweighted" column, no weights are used. 2,285 children are included in the treatment group means, and 1,410 children are included in control group means. All variables are measured in the Fall of 2002. 
Table 2. Effect of HS on parent involvement. The table shows coefficients and standard errors on the treatment dummy from IV regressions of parent involvement on $H S$ enrollment. The instrument for whether a child was enrolled in HS is the treatment dummy indicating that the child had access to HS. Dependent variable: measures of parent involvement.

\begin{tabular}{|c|c|c|c|c|c|c|}
\hline & \multicolumn{3}{|c|}{ During } & \multicolumn{3}{|c|}{ After } \\
\hline & (1) & (2) & (3) & (4) & $(5)$ & (6) \\
\hline A) All outcomes & $\begin{array}{c}0.15 \\
(.02)^{* * * *}\end{array}$ & $\begin{array}{c}0.15 \\
(0.02)^{* * *}\end{array}$ & 264,999 & $\begin{array}{c}0.06 \\
(0.02)^{* * *}\end{array}$ & $\begin{array}{c}0.06 \\
(0.02)^{* * *}\end{array}$ & 320,439 \\
\hline $\begin{array}{l}\text { B) Reading and } \\
\text { writing activities }\end{array}$ & $\begin{array}{c}0.20 \\
(0.03)^{* * * *}\end{array}$ & $\begin{array}{c}0.19 \\
(0.03)^{* * * *}\end{array}$ & 76,509 & $\begin{array}{c}0.04 \\
(0.03)\end{array}$ & $\begin{array}{c}0.04 \\
(0.03)\end{array}$ & 70,652 \\
\hline C) Math activities & $\begin{array}{c}0.20 \\
(0.04)^{* * *}\end{array}$ & $\begin{array}{c}0.19 \\
(0.04)^{* * *}\end{array}$ & 43,837 & $\begin{array}{c}0.10 \\
(0.03)^{* * *}\end{array}$ & $\begin{array}{c}0.10 \\
(0.04)^{* * *}\end{array}$ & 31,879 \\
\hline $\begin{array}{l}\text { D) Other parent- } \\
\text { child activities }\end{array}$ & $\begin{array}{c}0.07 \\
(0.03)^{* * *}\end{array}$ & $\begin{array}{c}0.06 \\
(0.03)^{* * *}\end{array}$ & 54,242 & $\begin{array}{c}0.07 \\
(0.03)^{* *}\end{array}$ & $\begin{array}{c}0.07 \\
(0.03)^{* *}\end{array}$ & 52,981 \\
\hline $\begin{array}{l}\text { E) Qualitative } \\
\text { parenting measures }\end{array}$ & $\begin{array}{c}0.08 \\
(0.03)^{* *}\end{array}$ & $\begin{array}{c}0.07 \\
(0.03)^{* *}\end{array}$ & 24,915 & $\begin{array}{c}0.08 \\
(0.03)^{* *}\end{array}$ & $\begin{array}{c}0.07 \\
(0.03)^{* *}\end{array}$ & 49,298 \\
\hline $\begin{array}{l}\text { F) Rules and } \\
\text { routines }\end{array}$ & $\begin{array}{c}0.13 \\
(0.03)^{* * *}\end{array}$ & $\begin{array}{c}0.12 \\
(0.03)^{* * *}\end{array}$ & 43,592 & $\begin{array}{c}0.10 \\
(0.03)^{* * *}\end{array}$ & $\begin{array}{c}0.09 \\
(0.03)^{* * *}\end{array}$ & 35,258 \\
\hline $\begin{array}{l}\text { G) Tracking child } \\
\text { learning }\end{array}$ & $\begin{array}{c}0.22 \\
(0.04)^{* * *}\end{array}$ & $\begin{array}{c}0.23 \\
(0.04)^{* * *}\end{array}$ & 18,459 & -- & -- & -- \\
\hline $\begin{array}{l}\text { H) Father } \\
\text { involvement }\end{array}$ & $\begin{array}{c}0.00 \\
(0.07)\end{array}$ & $\begin{array}{c}0.00 \\
(0.07)\end{array}$ & 3,445 & $\begin{array}{c}0.05 \\
(0.07)\end{array}$ & $\begin{array}{c}0.06 \\
(0.06)\end{array}$ & 6,693 \\
\hline $\begin{array}{l}\text { I) Parent-school } \\
\text { involvement }\end{array}$ & -- & -- & -- & $\begin{array}{c}0.01 \\
(0.03)\end{array}$ & $\begin{array}{c}0.01 \\
(0.03)\end{array}$ & 62,356 \\
\hline $\begin{array}{l}\text { J) Teacher and } \\
\text { interviewer reports }\end{array}$ & $\begin{array}{c}0.11 \\
(0.07)\end{array}$ & $\begin{array}{c}0.11 \\
(0.07)\end{array}$ & 3,097 & $\begin{array}{c}0.09 \\
(0.04)^{* *}\end{array}$ & $\begin{array}{c}0.09 \\
(0.04)^{* *}\end{array}$ & 25,577 \\
\hline $\begin{array}{l}\text { Covariates } \\
\text { General. Hausman }\end{array}$ & $0.00 * * *$ & $\begin{array}{c}\mathrm{X} \\
0.00 * * *\end{array}$ & & $0.00 * * *$ & $\begin{array}{c}\mathrm{X} \\
0.00 * * * \\
\end{array}$ & \\
\hline
\end{tabular}

Notes: The table shows the results of regressions in which measures of parent involvement listed in Appendix Table 2 are related to HS enrollment or access. Following Kling, Liebman, and Katz (2007), we normalize the outcome variables by subtracting their mean and dividing by their standard deviation in the control group. We then form the coefficient estimate by running IV regression (2) of each outcome on HS enrollment, in which HS enrollment is instrumented using HS access, and averaging the coefficient estimates across regressions. We form the standard error by pooling the outcome variables and running IV regression (2). In Row A we report the results in which all outcome variables are pooled; in rows B-J we report the results on distinct categories of variables (defined in Appendix Table 2). The generalized Hausman test examines the hypothesis that across all of the reduced form regressions (3), the coefficients on treatment are jointly different from zero. "Covariates" in Columns 2 and 5 include dummies for child gender, race, language at home, and whether the child resides in an urban area, which are added as independent variables to regressions (1) and (2). Columns 3 and 6 show the number of observations in each category; the N's in each separate category do not add up to the total for "all outcomes" because we do not include interviewer reports in "all outcomes." Columns 1-3 show information for the During period, and Columns 4-6 show information for the After period. Standard errors are clustered at the level of the program. All observations are weighted by the final parent weights. The number of unique individuals represented in the regressions is 3,916. The first-stage F-statistics when we pool all outcomes without (with) covariates is 537.34 (543.48) in the During period and 490.43 (495.22) in the After period; all of the other first-stage Fstatistics are over $375 . * *$ denotes significance at the $1 \%$ level; $* *$ at the $5 \%$ level; and $*$ at the $10 \%$ level. 
Table 3. Effect of HS on particular parent involvement outcomes. The table shows coefficients and standard errors on the treatment dummy from probit, ordered probit, or IV regressions of parent involvement on HS enrollment. Dependent variable: measures of parent involvement (listed in column headings)

\begin{tabular}{|c|c|c|c|c|c|c|c|c|}
\hline & $\begin{array}{c}(1) \\
\text { Number } \\
\text { of Times } \\
\text { Read }\end{array}$ & $\begin{array}{l}(2) \\
\text { How long } \\
\text { read }\end{array}$ & $\begin{array}{l}(3) \\
\text { Minutes } \\
\text { reading }\end{array}$ & $\begin{array}{l}\text { (4) } \\
\text { Days with } \\
\text { father }\end{array}$ & $\begin{array}{c}(5) \\
\text { Practiced } \\
\text { math }\end{array}$ & $\begin{array}{c}(6) \\
\text { Visited } \\
\text { art gallery }\end{array}$ & $\begin{array}{c}\text { (7) } \\
\text { Track } \\
\text { child's } \\
\text { learning } \\
\end{array}$ & $\begin{array}{l}\text { (8) } \\
\text { Learning } \\
\text { materials } \\
\text { available } \\
\end{array}$ \\
\hline $\begin{array}{c}\text { Panel A: During } \\
\text { HS enrollment }\end{array}$ & $\begin{array}{c}0.21 \\
(0.09)^{* * *} \\
\end{array}$ & $\begin{array}{c}2.78 \\
(0.82)^{* * *} \\
\end{array}$ & $\begin{array}{c}18.71 \\
(4.79)^{* * *} \\
\end{array}$ & $\begin{array}{c}0.91 \\
(0.85) \\
\end{array}$ & $\begin{array}{c}0.26 \\
(0.09)^{* * *} \\
\end{array}$ & $\begin{array}{c}0.12 \\
(0.07)^{*}\end{array}$ & $\begin{array}{c}0.37 \\
(0.09)^{* * *} \\
\end{array}$ & $\begin{array}{c}0.10 \\
(0.07) \\
\end{array}$ \\
\hline $\begin{array}{l}\text { R-squared } \\
\text { Log-likelihood } \\
\text { N }\end{array}$ & $\begin{array}{c}-- \\
-1956648 \\
7257\end{array}$ & $\begin{array}{c}0.00 \\
-- \\
7211 \\
\end{array}$ & $\begin{array}{c}0.00 \\
-- \\
7232 \\
\end{array}$ & $\begin{array}{c}-- \\
-249374 \\
1729\end{array}$ & $\begin{array}{c}-- \\
-1161974 \\
3678\end{array}$ & $\begin{array}{c}-- \\
-744096 \\
7257\end{array}$ & $\begin{array}{c}-- \\
-548854 \\
3693 \\
\end{array}$ & $\begin{array}{c}- \\
-5679 \\
3097 \\
\end{array}$ \\
\hline $\begin{array}{l}\text { Panel B: After } \\
\text { HS enrollment }\end{array}$ & $\begin{array}{c}0.01 \\
(0.06)\end{array}$ & $\begin{array}{c}1.46 \\
(0.81)^{*}\end{array}$ & $\begin{array}{r}7.04 \\
(4.78) \\
\end{array}$ & $\begin{array}{c}1.38 \\
(0.69)^{* * *}\end{array}$ & $\begin{array}{c}0.15 \\
(0.07)^{*}\end{array}$ & $\begin{array}{c}0.03 \\
(0.06)\end{array}$ & -- & $\begin{array}{c}0.09 \\
(0.06) \\
\end{array}$ \\
\hline $\begin{array}{l}\text { R-squared } \\
\text { Log-likelihood } \\
\mathrm{N}\end{array}$ & $\begin{array}{c}-- \\
-2003609 \\
7075\end{array}$ & $\begin{array}{c}0.00 \\
-- \\
7035\end{array}$ & $\begin{array}{c}0.00 \\
-- \\
7051\end{array}$ & $\begin{array}{c}-- \\
0.00 \\
3336\end{array}$ & $\begin{array}{c}-- \\
-1092651 \\
3539\end{array}$ & $\begin{array}{c}-- \\
-857878 \\
7072\end{array}$ & $\begin{array}{l}-- \\
-- \\
--\end{array}$ & $\begin{array}{c}-- \\
-10212 \\
5908\end{array}$ \\
\hline
\end{tabular}

Notes: The table shows the results of regressions in which measures of parent involvement are related to HS enrollment or access. The dependent variable in question is listed in each column heading. The regression is a probit in Columns 5 and 6; an ordered probit in Columns 1, 4, and 8; and two-stage least squares in Columns 2, 3, and 7. In Columns 1, 4, 5, 6, and 8, we form the Wald estimate by dividing the coefficient estimate by the first stage $(0.68)$. The table shows coefficient estimates and standard errors; since the regressions are estimated using different methods, these coefficient estimates must be interpreted accordingly. Panel A shows results for the During period, while children are potentially enrolled in HS, and Panel B shows results for the period after which children are potentially enrolled. The standard deviation of the dependent variable in the During (After) period is 15.97 (16.13), 103.0 (101.3), and 9.53 (8.41) in Columns 2, 3, and 4 respectively. Standard errors are clustered at the level of the program. All observations are weighted by the final parent weights. In Column 1, the dependent variable is the number of times a parent read to the child per week (ordered in categories). In Column 2, the dependent variable is how long in minutes the parent read to the child at each sitting. In Column 3, the dependent variable is how many minutes per week the parent reads to the child, constructed by multiplying the dependent variables from Columns 1 and 2. The sample size is slightly bigger for the constructed variable in Column 3 than in Column 2 because those occasional individuals who report that they do not read to their child (as recorded in Column 1) do not answer the question about how many minutes per sitting they read to their child (in Column 2 ), but we infer in constructing the dependent variable in Column 3 that they read to their child 0 minutes per week. In Column 4, the dependent variable is "In the past month, on about how many days has [CHILD] seen (his/her) father." In Column 5, the dependent variable is "Use dance or act out stories to practice math ideas such as numbers or size." In Column 6, the dependent variable is "Visited an art gallery, museum, or historical site." In Column 7, the dependent variable is "Track how child learns and grows by keeping notes about (his/her) behavior or progress"; this variable is not available in the After period. In Column 8, the dependent variable is "A variety of learning materials are available," which is reported by the HSIS interviewer. The results are extremely similar when controlling for the covariates included in Columns 2 and 5 of Table 2. *** denotes significance at the $1 \%$ level; ** at the 5\% level; and $*$ at the $10 \%$ level. 
Table 4. Alternative specifications. The table shows coefficients and standard errors on the treatment dummy from IV (reduced form) regressions of parent involvement on HS enrollment (access). In the IV regressions, the instrument for whether a child was enrolled in HS is the treatment dummy indicating that the child had access to HS. Dependent variable: pooled measures of parent involvement

\begin{tabular}{|c|c|c|c|c|c|c|c|c|}
\hline & \multicolumn{3}{|c|}{ Reduced form } & \multicolumn{5}{|c|}{ Normalized IV } \\
\hline & $\begin{array}{l}\text { (1) Final } \\
\text { parent } \\
\text { weights }\end{array}$ & $\begin{array}{c}(2) \\
\text { Jackknife } \\
\text { weights }\end{array}$ & $\begin{array}{l}\text { (3) Lee } \\
\text { lower } \\
\text { bound }\end{array}$ & $\begin{array}{c}(4) \\
\text { Center } \\
\text { Access }\end{array}$ & $\begin{array}{c}\text { (5) Inc. } \\
\text { medical } \\
\text { variables }\end{array}$ & $\begin{array}{l}\text { (6) No } \\
\text { weights }\end{array}$ & $\begin{array}{c}\text { (7) } \\
\text { Alternative } \\
\text { Imputation }\end{array}$ & $\begin{array}{c}\text { (8) } \\
\text { IV for time } \\
\text { in HS }\end{array}$ \\
\hline \multicolumn{9}{|l|}{ Panel A: During } \\
\hline $\begin{array}{l}\text { Coefficient } \\
\text { on HS }\end{array}$ & $\begin{array}{c}0.10 \\
(0.02)^{* * *}\end{array}$ & $\begin{array}{c}0.10 \\
(0.02)^{* * *}\end{array}$ & $\begin{array}{c}0.04 \\
(0.02)^{* *}\end{array}$ & $\begin{array}{c}0.19 \\
(0.03)^{* * *}\end{array}$ & $\begin{array}{c}0.16 \\
(0.03)^{* * *}\end{array}$ & $\begin{array}{c}0.14 \\
(0.02)^{* * *}\end{array}$ & $\begin{array}{c}0.14 \\
(0.02)^{* * *}\end{array}$ & $\begin{array}{c}0.15 \\
(0.02)^{* * *}\end{array}$ \\
\hline $\begin{array}{l}\text { F-statistic in } \\
\text { first stage }\end{array}$ & -- & -- & -- & 276.89 & 541.19 & 949.75 & 528.07 & 537.34 \\
\hline & 264,999 & 264,999 & 264,999 & 264,999 & 284,394 & 264,999 & 429,528 & 264,999 \\
\hline \multicolumn{9}{|l|}{ Panel B: After } \\
\hline $\begin{array}{l}\text { Coefficient } \\
\text { on HS }\end{array}$ & $\begin{array}{c}0.04 \\
(0.02)^{* * *}\end{array}$ & $\begin{array}{c}0.04 \\
(0.02)^{* *}\end{array}$ & $\begin{array}{l}-0.01 \\
(0.02)\end{array}$ & $\begin{array}{c}0.08 \\
(0.03)^{* * *}\end{array}$ & $\begin{array}{c}0.06 \\
(0.02)^{* * *}\end{array}$ & $\begin{array}{c}0.03 \\
(0.02)^{* *}\end{array}$ & $\begin{array}{c}0.07 \\
(0.02)^{* * *}\end{array}$ & $\begin{array}{c}0.05 \\
(0.02)^{* * *}\end{array}$ \\
\hline $\begin{array}{l}\text { F-statistic in } \\
\text { first stage }\end{array}$ & -- & -- & -- & 249.92 & 493.76 & 933.98 & 564.29 & 256.67 \\
\hline $\mathrm{N}$ & 320,439 & 320,439 & 320,439 & 320,439 & 348,210 & 320,439 & 663,504 & 320,439 \\
\hline
\end{tabular}

Notes: In Columns 1-3, we run the reduced form regression (3), in which we pool measures of parent involvement and regress them on the dummy measuring HS access. In Column 1 (as well as Columns 3-8), we use the final parent weight in weighting the observations. Column 1 shows that the IV regressions have very similar significance levels to the OLS regressions, and that the coefficient estimates in the IV regressions are approximately 1.47 multiplied by the coefficient estimates in the OLS regressions. In Column 2, we use the jackknife variance weights that are meant to account for sampling error in forming a nationally representative sample, as discussed in Appendix A. In Column 3, we show the Lee (2009) lower bounds on the treatment effect from the pooled reduced form regression (3), with standard errors calculated as suggested in Lee (2009). These bounds are for the intent-to-treat, so we do not show an IV version of the bounds regressions. In Column 4, we show the results when we instrument for whether the child was in any center-based program using the HS dummy. In Column 5, we include medical outcomes in the analysis, such as whether the parent took the child to a doctor's appointment. In Column 6, we use no weights. In Column 7, we show the results when we run the two-stage least squares regressions (1) and (2) and impute missing data by matching missing and non-missing observations using a propensity score, as described in Appendix A. The sample size is substantially larger than the other columns because we sometimes match observations to multiple nearest neighbors (in those cases in which multiple neighbors are equally near). In Column 8 , we instrument for the amount of time an individual is enrolled in HS using the treatment dummy interacted with dummies for the 3-year-old and 4-year-old cohorts, as described in the text. Panel A shows results for the During period, and Panel B shows results for the After period. All of the results are extremely similar when we use the controls in Table 2. Standard errors are clustered at the level of the program, except in Column 2 in which we use the jackknife procedure. $* * *$ denotes significance at the $1 \%$ level; $* *$ at the $5 \%$ level; $*$ at the $10 \%$ level. 


\section{Appendix A: Description of Variables and Sample Selection}

This appendix describes how we construct the variables and sample in the analysis in the paper. Our sample size is slightly smaller than that in HHS (2010) because the data provided to us exclude Puerto Rico, whereas HHS (2010) includes Puerto Rico.

The regression sample sizes are sometimes slightly different from table to table. This is because when using independent variables from different samples, there are different amounts of missing data. As a rule, for each table we drop each observation that is either missing the dependent variable or missing all of the independent variables. When only some of the independent variables are missing, we "dummy out" the missing observations by setting missing variables equal to the mean of the variables for the non-missing observations and controlling for a dummy that equals 1 when that variable is missing and 0 otherwise. The results are robust to dropping all observations when at least one independent variable is missing.

Final weights are calculated for parent interview questions and child cognitive and non-cognitive measures in each year, in order to make the sample nationally representative of the Head Start population. We use the appropriate weights for each variable. When the regressions include observations on both parent involvement and cognitive scores, we use the weights that are appropriate to the left-hand-side variable in question. The correlation among the weights is near 1 , and the results are robust to using any set of weights.

Parent age, number of other children in the household, and immigration status are not observed for all individuals and therefore have smaller sample sizes. As a result, we do not include these as control variables in the regressions reported, although the results are very similar if the missing values are dummied out.

Consistent with most previous literature on experiments, we use the final weight for variance estimation. As shown in Table 4, using the jackknife variance weights gives similar results but generally gives standard errors that are approximately $20 \%$ larger. This implies that the estimated significance levels generally do not change, but in rare cases they drop. Results from Appendix Table 2 using the jackknife weights are available from the authors upon request. The weights that we use for variance estimation are appropriate for estimating the variance of the estimates on the sample of HS Centers examined in the experiment. The jackknife weights are ostensibly used to make the sample nationally representative, but the experiment was only run on over-subscribed HS centers, which may differ systematically from other HS centers even after applying the calculated weights.

We typically cluster our standard errors at the HS program level, which is the most aggregated available partition of our sample. In Figure 2, we also run a bootstrap to calculate the standard error on the correlation between the fixed effects-treatment interaction on parent involvement and cognitive scores, running 100 replications and sampling at the program level.

For the cognitive and non-cognitive variables, we use all of the measures analyzed in HHS at the end of the experiment. Eleven cognitive measures from Spring 2003 are reported: 1) Preschool Comprehensive Test of Phonological and Print Processing: Elision, which measures the phonetics of words, syllables, and phonemes; 2) Peabody Picture Vocabulary Test III (Test de Vocabulario en Imágenes Peabody for Spanish speakers), which measures vocabulary knowledge and receptive language; 3) Counting Bears, which measures ability to identify one-to-one correspondence; 4) Color Names, which measures color identification; 5) McCarthy Draw-ADesign, which measures perceptual motor skills; 6) Letter Naming, which measures the ability to 
recognize letters of the alphabet; 7) Woodcock-Johnson III Applied Problems, which measures the ability to analyze and solve math problems; 8) Woodcock-Johnson III Oral Comprehension, which measures oral comprehension using syntactic and semantic clues; 9) Woodcock-Johnson III Spelling, which measures early writing and spelling; 10) Woodcock-Johnson III Letter-Word Identification (Woodcock-Muñoz Letter-Word Identification for Spanish speakers), which measures letter and word identification skills; and 11) emergent literacy scale which measures literacy. The last of these measures is reported by parents; all of the results in the paper are extremely similar when we exclude this measure from the analysis. Nine indeces measuring noncognitive skills are analyzed in the report, pertaining to the following domains: 1) aggressive behavior; 2) hyperactive behavior; 3) closeness; 4) conflict; 5) positive relationships; 6) social competencies; 7) social skills and positive approaches to learning; 8) problem behavior; and 9) withdrawn behavior. All of these variables are reported by parents. The directions of all the variables are made consistent, so that the measures of "positive" behavior (such as "positive relationships") are increasing while negative behavior (such as "conflict") are decreasing. For both cognitive and non-cognitive measures, in order to make the variables comparable across measures, we standardize each variable by subtracting the mean and dividing by the standard deviation of the variable in the control group. Finally, in Table 5, we take the average of all the normalized cognitive scores as our measure of cognitive scores, in order to reduce the sample size by an order of magnitude and keep it in the hundreds of thousands; the results are nearly identical if we stack each measure instead.

In order to address the fact that some observations of the dependent variable are missing, we undertake an alternative procedure to impute missing data in Column 7 of Table 4. We exploit the fact that the data include demographic information on all children, including those missing in every year. Specifically, we have information on child gender, race, language at home, and whether the child resides in an urban area for both missing and non-missing children. For each time period, we run a probit to calculate the propensity of being in the sample. Specifically, we run a probit in which the dependent variable is a dummy for being missing and independent variables are all of the demographics above and their interactions along with dummies for the HS centers to which the parents applied, weighting each observation by the child base weight (which is available for all children and adjusts for the probability of being sampled but does not adjust for non-response). We then replace missing data with data on the nearest non-missing neighbor as given by the propensity score, weighting the imputed data by the missing individual's base weight.

In the text, we mention the results of a factor analysis of the variables, which are displayed in Appendix Table 3. A factor analysis can only be run on observations that are missing no data for any variable. While there is a large overlap across samples, different questions are asked in different years. To address this issue, we run the following separate factor analyses in the During period: one on the Fall 2002 data, one on the Spring 2003 data (excluding the questions asked of households missing a father), and one on the question asked of the single mother households. Using the Kaiser criterion, the process yielded two factors in Fall 2002, two factors in the Spring 2003 main sample, and no factors for the single parent household variables as the procedure did not find enough commonality between these variables. In the After period, different questions were asked by grade level, leading to a consistent set of questions for the kindergarten sample (the 4-year-olds in Spring 2004 and the 3-year-olds in Spring 2005) and the first grade sample (the 4-year-olds in Spring 2005 and the 3-year-olds in Spring 2006). Again, we ran a separate factor analysis on the questions asked of single mother households and the teacher-reported variables (since project staff were unable to interview every kindergarten and first grade teacher, leading to about $25 \%$ otherwise non-missing children missing data for teacher reports; we use the teacher interview weights for these variables). The procedure yielded five factors in the main 
kindergarten sample, four factors in the main first grade sample, and no factors in the other samples that have substantially fewer variables. Given these issues relating to missing data, the sample sizes tend to be smaller than in the other analyses, and they also vary across periods and samples. The results are robust to alternative means of addressing these issues-either imputing each missing variable or adding indicators for all missing variables and including them in the factor analysis.

In Appendix Table 5, we employ 58 measures of the degree to which HS centers encouraged parents to be involved with their children or otherwise interacted with parents. We use these measures to instrument for parent-reported measures of parent-center involvement. These measures are collected for children who attend any center-based child care, for both children in the treatment and control groups, including both HS and other forms of child care such as non-HS preschool or day care. For those children who did not attend any center-based care-typically children who are cared for at home-we set the values of the variables measuring center directors' reports of center encouragement to zero because parents of those not in a center mechanically received no encouragement from a center; the results are similar when setting these values to missing rather than zero, or when using a propensity score (estimated using all available demographics) to match missing and non-missing observations and replace missing with matched non-missing observations.

The characteristics of the center a child attends are potentially correlated with unobserved determinants of parent involvement, for example because parents who invest more in their children could systematically choose to send their children to better centers (particularly in the control group). Thus, in order to form the cleanest possible measure of the degree to which the center encourages parent involvement, we exclude own observations in forming the measure of center encouragement and only include the compliers. In other words, for individual $i$ in experimental group $g$ in program $p$, we calculate measure $m$ of center-based encouragement as follows:

(7) Encouragement $_{i p g m}=\frac{1}{n_{g p}-1} \sum_{j=1, j \neq i}^{n_{g p}}$ Encouragement $_{g p}$

Here $m$ indexes all 58 measures of center encouragement; experimental group $g \in\{0,1\}$ indexes whether individual $\mathrm{i}$ is in the treatment or control group; and $n_{g p}$ represents the number of compliers in experimental group $g$ in program $p .{ }^{53}$ (The results are similar regardless of whether we measure encouragement based on the average of the observations of others in the program and experimental group or based on the encouragement measure of the actual center that each child attended.) We only use data on those individuals that comply with their treatment status in each individual's program experimental group in order to form these measures of center encouragement (excluding own observations as described above); the results are extremely similar when using data on all individuals in order to form the measures of center encouragement. We obtain similar results when we aggregate to the level of the center and experimental group, rather than the program and experimental group (but do so on the level of the program because the Appendix Table 5 regressions effectively rely on variation at the level of the program).

Children's parents can decide whether to participate in the opportunities offered by the centers, such as volunteering in the center or seeking or accepting help from the center in providing

${ }^{53}$ For compliers in the treatment group, this measure of encouragement is the same for all children in a given center. 
medical care for their child. Thus, the eight parent-reported variables relating to involvement in their center are potentially endogenous to parent involvement but still contain information on the degree to which the center encouraged parent involvement. The parent-reported measures of involvement in the center therefore serve as natural endogenous variables. We measure these variables at the level of the individual child. These measures are instrumented using the director reported measures, in order to address the possibility of error in measuring the degree to which a center encouraged parent involvement.

\section{Appendix B: Description of Similarities and Differences from HHS (2010)}

Overall, we view our results as complementary to HHS (2010). There are just a few similarities between our paper and HSIS. In the main tables and figures of our paper, there is no overlap.

Overall, HHS (2010) finds only scant evidence that HS affected parent involvement. Only one of 61 measures of parent involvement that HHS (2010) examines is found to have been significantly affected by treatment at the $5 \%$ level after performing a correction for multiple comparisons. ${ }^{54}$ (Each of the 9 outcomes HHS (2010) examines was observed in multiple time periods, making 61 total.) In Appendix Table 2, 5 outcomes that we use are also examined in HHS (2010), but 84 other parent involvement outcomes that we use are not analyzed at all in HHS (2010). Among these 5 outcomes (dentist visits, one measure of reading with children, cultural activities, school contact, and parent participation in school), we examine the reading and dentist variables differently than HHS (2010). HHS (2010) codes the reading variable as binary, but we keep in its original multiple-category form. We exclude observations of the dentist variable for which the parent reported that HS helped them get the care for their child (in Table 4 where this variable is used), while HHS (2010) did not, and we wholly exclude the dentist outcome when aggregating results in the main tables. (The purpose of HHS (2010) is to investigate how attending HS influences the receipt of dental care, and thus it make sense that HHS (2010) included these observations. By contrast, we are interested in abstracting from the effect that HS-specific measures had on parent involvement, in order to understand the mechanisms that underlie the effect of HS on parent involvement. Our results are extremely similar whether or not we exclude these variables.)

There are also four other "parent" measures that HSIS include in their report that we do not include in our analysis (spanking, use of timeout, a 10-item safety precaution scale, and "parenting style"). Among other reasons, we do not include these because they are difficult to interpret as parent involvement. Spanking and the use of timeout are difficult to interpret as measures of parent involvement because they may be a reaction to the children's behavior, and also because parents may spank and send their children to timeout less because they are mechanically around their children for fewer hours in the day. The 10-item safety precaution scale includes questions, for example, about whether the parents have a working smoke detector in the home, a choice that does not necessarily relate directly to investment in children. Parenting style, such as the degree of authoritativeness, is classified via Baumrind's typology of parenting styles, but none of these parenting styles necessarily indicates greater or lesser investment with children. Again, the examination of these measures are fully consistent with the goal of the HSIS analysis, which is about understanding the broad impacts of HS; nonetheless, for our purposes, they are often difficult to characterize as parent involvement.

\footnotetext{
${ }^{54}$ HHS (2010) corrects for multiple comparisons within each of several time periods and within each of the two cohorts, so that the typical correction they perform is across approximately 7 outcomes.
} 
HHS (2010) finds that none of the measures is significantly affected after the experiment, which is at odds with our finding of a positive and statistically significant impact on parent involvement in the After period. HHS (2010) always examines each cohort-time period separately and does not include data from Fall 2002.

\section{Appendix C: Description of Jackknife Procedure and results in Appendix Table 5}

Let $g \in\{0,1\}$ be an indicator for the experimental group in question, which equals 1 if an observation is in the treatment group and 0 if an observation is in the control group. Similarly to Chetty et al. (2011), we calculate the quality of each individual $i$ 's program $p$ in the During period $\left(C Q u a l_{i p}\right)$ as the difference between the average scores of the $n_{g p}-1$ other students from $i$ 's program $p$ and experimental group $g$ and the average scores of the $m_{-g p}$ students assigned to $i$ 's program $p$ in the opposing experimental group $-g .:^{.5}$

$$
\text { (8) } C \text { Qual }_{i p}=\frac{1}{n_{g p}-1} \sum_{j \in g, j \neq i} \operatorname{Cog}_{j p}-\frac{1}{m_{-g p}} \sum_{k \in-g} \operatorname{Cog}_{k p}
$$

This serves as a measure of the program's quality because high-quality programs will tend to have larger differences in mean cognitive scores between the treatment group and the control group (excluding own score) ${ }^{56}$ To form the measure of cognitive scores in (8), we normalize each child's cognitive measures to have mean 0 and standard deviation 1 and take the mean.

In Column 1 of Appendix Table 5, we then regress normalized parent inputs for individual $i$ on $i$ 's cognitive scores, pooling data on all measures of parent inputs. In particular, the "reduced form" regression we run in Columns 1-3 of the table is:

(9) Involvement $_{i p}=\alpha_{o}+\alpha_{1}\left(T_{i p} * C Q u a l_{i p}\right)+\alpha_{2} T_{i p}+\alpha_{3} C Q u a l_{i p}+\delta_{p}+\varepsilon_{i p}$

where $\alpha_{1}$ represents the coefficient of interest on the interaction between treatment and the measure of program quality $\left(T_{i p}{ }^{*} C Q u a l_{i p}\right) ; T_{i p}$ represents the treatment dummy; and $\delta_{p}$ represents program fixed effects. Intuitively, these regressions estimate the association between parent inputs and an increase in cognitive scores (after conditioning on the main effect of treatment, the main effect of program quality, and program fixed effects). Column 1 of Appendix Table 5 shows that program quality is highly correlated with parent involvement: the coefficient on program quality in the During (After) period is $0.25(0.13)$, with a standard error of $0.09(0.07)$ (significantly different from zero at the $1 \%(10 \%)$ level). ${ }^{57}$

\footnotetext{
${ }^{55}$ The "opposing experimental group" of the treatment group is the control group, and the "opposing experimental group" of the control group is the treatment group.

${ }^{56} \mathrm{We}$ calculate this measure for both individuals in the treatment and control groups; within a program, the measure of quality will therefore tend to be positive in one experimental group and negative in the other.

${ }^{57}$ Note that when we perform our regressions in the After period, we form our measure of program quality using cognitive or non-cognitive scores from the During period, whereas our dependent variable is formed using parent involvement measures from the After period. Thus, it is important to note that in these regressions, we are effectively correlating program impacts on cognitive or non-cognitive scores in the During period with program impacts on parent involvement in the After period. We do so because cognitive and non-cognitive scores are insignificantly affected by treatment in the After period (as shown in Appendix Table 4), so there is effectively no useful variation in cognitive or non-cognitive scores across programs in the After period. When we instead construct a measure of program quality using cognitive or non-cognitive scores in the After period, we find that these are insignificantly associated with impacts on parent involvement. It remains of interest to investigate whether impacts on cognitive or non-cognitive
} 
We analogously calculate a measure of the program's quality NCQual ${ }_{i p}$ based on children's noncognitive scores $N C o g$ :

$$
\text { (10) } N_{C Q u a l}=\frac{1}{n_{g p}-1} \sum_{j \in g, j \neq i} N \operatorname{Cog}_{j p}-\frac{1}{m_{-g p}} \sum_{k \in-g} N \operatorname{Cog}_{k p}
$$

In Column 2 of Appendix Table 5, we use this measure of program quality based on normalized non-cognitive scores of peers in the program and use NCQual in regression (9) instead of CQual. This shows that peers' non-cognitive scores have no significant association with parent inputs in the During period (and a marginally significant association in the After period). When we add both measures of program quality to the regression in Column 3, the cognitive score-based measure of program quality picks up most of the variation in both the During and After periods. In the During period, the coefficient on the cognitive score-based measure of program quality is significantly different from zero at the $5 \%$ level, whereas the point estimate of the coefficient on the non-cognitive score-based measure of program quality is small and insignificantly different from zero.

As an alternative, we follow the spirit of Chetty et al. (2011) by instrumenting for cognitive (noncognitive) scores with the interaction of program quality and treatment status. In particular, the first stage regression for cognitive scores is:

$$
\text { (11) } \operatorname{Cog}_{i p}=\beta_{o}+\beta_{1}\left(T_{i p} * C Q u a l_{i p}\right)+\beta_{2}\left(T_{i p} * N C Q u a l i p\right)+\beta_{3} C Q u a l_{i p}+\beta_{4} N C Q u a l_{i p}+\beta_{5} T_{i p}+\delta_{p}+u_{i p}
$$

where $\beta_{1}$ and $\beta_{2}$ represent the coefficients on the interactions between treatment and the measures of program quality ( $T_{i p} * C Q u a l_{i p}$ and $T_{i p} * N C Q u a l_{i p}$, respectively), which serve as excluded instruments. We run an analogous first-stage regressions in which non-cognitive scores and Head Start attendance serve as the dependent variables. The second stage is:

$$
\text { (12) Involvement } \text { Ip }_{i}=\gamma_{o}+\gamma_{1} C H A T+\gamma_{2} N C H A T+\gamma_{3} C Q u a l_{i p}+\gamma_{4} N C Q u a l_{i p}+\gamma_{5} H S_{i p}+\delta_{p}+v_{i p}
$$

Here CHAT represents the fitted values from the first stage regression (10), NCHAT represents the fitted values from the analogous first stage regression for non-cognitive scores, $H S$ represents the fitted values from the first stage regression of the Head Start enrollment dummy on the Head Start access dummy, and $\gamma_{1}$ and $\gamma_{2}$ represent the coefficients of interest. ${ }^{58}$ In the During period, the regression in Column 4 confirms the finding that effects on cognitive scores are highly correlated across programs with effects on parent involvement, whereas non-cognitive scores have no significant association with parent involvement. ${ }^{59}$ In the After period, cognitive and non-

scores in the During period are correlated with impacts on parent involvement in the After period, for example because parents in the After period could observe the impact on child cognitive scores in the During period and expect them to continue to the After period.

${ }^{58}$ This regression could estimate biased effects of cognitive scores on parent involvement if the effects of treatment on cognitive scores are correlated across programs with unobserved determinants of parent involvement. We emphasize that our primary goal in Appendix Table 5 is rather to estimate the association between program effects on cognitive scores and on parent inputs.

${ }^{59}$ When we put cognitive or non-cognitive scores in the IV regression separately (as in the reduced form regressions in Columns 1 and 2), we again estimate that cognitive scores have a highly significant positive association with parent involvement and that non-cognitive scores have an insignificant positive association with parent involvement. 
cognitive score impacts are both insignificantly associated with parent involvement, though the point estimates are both positive. ${ }^{60}$

In Columns 5 and 6, we investigate how these results are affected by controlling for other factors that could mediate the relationship between Head Start enrollment and parent inputs. As noted in the text, it is possible that certain programs could be particularly effective both in raising cognitive scores and in raising parent inputs. However, we find that the degree to which programs encourage parent involvement has little association with the estimated effects.

In Column 5, we show that the coefficient on cognitive scores is little changed from Column 4 by controlling for center directors' detailed reports of measures that their centers sponsor that involve parents. Center directors in both the treatment and control groups filled out an exhaustive survey about ways in which their center encouraged parents to be involved in school-related activities or otherwise may have interacted with parents. (For those in the control group, these variables measure the degree to which their childcare center encouraged these activities) ${ }^{61}$ These 58 variables, listed in Appendix Table 1, include detailed questions about the degree to which parents volunteer in the center, detailed aspects of the services provided to the community by the center (such as through parent education meetings), and other ways parents might be included in the preschool experience (such as informing parents of their children's progress in school or home visits by center staff). These arguably collectively constitute the main ways that HS may potentially involve parents. Note that moreover, we do not take a stand a priori on which of these measures, if any, influences parent involvement; rather, the regressions will reveal which if any of these measures is correlated with parent involvement.

These reports by center directors of the actions their centers take to involve parents may measure with error the degree to which the center encourages parent involvement. In order to address this concern, we instrument for one measure of the degree to which centers encouraged parent involvement using another measure, in the hope that these two measures may have uncorrelated measurement errors. ${ }^{62}$ Parents also reported eight measures of ways in which they are involved with their children's center-based program (which again may include Head Start, other preschools, or other childcare centers) or ways in which the program involves the family, and

\footnotetext{
${ }^{60} \mathrm{As}$ in Chetty et al. (forthcoming), interpreting these results is potentially confounded by the presence of peer effects. With peer effects, a high ability student may raise his peers' scores; since cognitive ability and parent involvement are correlated in a cross-section of students, this could lead in a finite sample to a positive correlation across programs in the estimated effect of treatment on peers' cognitive scores and peers' parent involvement. While we cannot entirely purge our estimator of the influence of peer effects, peer effects are likely to account for at most a tiny fraction of the correlation documented in Appendix Table 5 (much as Chetty et al. argue in their context). This is because the results are estimated with variation at the level of the program, which on average enrolls a total of over 400 students, representing children spread across multiple locations and multiple classrooms within a location. A treated student in our sample shares a classroom (that has an estimated mean class size of 18.5 students) with a mean of 1.37 out of the 36.16 other treated children from each program in our sample. In a linear-in-means model of peer effects, this implies that the scope for potential peer effects within the treatment group is very small and highly unlikely to explain even a minor part of the strong correlation documented in Figure 2 and Appendix Table 5.

${ }^{61}$ A "center" may include a childcare center, preschool or pre- kindergarten program. The construction of these variables is discussed in Appendix A.

${ }^{62}$ When we control for the 58 center director reports and omit parent reports from the regression equation, rather than using the 58 center director reports as instruments for parent reports-that is, we run the reduced form regression-we estimate qualitatively similar results to those shown in Columns 5 and 6.
} 
these parent reports are in fact highly correlated with the director reports (with first-stage Fstatistics typically in the hundreds). ${ }^{63}$

Consistent with the argument that the measures HS centers took to involve parents have little association with the impacts on parent involvement, Appendix Table 5 shows that the average coefficient on the eight normalized parent-reported center measures is small and insignificantly different from zero. Moreover, the next row of Appendix Table 5 shows that the F-statistic on parent reports of measures that HS centers took to involve them indicates that they are jointly insignificantly different from zero in the During and After periods in both Columns 5 and 6. In comparison with the estimated coefficients on cognitive (or non-cognitive) scores, the average point estimate of the coefficients on center measures is very small. The estimated association between cognitive scores and parent involvement is also insignificantly different in Columns 4 and 5 in both the During and After periods ( $>00.40)$.

We also may be interested in the extent to which changes in measures of parent labor force participation are associated with the changes in investment in children. To shed some suggestive light on this question, we additionally control for (endogenous) measures of mothers' and fathers' labor force participation in the During (After) period. The presumption that these should matter little to the results - given the weak effects of HS enrollment on parent labor force participation later estimated in Appendix Table 6-is confirmed. The coefficients on cognitive and noncognitive scores are little changed by controlling for parents' labor force participation from Column 5 to Column 6 ( $\mathrm{p}>0.40)$.

These results document an association between program effects on parent involvement and program effects on cognitive scores (or, to a lesser extent, non-cognitive scores). Unsurprisingly, these program effects are also estimated to be positively correlated when the dependent variable is formed by pooling normalized cognitive score measures, and the independent variable is constructed by forming a measure of program quality based on the extent to which it raises parent involvement. ${ }^{64}$ We implement this in Column 7 of Appendix Table 5. Specifically, we form a measure of program quality based on the difference in normalized mean parent involvement in the During period in the treatment and control groups, which we call PQual ${ }_{i p}$ :

$$
\text { PQual }_{i p}=\frac{1}{n_{g p}-1} \sum_{j \in g, j \neq i} \text { Parent }_{j p}-\frac{1}{m_{-g p}} \sum_{k \in-g} \text { Parent }_{k p}
$$

We then pool cognitive scores and regress these on the parent involvement-based measure of program quality formed above:

$$
\text { (14) } \operatorname{Cog}_{i p}=\phi_{o}+\phi_{1}\left(T_{i p} * P Q u a l_{i p}\right)+\phi_{2} T_{i p}+\phi_{3} P Q u a l_{i p}+\delta_{p}+\varepsilon_{i p}
$$

\footnotetext{
${ }^{63}$ These measures are the following: how often the parents attended parent teacher/child-care provider conferences, how often the parents attended parent education meetings or workshops, how often the parents volunteered in the childcare setting, how often the parents attended or helped out with activities such as fieldtrips, fundraising, policy council, or other planning activities, how often parents participated in other activities at the child's setting, whether the center staff visited the home, whether the center helped the parents acquire dental care for their child, and whether the center helped the parents acquire a health screening for their child.

${ }^{64}$ As noted in the text, the cross-program correlation of effects on parent involvement and effects on cognitive scores could arise inter alia from effects of cognitive scores on parent involvement, or vice versa.
} 
Column 7 of Appendix Table 5 reports the coefficient $\phi_{1}$ from this regression, showing that program effects on parent quality and cognitive scores are again highly positively and significantly correlated in both the During and After periods. Implementing the IV version of this regression (analogous to the specification in Columns 4-6) again shows similar results. When non-cognitive scores are made the dependent variable, and parent involvement-based measure of quality is the independent variable of interest (as in Column 7), the results again show a weaker and insignificant correlation between the two.

Collectively, these results are suggestive of the conclusion that parent inputs are strongly associated across HS programs with gains in cognitive scores, somewhat associated across HS programs with gains in non-cognitive scores, but little (and insignificantly) associated with observable measures that centers take to involve parents, and little (and insignificantly) associated with changes in parent time allocation. (Note that parent inputs are little associated with observable measures that centers take to involve parents even though these center directorreported characteristics do successfully predict parent-reported parent involvement in center activities, indicating that the measures reported by center directors do provide useful information.) As we note in the text, in keeping with the spirit of results, which document an association of parent involvement with cognitive scores but not with Head Start center characteristics, when we instrument for own cognitive scores using the cognitive scores of peers in Column 4 of Appendix Table 5, the coefficient on the HS dummy is greatly affecteddecreasing from 0.16 when we implement the specification in Appendix Table 5 without including cognitive scores as a regressor, to 0.08 when we do include cognitive scores $(\mathrm{p}<.01)$ but when we control for HS center characteristics in Column 5, the coefficient on the HS dummy stays at 0.08 ( $p>0.40)$. Similarly, when we run the regression from Table 2 Row A and control for cognitive scores, the coefficient on the HS dummy is greatly affected (going down by $56 \%, \mathrm{p}<.01$ for the test of equal coefficients to Table 2 Row A), but when we control for HS center characteristics, the coefficient on the HS dummy is insignificantly affected ( $p>0.40)$ and the point estimate changes little. Unsurprisingly, controlling for changes in parents' time allocation in the Table 2 Row A also matters negligibly to the coefficient on the HS dummy ( $p>0.40)$. Nonetheless, due to the caveats noted above-omitted variable bias may impact how to interpret the coefficient estimate on the program quality measures, and it is possible that parent inputs could be partly responsible for the increase in cognitive and non-cognitive measures, rather than the reverse-we stress that the results in this section constitute suggestive, rather than definitive, evidence.

\section{Appendix D: Description of Appendix Table 6 Results not Discussed in Main Text}

Appendix Table 6 Panel A shows the estimated effect of HS on parents' choices. Row A shows that childcare expenses fall significantly in response to Head Start enrollment. Rows B through E show that both during and after the experiment, mothers' and fathers' probability of working is affected insignificantly by treatment at the $5 \%$ level. ${ }^{65}$ (Though note that the confidence intervals are wide enough that we cannot rule out substantial changes in work.)

\footnotetext{
${ }^{65}$ The finding of no significant effect of HS on mothers' labor supply is perhaps surprising in light of the finding of Jonah Gelbach (2002), who found strong effects of child schooling opportunities on mothers' labor supply. The discrepancy in the results suggests either that HS represents a substantially different context or study population than that in previous studies or that such effects exist but the sample size is not large enough for us to detect effects. The effect on fathers' probability of working in the During period is insignificant at the $10 \%$ level under our alternative imputation procedure in Column 4 of Table 2.
} 
Further insight on children's time allocation is gained by investigating the impact of HS on other measures of children's time in Appendix Table 6 Panel B. There is a positive and significant (at $1 \%$ ) effect of HS on non-parent childcare (Row F). By contrast, there is a strong negative and significant (at the 1\% level) effect of HS on weekly hours at a center-based daycare other than HS (Row G), on weekly hours at a day care run from a home (Row H), and on weekly childcare hours with non-parent relatives (Row I). ${ }^{66}$

\section{Appendix E: Conceptual Framework}

This appendix presents a toy conceptual framework. The goal of this appendix is to sketch an extremely stripped-down framework that is consistent with the empirical findings, specifically that parent inputs rise when children are enrolled in Head Start, that this effect is correlated with the effect of Head Start on child cognitive scores, and that total parent-child time may have decreased. The aim is simply to fix ideas about a small number of key determinants of parents' decisions, in order to illustrate that the findings may be consistent with a simple framework, rather than to present a fully-fledged model of parent investment and child schooling. This model is taken as representing parents' choices in the During period, while children are potentially enrolled in Head Start. ${ }^{67}$

Parents maximize their utility $U$, which is defined over parent-child teaching time $P_{l}$, parent-child non-teaching time $P_{2}$, non-child parent time $N$, and child quality $V$ :

$$
\text { (15) } \max _{P_{1}, P_{2}} U=U\left(P_{1}, P_{2}, N, V\right)
$$

We assume that $U_{i}>0$ and $U_{i i}<0$ for all $i$ (and that $U$ is twice continuously differentiable in all of its arguments). The subscript $i$ on $U$ denotes the partial derivative of $U$ with respect to the $i$-th argument. Parent-child teaching time $P_{l}$ represents the time parents spend engaging in activities that are likely to have a particularly large positive effect on their children's human capital. Other parent-child time $P_{2}$ represents other activities that parents may do with their children, such as watching TV while their children are in the room, that are less likely to raise their children's human capital. We include two possible types of parent-child time in order to accommodate the possibility that total parent-child time falls even while parent-child investment time rises, which is indicated by the empirical results. (Appendix Table 6 Panel B shows that HS access raises children's weekly number of hours in childcare including HS (other than childcare by parents) by 11.71 hours per week, and the effect is significantly different from zero at the $1 \%$ level. Assuming that children must either be with their parents or in non-parent child care-a reasonable approximation for 3- and 4-year-olds that we discuss further when we present the time budget constraints below-this implies that total time with parents must have decreased.)

Non-child parent time $N$ encompasses all other activities that parents may engage in, including market work, leisure, and housework not involving children. We collapse all other parent activities into a single aggregate under the rationale that distinguishing, for example, between work and non-work activities is not central to the mechanisms we intend to illustrate in this

\footnotetext{
${ }^{66}$ Weekly hours at a center-based daycare other than HS and weekly hours at a daycare run from a home are mutually exclusive categories and differ because receiving home-based daycare rules out the possibility that this daycare is run at a center.

${ }^{67}$ A framework with multiple periods-i.e. both During and After periods-would complicate the presentation while not providing additional insight about the interaction of Head Start and parents' and children's budget constraints, which are the focus of the model presented.
} 
appendix. ${ }^{68}$ Child characteristics $V$ may include children's human capital, long-run earnings outcomes, or other child characteristics that parents value and that motivate parents to invest in their children. Child quality $V$ is in turn a function of their time in Head Start $H$, their time in nonHead Start non-parent child care $D$, parent teaching time $P_{l}$, and parent-child non-teaching time $P_{2}: V=V\left(H, D, P_{1}, P_{2}\right)$. We may assume that $V$ is twice continuously differentiable in all of its arguments, and it is also reasonable to assume that $V_{1}>0$ and $V_{3}>0$. D may encompass day care, non-Head Start schooling, or other child care settings. $H$ is an exogenous parameter that depends on Head Start enrollment (and depends in expectation on Head Start access).

Note that $V$ depends directly on Head Start time $H$, even though we could alternatively assume with no substantive impact on the results that $V$ depends inter alia on the interaction of $P_{l}$ with prior child cognitive characteristics, which in turn depends on Head Start enrollment. In other words, we could alternatively write $V=V\left(Q(H), D, P_{1}, P_{2}\right)$, where $Q(H)$ represents child cognitive characteristics $Q$, which may depend on the influence of Head Start $H$. This shows parents reacting to the cognitive impacts of Head Start, rather than directly to Head Start, which may be rhetorically closer to the mechanism postulated in the text. Above we instead let $V$ depend directly on Head Start time $H$ for notational convenience.

As discussed in the text, we sometimes refer to $P_{l}$ as an "investment," but strictly speaking we mean simply that $P_{l}$ has both a direct impact on utility and an indirect effect through child characteristics (whose value to parents may in part be realized later in life, for example through child earnings outcomes, much as an investment would). All of the key points discussed belowthe fact that parent-child teaching time can rise in response to Head Start even as total parentchild time falls, and that the effect of Head Start on parent-child teaching time can be strengthened as the complementarity of teaching time and Head Start rises-are also consistent with a model in which $U_{1}<0$ (and $U_{11}>0$ ), so that the direct effect of parent-child teaching time on utility is negative (at the margin) and parents teach their children only because it produces valued child characteristics $V$.

The above assumption on $V$ implies that we can re-write (15) above as:

$$
\max _{P_{1}, P_{2}} U=U\left(P_{1}, P_{2}, N, V\left(H, D, P_{1}, P_{2}\right)\right)
$$

Parents therefore value $P_{1}$ and $P_{2}$ both directly in the utility function, and indirectly insofar as these inputs change child characteristics $V$.

Importantly, this expression shows that parent effort costs must be included in any calculation of the welfare effect of Head Start (due to the direct dependence of $U$ on $P_{l}$ ). If social welfare were the sum of parent and child utility (e.g. $W=U+U_{C}\left(P_{1}, P_{2}, H, D\right)$, where $W$ is social welfare and $U_{C}$ is child welfare), then the dependence of both $U$ and $U_{C}$ on (inter alia) $P_{l}$ must be taken into account in a social welfare calculation.

Parents maximize (16) subject to the parents' and children's time budget constraints, (17) and (18) respectively:

$$
P_{1}+P_{2}+N=T
$$

\footnotetext{
${ }^{68}$ We do so while recognizing that childcare availability is likely to change parents' effective wage by decreasing hourly childcare expenditures; our framework represents a convenient simplification that abstracts from this issue.
} 


$$
P_{1}+P_{2}+H+D=T
$$

The parent's time budget constraint says that the parent's time endowment $T$ is devoted to parentchild teaching time, parent-child non-teaching time, or other activities. The child's time budget constraint says that the child's time endowment $T$ is devoted to parent-child teaching time, parent-child non-teaching time, time in Head Start, or time in non-parent non-Head Start child care. (It is possible that preschool-aged children also spend time with friends or by themselves, without any form of supervision from parents, school, or other child-care providers. The model can encompass these possibilities by subsuming them in $D .{ }^{69}$ ) The implication of the child time budget constraint is that children who are enrolled in HS mechanically have less potential time to spend with their parents, since a large fraction of their day is now spent in HS rather than with their parents.

Solving this model yields the following expressions for the effect of $H$ on $P_{1}$ and $P_{2}$ :

$$
\begin{aligned}
& \frac{\partial P_{1}}{\partial H}=\frac{C E-B F}{B D-A E} \\
& \frac{\partial P_{2}}{\partial H}=\frac{C D-A F}{A E-B D}
\end{aligned}
$$

where $A, B, C, D, E$, and $F$ are defined as follows:

$$
\begin{aligned}
A= & U_{11}+U_{33}-2 U_{13}+\left[2 U_{14}-2 U_{34}+U_{44}\left(V_{3}-V_{2}\right)\right]\left(V_{3}-V_{2}\right)+U_{4}\left(V_{22}+V_{33}-2 V_{23}\right) \\
B= & U_{12}+U_{33}-U_{13}-U_{23}+\left(U_{14}-U_{34}\right)\left(V_{4}-V_{2}\right)+\left[U_{24}-U_{34}+U_{44}\left(V_{4}-V_{2}\right)\right]\left(V_{3}-V_{2}\right) \\
& +U_{4}\left(V_{22}+V_{34}-V_{23}-V_{24}\right) \\
C= & {\left[U_{14}-U_{34}+U_{44}\left(V_{3}-V_{2}\right)\right]\left(V_{1}-V_{2}\right)+U_{4}\left(V_{13}+V_{22}-V_{12}-V_{23}\right) } \\
D= & U_{12}+U_{33}-U_{13}-U_{23}+\left(U_{24}-U_{34}\right)\left(V_{3}-V_{2}\right)+\left[U_{14}-U_{34}+U_{44}\left(V_{3}-V_{2}\right)\right]\left(V_{4}-V_{2}\right) \\
& +U_{4}\left(V_{22}+V_{34}-V_{23}-V_{24}\right) \\
E= & U_{22}+U_{33}-2 U_{23}+\left[2 U_{24}-2 U_{34}+U_{44}\left(V_{4}-V_{2}\right)\right]\left(V_{4}-V_{2}\right)+U_{4}\left(V_{22}+V_{44}-2 V_{24}\right) \\
F= & {\left[U_{24}-U_{34}+U_{44}\left(V_{4}-V_{2}\right)\right]\left(V_{1}-V_{2}\right)+U_{4}\left(V_{14}+V_{22}-V_{12}-V_{24}\right) }
\end{aligned}
$$

This solution illustrates a number of points. First, it is possible that $\partial P_{l} / \partial H$ can be positive (if $(C E-B F) /(B D-A E)>0$, which is not ruled out by the weak assumptions on utility): parent-child teaching time can increase in response to Head Start enrollment. Second, this is possible even if $\partial P_{2} / \partial H$ is negative (indeed, note that the denominator of the expression for $\partial P_{2} / \partial H$ is the negative of the denominator of the expression for $\partial P_{l} / \partial H$ ). Third, it is moreover possible that total parent time can fall with $H$ (i.e. $\left.\partial\left(P_{l}+P_{2}\right) / \partial H<0\right)$ even if $\partial P_{l} / \partial H>0$. As an example, suppose that $B D$ $A E>0$. Then $C>B F / E$ and $C>A F / D$ imply $\partial P_{l} / \partial H>0$ and $\partial P_{2} / \partial H<0 .{ }^{70}$ Moreover, if $C E$ $B F<C D-A E$ (which is guaranteed, for example, if $G_{1}>G_{2}$ and $F_{2}>F_{1}$ ), then $\partial P_{1} / \partial H<-\partial P_{2} / \partial H$ (implying $\left.\partial\left(P_{l}+P_{2}\right) / \partial H<0\right)$, even though $\partial P_{l} / \partial H>0$. Again, given the weak conditions on utility above, all of these scenarios are possible. Fourth, increased complementarity between Head Start

\footnotetext{
${ }^{69}$ If child time alone or with friends rises enough in response to Head Start enrollment, it could imply that the empirical results are consistent with the possibility that $P_{1}+P_{2}$ rises when in response to Head Start enrollment. As discussed in the text, we consider this to be a remote possibility. Nonetheless, we note that the framework in this section is also consistent with the possibility that $\partial\left(P_{1}+P_{2}\right) / \partial H>0$.

${ }^{70}$ If $B D-A E<0$, then $C<B F / E$ and $C<A F / D$ guarantee $\partial P_{1} / \partial H>0$ and $\partial P_{2} / \partial H<0$.
} 
$H$ and parent investment $P_{l}$ in producing valued child characteristics $V$ can increase the effect of Head Start on parent investment $\partial P_{l} / \partial H$. As the complementarity $V_{13}$ of $H$ and $P_{l}$ rises, this raises $C$; if $V_{13}$ is large enough in the scenario outlined above, this can cause $C>B F / E$ and $C>A F / D$. While $V_{13}>0$ is not a necessary condition for $\partial P_{l} / \partial H>0$ and $\partial\left(P_{1}+P_{2}\right) / \partial H<0$, it may push the results in this direction and is consistent with the empirical results presented.

Note that this captures Explanations 2 (or 3 ) in the text, but that Explanation 4 is different because it posits that parents directly derive more utility from spending more time with children who have been enrolled in Head Start (as opposed to deriving utility from parent involvement through the impact of Head Start on child characteristics $V$ ). In other words, Explanation 4 might postulate instead that parent utility is as follows:

$$
\max _{P_{1}, P_{2}} U=U\left(P_{1}, P_{2}, N, V(H)\right)
$$

and that $U_{14}>0$ and $V^{\prime}(H)>0$. Here child characteristics $V$ depend on Head Start enrollment $H$, and parents enjoy spending time more with children when their characteristics change due to Head Start $\left(U_{14}>0\right)$. Note that under this alternative utility function, the effect of Head Start on parentchild teaching time $P_{l}$ still would relevant to a calculation of the welfare impact of Head Start due to the direct dependence of $U$ on $P_{l}$. 
Appendix Table 2A. Effect of treatment on parent involvement during the experiment

\begin{tabular}{|c|c|c|c|c|c|c|c|}
\hline (1) Dependent Variable & $\begin{array}{l}(2) \\
\text { Scale }\end{array}$ & $\begin{array}{l}(3) \\
\text { Reduced } \\
\text { form }\end{array}$ & $\begin{array}{l}\text { (4) } \\
\text { IV }\end{array}$ & $\begin{array}{c}(5) \\
\text { Holm } \\
\text { adjust- } \\
\text { ment (p- } \\
\text { value) }\end{array}$ & $\begin{array}{l}(6) \\
\text { Lee } \\
\text { lower } \\
\text { bound }\end{array}$ & $\begin{array}{l}(7) \\
\mathrm{N}\end{array}$ & $\begin{array}{c}(8) \\
\text { R-sq./ } \\
\text { log- } \\
\text { likeli- } \\
\text { hood }\end{array}$ \\
\hline \multicolumn{8}{|c|}{ Learning-related activities with child } \\
\hline Practiced writing the alphabet & $0-2$ & $\begin{array}{c}0.12 \\
(0.05)^{* *}\end{array}$ & $\begin{array}{c}0.18 \\
(0.07)^{* *}\end{array}$ & 0.582 & -0.07 & 3571 & -811371 \\
\hline $\begin{array}{l}\text { Practiced writing/spelling } \\
\text { name }\end{array}$ & $0-2$ & $\begin{array}{c}0.22 \\
(0.05)^{* * *}\end{array}$ & $\begin{array}{c}0.32 \\
(0.07)^{* * *}\end{array}$ & 0.00 & 0.06 & 3564 & -807193 \\
\hline Practiced rhyming words & $0-2$ & $\begin{array}{c}0.13 \\
(0.05)^{* * *}\end{array}$ & $\begin{array}{c}0.19 \\
(0.07)^{* * *}\end{array}$ & 0.25 & -0.21 & 3550 & -671933 \\
\hline $\begin{array}{l}\text { Help with letters, words, or } \\
\text { numbers }\end{array}$ & $0-2$ & $\begin{array}{c}0.10 \\
(0.06)^{*}\end{array}$ & $\begin{array}{c}0.15 \\
(0.09)^{*}\end{array}$ & 1 & -0.03 & 3575 & -669388 \\
\hline Told Stories & $0-2$ & $\begin{array}{c}0.04 \\
(0.05)\end{array}$ & $\begin{array}{c}0.06 \\
(0.07)\end{array}$ & 1 & -0.14 & 3573 & -790609 \\
\hline $\begin{array}{l}\text { How many times read to child } \\
\text { in past week }\end{array}$ & $1-4$ & $\begin{array}{c}0.14 \\
(0.04)^{* * * *}\end{array}$ & $\begin{array}{c}0.21 \\
(0.09)^{* * *}\end{array}$ & 0.05 & 0.00 & 7257 & -1956648 \\
\hline For about how long at a sitting & $\begin{array}{l}\text { Contin- } \\
\text { uous }\end{array}$ & $\begin{array}{c}1.89 \\
(0.56)^{* * * *}\end{array}$ & $\begin{array}{c}2.78 \\
(0.82)^{* * *}\end{array}$ & 0.06 & -0.21 & 7211 & 0.00 \\
\hline $\begin{array}{l}\text { Time spent reading to child in } \\
\text { past week (constructed) }\end{array}$ & $\begin{array}{l}\text { Contin- } \\
\text { uous }\end{array}$ & $\begin{array}{c}12.73 \\
(3.26)^{* * *}\end{array}$ & $\begin{array}{c}18.71 \\
(4.79)^{* * *}\end{array}$ & -- & -14.25 & 7232 & 0.00 \\
\hline $\begin{array}{l}\text { Work on learning the names } \\
\text { of the letters }\end{array}$ & $1-6$ & $\begin{array}{c}0.17 \\
(0.05)^{* * *}\end{array}$ & $\begin{array}{c}0.25 \\
(0.07)^{* * *}\end{array}$ & 0.08 & 0.06 & 3692 & -1315266 \\
\hline Discuss new words & $1-6$ & $\begin{array}{c}0.20 \\
(0.05)^{* * *}\end{array}$ & $\begin{array}{c}0.29 \\
(0.07)^{* * *}\end{array}$ & 0.00 & 0.10 & 3678 & -1321145 \\
\hline Have [CHILD] tell you a story & $1-6$ & $\begin{array}{c}0.14 \\
(0.06)^{* *}\end{array}$ & $\begin{array}{c}0.21 \\
(0.09)^{* *}\end{array}$ & 0.70 & 0.03 & 3684 & -1353535 \\
\hline $\begin{array}{l}\text { Practice the sounds that letters } \\
\text { make or phonics }\end{array}$ & $1-6$ & $\begin{array}{c}0.25 \\
(0.05)^{* * *}\end{array}$ & $\begin{array}{c}0.37 \\
(0.07)^{* * *}\end{array}$ & 0.00 & 0.12 & 3684 & -1388395 \\
\hline $\begin{array}{l}\text { Listen to you read stories } \\
\text { where [CHILD] sees the print } \\
\text { such as Big Books }\end{array}$ & $1-6$ & $\begin{array}{c}0.19 \\
(0.05)^{* * *}\end{array}$ & $\begin{array}{c}0.28 \\
(0.07)^{* * *}\end{array}$ & 0.01 & 0.08 & 3689 & -1329234 \\
\hline $\begin{array}{l}\text { Listen to you read stories } \\
\text { where (he/she) doesn't see the } \\
\text { print. }\end{array}$ & $1-6$ & $\begin{array}{c}0.06 \\
(0.05)\end{array}$ & $\begin{array}{c}0.09 \\
(0.07)\end{array}$ & 1 & -0.11 & 3679 & -1320080 \\
\hline Retell or make up stories. & $1-6$ & $\begin{array}{c}0.06 \\
(0.05)\end{array}$ & $\begin{array}{c}0.09 \\
(0.07)\end{array}$ & 1 & -0.06 & 3681 & -1384593 \\
\hline
\end{tabular}


Appendix Table 2A (continued). Effect of treatment on parent involvement during the experiment

\begin{tabular}{|c|c|c|c|c|c|c|c|}
\hline (1) Dependent Variable & $\begin{array}{l}(2) \\
\text { Scale }\end{array}$ & $\begin{array}{l}(3) \\
\text { Reduced } \\
\text { form }\end{array}$ & $\begin{array}{l}(4) \\
\text { IV }\end{array}$ & $\begin{array}{c}(5) \\
\text { Holm } \\
\text { adjust- } \\
\text { ment (p- } \\
\text { value) }\end{array}$ & $\begin{array}{c}\text { (6) } \\
\text { Lee } \\
\text { lower } \\
\text { bound }\end{array}$ & $\begin{array}{l}(7) \\
N\end{array}$ & $\begin{array}{c}(8) \\
\text { R-sq./ } \\
\text { log- } \\
\text { likeli- } \\
\text { hood }\end{array}$ \\
\hline \multicolumn{8}{|l|}{ Learning-related activities with child } \\
\hline $\begin{array}{l}\text { Show [CHILD] how to read a } \\
\text { book or magazine }\end{array}$ & $1-6$ & $\begin{array}{l}0.16 \\
(0.06)^{* * * *}\end{array}$ & $\begin{array}{c}0.24 \\
(0.09)^{* * *}\end{array}$ & 0.22 & 0.04 & 3672 & -1367371 \\
\hline $\begin{array}{l}\text { Have [CHILD] practice } \\
\text { writing or spelling (his/her) } \\
\text { name. }\end{array}$ & $1-6$ & $\begin{array}{c}0.29 \\
(0.05)^{* * * *}\end{array}$ & $\begin{array}{c}0.43 \\
(0.07)^{* * * *}\end{array}$ & 0.00 & 0.20 & 3677 & -1326090 \\
\hline $\begin{array}{l}\text { Learn about rhyming words } \\
\text { and word families such as cat, } \\
\text { mat, sat. }\end{array}$ & $1-6$ & $\begin{array}{c}0.28 \\
(0.06)^{* * * *}\end{array}$ & $\begin{array}{c}0.41 \\
(0.09)^{* * * *}\end{array}$ & 0.00 & 0.12 & 3690 & -1315399 \\
\hline $\begin{array}{l}\text { Practice or teach directional } \\
\text { words such as over, up, or in. }\end{array}$ & $1-6$ & $\begin{array}{c}0.09 \\
(0.05)^{*}\end{array}$ & $\begin{array}{c}0.13 \\
(0.07)^{*}\end{array}$ & 1 & -0.02 & 3686 & -1375116 \\
\hline $\begin{array}{l}\text { Number of materials you use } \\
\text { to work on above reading and } \\
\text { language activities }\end{array}$ & $\begin{array}{l}\text { Contin- } \\
\text { uous }\end{array}$ & $\begin{array}{c}0.09 \\
(0.05)^{*}\end{array}$ & $\begin{array}{c}0.13 \\
(0.07)^{*}\end{array}$ & 1 & -0.00 & 3696 & 0.00 \\
\hline $\begin{array}{l}\text { Counted things that you can } \\
\text { see }\end{array}$ & $0-2$ & $\begin{array}{c}0.08 \\
(0.05)^{*}\end{array}$ & $\begin{array}{c}0.12 \\
(0.07)^{*}\end{array}$ & 1 & -0.06 & 3568 & -775208 \\
\hline Talk about the calendar & $0-2$ & $\begin{array}{c}0.01 \\
(0.05)\end{array}$ & $\begin{array}{c}0.01 \\
(0.07)\end{array}$ & 0.34 & -0.14 & 3571 & -757538 \\
\hline $\begin{array}{l}\text { Talk about how big something } \\
\text { is }\end{array}$ & $0-2$ & $\begin{array}{c}0.22 \\
(0.05)^{* * * *}\end{array}$ & $\begin{array}{c}0.32 \\
(0.07)^{* * * *}\end{array}$ & 0.00 & 0.02 & 3575 & -798032 \\
\hline $\begin{array}{l}\text { Help with letters, words, or } \\
\text { numbers }\end{array}$ & $0-2$ & $\begin{array}{l}0.10 \\
(0.06)^{*}\end{array}$ & $\begin{array}{c}0.15 \\
(0.09)^{*}\end{array}$ & 1 & -0.03 & 3575 & -669388 \\
\hline $\begin{array}{l}\text { Talk about the calendar or } \\
\text { days of the week. }\end{array}$ & $1-6$ & $\begin{array}{c}0.19 \\
(0.05)^{* * *}\end{array}$ & $\begin{array}{c}0.28 \\
(0.07)^{* * *}\end{array}$ & 0.05 & 0.08 & 3683 & -1358694 \\
\hline $\begin{array}{l}\text { Work with rulers, measuring } \\
\text { cups, spoons, or other } \\
\text { measuring instruments. }\end{array}$ & $1-6$ & $\begin{array}{l}0.17 \\
(0.05)^{* * * *}\end{array}$ & $\begin{array}{c}0.25 \\
(0.07)^{* * *}\end{array}$ & 0.08 & -0.04 & 3685 & -1200744 \\
\hline $\begin{array}{l}\text { Use dance or act out stories to } \\
\text { practice math ideas such as } \\
\text { numbers or size. }\end{array}$ & $1-6$ & $\begin{array}{c}0.18 \\
(0.06)^{* * *}\end{array}$ & $\begin{array}{c}0.26 \\
(0.09)^{* * * *}\end{array}$ & 0.08 & -0.01 & 3678 & -1161974 \\
\hline $\begin{array}{l}\text { Use music to understand math } \\
\text { ideas. }\end{array}$ & $1-6$ & $\begin{array}{c}0.18 \\
(0.06)^{* * * *}\end{array}$ & $\begin{array}{c}0.26 \\
(0.09)^{* * *}\end{array}$ & 0.08 & -0.02 & 3674 & -1087797 \\
\hline
\end{tabular}


Appendix Table 2A (continued). Effect of treatment on parent involvement during the experiment

\begin{tabular}{|c|c|c|c|c|c|c|c|}
\hline (1) Dependent Variable & $\begin{array}{c}(2) \\
\text { Scale }\end{array}$ & $\begin{array}{l}(3) \\
\text { Reduced } \\
\text { form }\end{array}$ & $\begin{array}{l}(4) \\
\text { IV }\end{array}$ & $\begin{array}{c}(5) \\
\text { Holm } \\
\text { adjust- } \\
\text { ment (p- } \\
\text { value) }\end{array}$ & $\begin{array}{l}\text { (6) } \\
\text { Lee } \\
\text { lower } \\
\text { bound }\end{array}$ & $\begin{array}{l}(7) \\
N\end{array}$ & $\begin{array}{c}(8) \\
\text { R-sq./ } \\
\text { log- } \\
\text { likeli- } \\
\text { hood }\end{array}$ \\
\hline \multicolumn{8}{|c|}{ Learning-related activities with child } \\
\hline Work with shape blocks. & $1-6$ & $\begin{array}{c}0.13 \\
(0.06)^{* *}\end{array}$ & $\begin{array}{c}0.19 \\
(0.09)^{* *}\end{array}$ & 0.82 & -0.01 & 3682 & -1365147 \\
\hline Count out loud. & $1-6$ & $\begin{array}{c}0.08 \\
(0.06)\end{array}$ & $\begin{array}{c}0.12 \\
(0.09)\end{array}$ & 1 & -0.00 & 3688 & -1109052 \\
\hline $\begin{array}{l}\text { Number of materials parents } \\
\text { use to work on above math } \\
\text { activities }\end{array}$ & $\begin{array}{l}\text { Contin- } \\
\text { uous }\end{array}$ & $\begin{array}{c}0.16 \\
(0.04)^{* * *}\end{array}$ & $\begin{array}{c}0.24 \\
(0.06)^{* * *}\end{array}$ & 0.02 & 0.07 & 3696 & 0.01 \\
\hline \multicolumn{8}{|l|}{ Other activities with child } \\
\hline $\begin{array}{l}\text { Played sports or exercised } \\
\text { together }\end{array}$ & $0-2$ & $\begin{array}{c}0.05 \\
(0.05)\end{array}$ & $\begin{array}{c}0.07 \\
(0.07)\end{array}$ & 1 & -0.14 & 3565 & -813850 \\
\hline $\begin{array}{l}\text { Played with toys or indoor } \\
\text { games together }\end{array}$ & $0-2$ & $\begin{array}{c}0.00 \\
(0.06)\end{array}$ & $\begin{array}{c}0.00 \\
(0.09)\end{array}$ & 0.99 & -0.11 & 3553 & -504379 \\
\hline Involved in chores & $0-2$ & $\begin{array}{c}0.04 \\
(0.05)\end{array}$ & $\begin{array}{c}0.06 \\
(0.07)\end{array}$ & 1 & -0.08 & 3573 & -661471 \\
\hline Took on errands & $0-2$ & $\begin{array}{c}0.02 \\
(0.05)\end{array}$ & $\begin{array}{c}0.03 \\
(0.07)\end{array}$ & 1 & -0.09 & 3573 & -561994 \\
\hline Arts \& Crafts & $0-2$ & $\begin{array}{c}0.06 \\
(0.05)\end{array}$ & $\begin{array}{c}0.09 \\
(0.07)\end{array}$ & 1 & -0.15 & 3559 & -802032 \\
\hline Arts \& Crafts & $1-6$ & $\begin{array}{c}0.09 \\
(0.05)^{*}\end{array}$ & $\begin{array}{c}0.13 \\
(0.07)^{*}\end{array}$ & 1 & -0.03 & 3682 & -1358100 \\
\hline $\begin{array}{l}\text { Number of materials parents } \\
\text { use to work on arts \& crafts }\end{array}$ & $\begin{array}{l}\text { Contin- } \\
\text { uous }\end{array}$ & $\begin{array}{c}0.12 \\
(0.06)^{*}\end{array}$ & $\begin{array}{c}0.18 \\
(0.09)^{*}\end{array}$ & 1 & -0.02 & 3696 & 0.00 \\
\hline $\begin{array}{l}\text { Gone to a play, concert, or } \\
\text { other live show }\end{array}$ & Binary & $\begin{array}{c}0.07 \\
(0.06)\end{array}$ & $\begin{array}{c}0.10 \\
(0.09)\end{array}$ & 1 & -0.33 & 7257 & -740270 \\
\hline $\begin{array}{l}\text { Talked with }[\mathrm{CHILD}] \text { about } \\
\text { family history or ethnic } \\
\text { heritage }\end{array}$ & Binary & $\begin{array}{c}0.09 \\
(0.05)^{*}\end{array}$ & $\begin{array}{c}0.13 \\
(0.07)^{*}\end{array}$ & 1 & -0.04 & 7262 & -1070025 \\
\hline $\begin{array}{l}\text { Visited an art gallery, } \\
\text { museum, or historical site }\end{array}$ & Binary & $\begin{array}{c}0.08 \\
(0.05)^{*}\end{array}$ & $\begin{array}{c}0.12 \\
(0.07)^{*}\end{array}$ & 1 & -0.30 & 7257 & -744096 \\
\hline $\begin{array}{l}\text { Attended an event sponsored } \\
\text { by a community, ethnic, or } \\
\text { religious group }\end{array}$ & Binary & $\begin{array}{c}0.06 \\
(0.05)\end{array}$ & $\begin{array}{c}0.09 \\
(0.07)\end{array}$ & 1 & -0.06 & 7265 & -1060156 \\
\hline
\end{tabular}


Appendix Table 2A (continued). Effect of treatment on parent involvement during the experiment

\begin{tabular}{|c|c|c|c|c|c|c|c|}
\hline (1) Dependent Variable & $\begin{array}{l}(2) \\
\text { Scale }\end{array}$ & $\begin{array}{l}(3) \\
\text { Reduced } \\
\text { form }\end{array}$ & $\begin{array}{l}(4) \\
\text { IV }\end{array}$ & $\begin{array}{c}(5) \\
\text { Holm } \\
\text { adjust- } \\
\text { ment (p- } \\
\text { value) }\end{array}$ & $\begin{array}{l}\text { (6) } \\
\text { Lee } \\
\text { lower } \\
\text { bound }\end{array}$ & $\begin{array}{l}(7) \\
\mathrm{N}\end{array}$ & $\begin{array}{c}(8) \\
\text { R-sq./ } \\
\text { log- } \\
\text { likeli- } \\
\text { hood }\end{array}$ \\
\hline \multicolumn{8}{|c|}{ Qualitative features of parenting practices } \\
\hline $\begin{array}{l}\text { "I encourage my child to be } \\
\text { curious, to explore, and to } \\
\text { question things" }\end{array}$ & $1-5$ & $\begin{array}{c}0.04 \\
(0.06)\end{array}$ & $\begin{array}{c}0.06 \\
(0.09)\end{array}$ & 1 & -0.08 & 3563 & -763701 \\
\hline $\begin{array}{l}\text { "Make sure my child knows I } \\
\text { appreciate what (he/she) tries } \\
\text { to accomplish." }\end{array}$ & $1-5$ & $\begin{array}{c}0.02 \\
(0.05)\end{array}$ & $\begin{array}{c}0.03 \\
(0.07)\end{array}$ & 1 & -0.08 & 3561 & -474905 \\
\hline $\begin{array}{l}\text { "I encourage my child to be } \\
\text { independent of me." }\end{array}$ & $1-5$ & $\begin{array}{c}0.02 \\
(0.04)\end{array}$ & $\begin{array}{c}0.03 \\
(0.06)\end{array}$ & 1 & -0.12 & 3554 & -837400 \\
\hline $\begin{array}{l}\text { "Once I decide how to deal } \\
\text { with misbehavior of child, I } \\
\text { follow through" }\end{array}$ & $1-5$ & $\begin{array}{c}0.06 \\
(0.04)\end{array}$ & $\begin{array}{c}0.09 \\
(0.06)\end{array}$ & 1 & -0.08 & 3551 & -949379 \\
\hline $\begin{array}{l}\text { "My child and I have warm } \\
\text { intimate moments together" }\end{array}$ & $1-5$ & $\begin{array}{c}0.11 \\
(0.06)^{* *}\end{array}$ & $\begin{array}{c}0.16 \\
(0.09)^{* *}\end{array}$ & 1 & 0.00 & 3564 & -644430 \\
\hline $\begin{array}{l}\text { "There are times I don't have } \\
\text { the energy to make my child } \\
\text { behave as (he/she) should" }\end{array}$ & $1-5$ & $\begin{array}{c}0.06 \\
(0.05)\end{array}$ & $\begin{array}{c}0.09 \\
(0.07)\end{array}$ & 1 & -0.11 & 3562 & -1097162 \\
\hline $\begin{array}{l}\text { "Teach child that misbehavior } \\
\text { or breaking the rules will } \\
\text { always be punished" }\end{array}$ & $1-5$ & $\begin{array}{c}0.11 \\
(0.05)^{* *}\end{array}$ & $\begin{array}{c}0.16 \\
(0.07)^{* *}\end{array}$ & 1 & -0.02 & 3560 & -905578 \\
\hline \multicolumn{8}{|l|}{ Medical } \\
\hline $\begin{array}{l}\text { Has [CHILD] been seen by a } \\
\text { dentist since September } \\
\text { (exclude if HS helped) }\end{array}$ & Binary & $\begin{array}{c}0.39 \\
(0.05)^{* * *}\end{array}$ & $\begin{array}{c}0.57 \\
(0.07)^{* * *}\end{array}$ & 0.00 & 0.35 & 6524 & -904456 \\
\hline $\begin{array}{l}\text { Do you have a place where } \\
\text { you usually take [CHILD] for } \\
\text { routine medical care }\end{array}$ & Binary & $\begin{array}{c}0.05 \\
(0.10)\end{array}$ & $\begin{array}{c}0.07 \\
(0.15)\end{array}$ & 1 & 0.01 & 7255 & -204014 \\
\hline $\begin{array}{l}\text { Has a professional tested } \\
\text { [CHILD's] hearing (exclude if } \\
\text { HS helped) }\end{array}$ & Binary & $\begin{array}{c}0.27 \\
(0.06)^{* * * *}\end{array}$ & $\begin{array}{c}0.40 \\
(0.09)^{* * *}\end{array}$ & 0.00 & 0.20 & 2806 & -421031 \\
\hline $\begin{array}{l}\text { Has a professional tested } \\
\text { [CHILD's] vision (exclude if } \\
\text { HS helped) }\end{array}$ & Binary & $\begin{array}{c}0.29 \\
(0.06)^{* * * *}\end{array}$ & $\begin{array}{c}0.43 \\
(0.09)^{* * *}\end{array}$ & 0.00 & 0.21 & 2810 & -421489 \\
\hline
\end{tabular}


Appendix Table 2A (continued). Effect of treatment on parent involvement during the experiment

\begin{tabular}{|c|c|c|c|c|c|c|c|}
\hline (1) Dependent Variable & $\begin{array}{l}(2) \\
\text { Scale }\end{array}$ & $\begin{array}{l}\text { (3) } \\
\text { Reduced } \\
\text { form }\end{array}$ & $\begin{array}{l}\text { (4) } \\
\text { IV }\end{array}$ & $\begin{array}{c}\text { (5) } \\
\text { Holm } \\
\text { adjust- } \\
\text { ment (p- } \\
\text { value) }\end{array}$ & $\begin{array}{c}\text { (6) } \\
\text { Lee } \\
\text { lower } \\
\text { bound }\end{array}$ & $\begin{array}{l}\text { (7) } \\
\mathrm{N}\end{array}$ & $\begin{array}{c}8) \\
\text { R-sq./ } \\
\text { log- } \\
\text { likeli- } \\
\text { hood }\end{array}$ \\
\hline \multicolumn{8}{|l|}{ Father inputs } \\
\hline $\begin{array}{l}\text { In the past month, on about } \\
\text { how many days has [CHILD] } \\
\text { seen (his/her) father }\end{array}$ & $\begin{array}{l}\text { Contin- } \\
\text { uous }\end{array}$ & $\begin{array}{c}0.62 \\
(0.58)\end{array}$ & $\begin{array}{c}0.91 \\
(0.85)\end{array}$ & 1 & -2.98 & 1729 & -249374 \\
\hline $\begin{array}{l}\text { Has your family received any } \\
\text { child support payments from } \\
\text { (his/her) father }\end{array}$ & Binary & $\begin{array}{l}-0.08 \\
(0.08)\end{array}$ & $\begin{array}{l}-0.12 \\
(0.12)\end{array}$ & 1 & -0.41 & 1716 & 0.00 \\
\hline \multicolumn{8}{|l|}{ Track how child learns and grows } \\
\hline $\begin{array}{l}\text { By keeping notes about } \\
\text { (his/her) behavior or progress }\end{array}$ & Binary & $\begin{array}{l}0.25 \\
(0.06)^{* * * *}\end{array}$ & $\begin{array}{c}0.37 \\
(0.09)^{* * * *}\end{array}$ & 0.01 & 0.14 & 3693 & -548854 \\
\hline $\begin{array}{l}\text { By collecting samples of } \\
\text { [CHILD]'s work }\end{array}$ & Binary & $\begin{array}{c}0.45 \\
(0.09)^{* * * *}\end{array}$ & $\begin{array}{c}0.66 \\
(0.13)^{* * *}\end{array}$ & 0.00 & 0.41 & 3692 & -299859 \\
\hline By collecting photos & Binary & $\begin{array}{c}0.21 \\
(0.07)^{* * * *}\end{array}$ & $\begin{array}{c}0.31 \\
(0.10)^{* * * *}\end{array}$ & 0.17 & 0.16 & 3691 & -283965 \\
\hline $\begin{array}{l}\text { By charting (his/her) behavior } \\
\text { or skills with stars or stickers }\end{array}$ & Binary & $\begin{array}{l}0.12 \\
(0.07)^{*}\end{array}$ & $\begin{array}{c}0.18 \\
(0.10)^{*}\end{array}$ & 1 & -0.02 & 3691 & -531240 \\
\hline By other means & Binary & $\begin{array}{c}0.13 \\
(0.07)^{*}\end{array}$ & $\begin{array}{c}0.19 \\
(0.10)^{*}\end{array}$ & 1 & -0.26 & 3692 & -329681 \\
\hline \multicolumn{8}{|l|}{ Rules or routines in the home } \\
\hline $\begin{array}{l}\text { Do you have a daily routine } \\
\text { that you usually follow with } \\
\text { your child }\end{array}$ & Binary & $\begin{array}{c}0.06 \\
(0.06)\end{array}$ & $\begin{array}{c}0.09 \\
(0.09)\end{array}$ & 1 & -0.01 & 3690 & -467397 \\
\hline $\begin{array}{l}\text { Do you regularly use an } \\
\text { organized educational } \\
\text { approach for activities }\end{array}$ & Binary & $\begin{array}{c}0.11 \\
(0.06)^{* *}\end{array}$ & $\begin{array}{c}0.16 \\
(0.09)^{* *}\end{array}$ & 1 & -0.01 & 3685 & -547512 \\
\hline $\begin{array}{l}\text { Rules or routines about } \\
\text { bedtime }\end{array}$ & Binary & $\begin{array}{c}0.32 \\
(0.06)^{* * *}\end{array}$ & $\begin{array}{c}0.47 \\
(0.09)^{* * *}\end{array}$ & 0.00 & 0.25 & 7269 & -615219 \\
\hline $\begin{array}{l}\text { Rule or routines about } \mathrm{TV} \\
\text { programs allowed to watch }\end{array}$ & Binary & $\begin{array}{c}0.11 \\
(0.06)^{* *}\end{array}$ & $\begin{array}{c}0.16 \\
(0.09)^{* *}\end{array}$ & 1 & 0.05 & 7209 & -572218 \\
\hline $\begin{array}{l}\text { Rules or routines about how } \\
\text { many hours of TV allowed to } \\
\text { watch }\end{array}$ & Binary & $\begin{array}{c}0.14 \\
(0.04)^{* * * *}\end{array}$ & $\begin{array}{c}0.21 \\
(0.06)^{* * * *}\end{array}$ & 0.08 & 0.04 & 7205 & -984131 \\
\hline $\begin{array}{l}\text { Rules or routines about what } \\
\text { kinds of food child eats }\end{array}$ & Binary & $\begin{array}{c}0.07 \\
(0.04)^{*}\end{array}$ & $\begin{array}{c}0.10 \\
(0.06)^{*}\end{array}$ & 1 & -0.03 & 7265 & -987202 \\
\hline
\end{tabular}


Appendix Table 2A (continued). Effect of treatment on parent involvement during the experiment

\begin{tabular}{|c|c|c|c|c|c|c|c|}
\hline (1) Dependent Variable & $\begin{array}{c}(2) \\
\text { Scale }\end{array}$ & $\begin{array}{c}(3) \\
\text { Reduced } \\
\text { form }\end{array}$ & $\begin{array}{l}\text { (4) } \\
\text { IV }\end{array}$ & $\begin{array}{c}\text { (5) } \\
\text { Holm } \\
\text { adjust- } \\
\text { ment (p- } \\
\text { value) }\end{array}$ & $\begin{array}{c}(6) \\
\text { Lee lower } \\
\text { bound }\end{array}$ & $\begin{array}{l}(7) \\
\mathrm{N}\end{array}$ & $\begin{array}{c}(8) \\
\text { R-sq./ } \\
\text { log- } \\
\text { likelihood }\end{array}$ \\
\hline \multicolumn{8}{|l|}{ Rules or Routines (continued) } \\
\hline $\begin{array}{l}\text { Rules or routines about what } \\
\text { chores child does }\end{array}$ & Binary & $\begin{array}{c}0.10 \\
(0.04)^{* *}\end{array}$ & $\begin{array}{c}0.15 \\
(0.06)^{* *}\end{array}$ & 0.51 & 0.01 & 7269 & -947540 \\
\hline \multicolumn{8}{|c|}{ Teacher- and Interviewer-Reported Parent Involvement } \\
\hline $\begin{array}{l}\text { A variety of learning materials } \\
\text { are available }\end{array}$ & $1-7$ & $\begin{array}{c}0.07 \\
(0.05)\end{array}$ & $\begin{array}{c}0.10 \\
(0.07)\end{array}$ & 1 & -0.15 & 3097 & -5679 \\
\hline
\end{tabular}


Appendix Table 2B. Effect of treatment on parent involvement after the experiment

\begin{tabular}{|c|c|c|c|c|c|c|c|}
\hline (1) Dependent Variable & $\begin{array}{l}(2) \\
\text { Scale }\end{array}$ & $\begin{array}{l}(3) \\
\text { Reduced } \\
\text { form }\end{array}$ & $\begin{array}{l}(4) \\
\text { IV }\end{array}$ & $\begin{array}{l}\text { (5) } \\
\text { Holm (p- } \\
\text { value) }\end{array}$ & $\begin{array}{l}(6) \\
\text { Lee lower } \\
\text { bound }\end{array}$ & $\begin{array}{l}(7) \\
\mathrm{N}\end{array}$ & $\begin{array}{l}\quad(8) \\
\text { R-sq./log- } \\
\text { likelihood }\end{array}$ \\
\hline \multicolumn{8}{|c|}{ Learning-related activities with the child } \\
\hline $\begin{array}{l}\text { How many time read to child } \\
\text { in past week }\end{array}$ & $1-4$ & $\begin{array}{c}0.01 \\
(0.04)\end{array}$ & $\begin{array}{c}0.01 \\
(0.06)\end{array}$ & 1 & -0.10 & 7075 & -2003609 \\
\hline For about how long at a sitting & $\begin{array}{l}\text { Contin- } \\
\text { uous }\end{array}$ & $\begin{array}{c}0.99 \\
(0.55)^{*}\end{array}$ & $\begin{array}{c}1.46 \\
(0.81)^{*}\end{array}$ & 1 & -2.55 & 7035 & 0.00 \\
\hline $\begin{array}{l}\text { How many minutes in the past } \\
\text { week did you read to your } \\
\text { child (constructed) }\end{array}$ & $\begin{array}{l}\text { Contin- } \\
\text { uous }\end{array}$ & $\begin{array}{c}4.79 \\
(3.25)\end{array}$ & $\begin{array}{c}7.04 \\
(4.78)\end{array}$ & -- & -18.64 & 7051 & 0.00 \\
\hline $\begin{array}{l}\text { Work on learning the names } \\
\text { of the letters }\end{array}$ & $1-6$ & $\begin{array}{l}-0.01 \\
(0.05)\end{array}$ & $\begin{array}{l}-0.01 \\
(0.07)\end{array}$ & 1 & -0.10 & 3533 & -1205496 \\
\hline Discuss new words & $1-6$ & $\begin{array}{c}0.02 \\
(0.05)\end{array}$ & $\begin{array}{c}0.03 \\
(0.07)\end{array}$ & 1 & -0.08 & 3531 & -1180900 \\
\hline Have [CHILD] tell you a story & $1-6$ & $\begin{array}{c}0.07 \\
(0.06)\end{array}$ & $\begin{array}{c}0.10 \\
(0.09)\end{array}$ & 1 & -0.04 & 3534 & -1312998 \\
\hline $\begin{array}{l}\text { Practice the sounds that letters } \\
\text { make or phonics }\end{array}$ & $1-6$ & $\begin{array}{l}-0.02 \\
(0.04)\end{array}$ & $\begin{array}{l}-0.03 \\
(0.06)\end{array}$ & 1 & -0.12 & 3543 & -1221099 \\
\hline $\begin{array}{l}\text { Listen to you read stories } \\
\text { where }[\text { CHILD] sees the print } \\
\text { such as Big Books }\end{array}$ & $1-6$ & $\begin{array}{c}0.04 \\
(0.05)\end{array}$ & $\begin{array}{c}0.06 \\
(0.07)\end{array}$ & 1 & -0.07 & 3543 & -1245700 \\
\hline $\begin{array}{l}\text { Listen to you read stories } \\
\text { where (he/she) doesn't see the } \\
\text { print. }\end{array}$ & $1-6$ & $\begin{array}{c}0.05 \\
(0.04)\end{array}$ & $\begin{array}{c}0.07 \\
(0.06)\end{array}$ & 1 & -0.12 & 3532 & -1313433 \\
\hline Retell or make up stories. & $1-6$ & $\begin{array}{c}0.05 \\
(0.05)\end{array}$ & $\begin{array}{c}0.07 \\
(0.07)\end{array}$ & 1 & -0.07 & 3535 & -1375566 \\
\hline $\begin{array}{l}\text { Show [CHILD] how to read a } \\
\text { book or magazine }\end{array}$ & $1-6$ & $\begin{array}{c}0.04 \\
(0.05)\end{array}$ & $\begin{array}{c}0.06 \\
(0.07)\end{array}$ & 1 & -0.07 & 3526 & -1348833 \\
\hline $\begin{array}{l}\text { Have }[\text { CHILD] practice } \\
\text { writing or spelling (his/her) } \\
\text { name. }\end{array}$ & $1-6$ & $\begin{array}{c}0.03 \\
(0.05)\end{array}$ & $\begin{array}{c}0.04 \\
(0.07)\end{array}$ & 1 & -0.04 & 3532 & -1015296 \\
\hline $\begin{array}{l}\text { Learn about rhyming words } \\
\text { and word families such as cat, } \\
\text { mat, sat. }\end{array}$ & $1-6$ & $\begin{array}{c}0.05 \\
(0.04)\end{array}$ & $\begin{array}{c}0.07 \\
(0.06)\end{array}$ & 1 & -0.06 & 3539 & -1313032 \\
\hline $\begin{array}{l}\text { Practice or teach directional } \\
\text { words such as over, up, or in. }\end{array}$ & $1-6$ & $\begin{array}{c}0.02 \\
(0.05)\end{array}$ & $\begin{array}{c}0.03 \\
(0.07)\end{array}$ & 1 & -0.09 & 3537 & -1343285 \\
\hline $\begin{array}{l}\text { Number of materials you use } \\
\text { to work on reading activities }\end{array}$ & $\begin{array}{l}\text { Contin- } \\
\text { uous }\end{array}$ & $\begin{array}{c}0.05 \\
(0.03)^{*}\end{array}$ & $\begin{array}{c}0.07 \\
(0.04)^{*}\end{array}$ & 1 & -0.01 & 3555 & 0.00 \\
\hline $\begin{array}{l}\text { Talk about the calendar or } \\
\text { days of the week. }\end{array}$ & $1-6$ & $\begin{array}{c}0.05 \\
(0.05)\end{array}$ & $\begin{array}{c}0.07 \\
(0.07)\end{array}$ & 1 & -0.03 & 3548 & -1231035 \\
\hline $\begin{array}{l}\text { Work with rulers, measuring } \\
\text { cups, spoons, or other } \\
\text { measuring instruments. }\end{array}$ & $1-6$ & $\begin{array}{c}0.11 \\
(0.05)^{* *}\end{array}$ & $\begin{array}{c}0.16 \\
(0.07)\end{array}$ & 1 & -0.08 & 3548 & -1310808 \\
\hline $\begin{array}{l}\text { Use dance or act out stories to } \\
\text { practice math ideas such as } \\
\text { numbers or size. }\end{array}$ & $1-6$ & $\begin{array}{c}0.10 \\
(0.05)^{*}\end{array}$ & $\begin{array}{c}0.15 \\
(0.07)^{*}\end{array}$ & 1 & -0.10 & 3539 & -1092651 \\
\hline
\end{tabular}


Appendix Table 2B (cont'd). Effect of treatment on parent involvement after experiment

\begin{tabular}{|c|c|c|c|c|c|c|c|}
\hline (1) Dependent Variable & $\begin{array}{l}(2) \\
\text { Scale }\end{array}$ & $\begin{array}{l}(3) \\
\text { Reduced } \\
\text { form }\end{array}$ & $\begin{array}{l}(4) \\
\text { IV }\end{array}$ & $\begin{array}{l}\text { (5) } \\
\text { Holm (p- } \\
\text { value) }\end{array}$ & $\begin{array}{l}(6) \\
\text { Lee } \\
\text { lower } \\
\text { bound }\end{array}$ & $\begin{array}{l}(7) \\
\mathrm{N}\end{array}$ & $\begin{array}{c}(8) \\
\text { R- } \\
\text { sq./loglik } \\
\text { eli-hood } \\
\end{array}$ \\
\hline \multicolumn{8}{|c|}{ Learning-related activities with the child (continued) } \\
\hline $\begin{array}{l}\text { Use music to understand math } \\
\text { ideas. }\end{array}$ & $1-6$ & $\begin{array}{c}0.14 \\
(0.05)^{* * *}\end{array}$ & $\begin{array}{c}0.21 \\
(0.07)^{* * *}\end{array}$ & 0.557 & -0.09 & 3527 & -1085386 \\
\hline Play math-related games & $1-6$ & $\begin{array}{c}0.09 \\
(0.05)^{* *}\end{array}$ & $\begin{array}{c}0.13 \\
(0.07)^{* *}\end{array}$ & 1 & -0.04 & 3532 & -1349387 \\
\hline $\begin{array}{l}\text { Count things such as small } \\
\text { toys or chips, to learn math }\end{array}$ & $1-6$ & $\begin{array}{c}0.07 \\
(0.03)^{* *}\end{array}$ & $\begin{array}{c}0.10 \\
(0.04)^{* *}\end{array}$ & 1 & -0.03 & 3545 & -1179669 \\
\hline Work with shape blocks. & $1-6$ & $\begin{array}{c}0.08 \\
(0.04)^{*}\end{array}$ & $\begin{array}{c}0.12 \\
(0.06)^{*}\end{array}$ & 1 & -0.06 & 3540 & -1345583 \\
\hline Count out loud. & $1-6$ & $\begin{array}{c}0.01 \\
(0.06)\end{array}$ & $\begin{array}{c}0.01 \\
(0.09)\end{array}$ & 1 & -0.07 & 3545 & -952843 \\
\hline $\begin{array}{l}\text { Number of materials parents } \\
\text { use to work on above math } \\
\text { activities }\end{array}$ & $\begin{array}{l}\text { Contin- } \\
\text { uous }\end{array}$ & $\begin{array}{l}-0.02 \\
(0.04)\end{array}$ & $\begin{array}{c}-0.03 \\
0.06\end{array}$ & 1 & -0.09 & 3555 & 0.00 \\
\hline $\begin{array}{l}\text { Practice reading, writing, or } \\
\text { working with numbers }\end{array}$ & $1-4$ & $\begin{array}{c}0.04 \\
(0.05)\end{array}$ & $\begin{array}{c}0.06 \\
(0.07)\end{array}$ & 1 & -0.05 & 3528 & -845417 \\
\hline Read books to child & $1-4$ & $\begin{array}{c}0.03 \\
(0.06)\end{array}$ & $\begin{array}{c}0.04 \\
(0.09)\end{array}$ & 1 & -0.08 & 3522 & -988111 \\
\hline Tell stories & $1-4$ & $\begin{array}{c}0.04 \\
(0.06)\end{array}$ & $\begin{array}{c}0.06 \\
(0.09)\end{array}$ & 1 & -0.13 & 3528 & -979109 \\
\hline Sing songs & $1-4$ & $\begin{array}{c}0.03 \\
(0.05)\end{array}$ & $\begin{array}{c}0.04 \\
(0.07)\end{array}$ & 1 & -0.11 & 3524 & -1043347 \\
\hline $\begin{array}{l}\text { Other activities with the child } \\
\text { Arts \& Crafts }\end{array}$ & $1-6$ & $\begin{array}{c}0.11 \\
(0.05)^{* *}\end{array}$ & $\begin{array}{c}0.16 \\
(0.07)^{* *}\end{array}$ & 1 & 0.00 & 3547 & -1373199 \\
\hline $\begin{array}{l}\text { Gone to a play, concert, or } \\
\text { other live show }\end{array}$ & Binary & $\begin{array}{c}0.08 \\
(0.05)\end{array}$ & $\begin{array}{c}0.12 \\
(0.07)\end{array}$ & 1 & -0.16 & 7078 & -839174 \\
\hline $\begin{array}{l}\text { Talked with [CHILD] about } \\
\text { family history or ethnic } \\
\text { heritage }\end{array}$ & Binary & $\begin{array}{c}0.04 \\
(0.04)\end{array}$ & $\begin{array}{c}0.06 \\
(0.06)\end{array}$ & 1 & -0.05 & 7077 & -1066449 \\
\hline $\begin{array}{l}\text { Visited an art gallery, } \\
\text { museum, or historical site }\end{array}$ & Binary & $\begin{array}{c}0.02 \\
(0.04)\end{array}$ & $\begin{array}{c}0.03 \\
(0.06)\end{array}$ & 1 & -0.23 & 7072 & -857878 \\
\hline $\begin{array}{l}\text { Attended an event sponsored } \\
\text { by a community, ethnic, or } \\
\text { religious group }\end{array}$ & Binary & $\begin{array}{l}0.05 \\
(0.05)\end{array}$ & $\begin{array}{c}0.07 \\
(0.07)\end{array}$ & 1 & -0.04 & 7079 & -1071292 \\
\hline $\begin{array}{l}\text { Talk about nature or do } \\
\text { science projects with } \\
\text { [CHILD] }\end{array}$ & $1-4$ & $\begin{array}{l}0.05 \\
(0.04)\end{array}$ & $\begin{array}{c}0.07 \\
(0.06)\end{array}$ & 1 & -0.19 & 3524 & -962962 \\
\hline $\begin{array}{l}\text { Play games or do puzzles with } \\
\text { [CHILD] }\end{array}$ & $1-4$ & $\begin{array}{c}0.05 \\
(0.05)\end{array}$ & $\begin{array}{c}0.07 \\
(0.07)\end{array}$ & 1 & -0.11 & 3519 & -1028164 \\
\hline $\begin{array}{l}\text { Build something or play with } \\
\text { construction toys with } \\
\text { [CHILD] }\end{array}$ & $1-4$ & $\begin{array}{l}0.08 \\
(0.05)\end{array}$ & $\begin{array}{c}0.12 \\
(0.07)\end{array}$ & 1 & -0.15 & 3522 & -990260 \\
\hline
\end{tabular}


Appendix Table 2B (continued). Effect of treatment on parent involvement after the experiment

\begin{tabular}{|c|c|c|c|c|c|c|c|}
\hline (1) Dependent Variable & $\begin{array}{l}(2) \\
\text { Scale }\end{array}$ & $\begin{array}{l}(3) \\
\text { Reduced } \\
\text { form }\end{array}$ & $\begin{array}{l}(4) \\
\text { IV }\end{array}$ & $\begin{array}{l}(5) \\
\text { Holm }(\mathrm{p}- \\
\text { value })\end{array}$ & $\begin{array}{l}(6) \\
\text { Lee } \\
\text { lower } \\
\text { bound }\end{array}$ & $\begin{array}{l}(7) \\
\mathrm{N}\end{array}$ & $\begin{array}{l}(8) \\
\text { R-sq./log } \\
\text { likeli- } \\
\text { hood } \\
\end{array}$ \\
\hline \multicolumn{8}{|c|}{ Other activities with the child (continued) } \\
\hline $\begin{array}{l}\text { Help [CHILD] do arts and } \\
\text { crafts }\end{array}$ & $1-4$ & $\begin{array}{c}0.04 \\
(0.04)\end{array}$ & $\begin{array}{c}0.06 \\
(0.06)\end{array}$ & 1 & -0.17 & 3516 & -990707 \\
\hline $\begin{array}{l}\text { Play a sport or exercise } \\
\text { together? }\end{array}$ & $1-4$ & $\begin{array}{c}0.00 \\
(0.06)\end{array}$ & $\begin{array}{c}0.00 \\
(0.09)\end{array}$ & 1 & -0.15 & 3521 & -1078834 \\
\hline $\begin{array}{l}\text { Involve [CHILD] in } \\
\text { household chores, like } \\
\text { cooking, cleaning, or caring } \\
\text { for pets }\end{array}$ & $1-4$ & $\begin{array}{c}0.10 \\
(0.05)^{*}\end{array}$ & $\begin{array}{c}0.15 \\
(0.07)^{*}\end{array}$ & 1 & 0.01 & 3526 & -888777 \\
\hline \multicolumn{8}{|c|}{ Qualitative features of parenting practices } \\
\hline $\begin{array}{l}\text { "I encourage my child to be } \\
\text { curious, to explore, and to } \\
\text { question things" }\end{array}$ & $1-5$ & $\begin{array}{c}0.13 \\
(0.04)^{* * *}\end{array}$ & $\begin{array}{c}0.19 \\
(0.06)^{* * *}\end{array}$ & 0.07 & 0.05 & 7047 & -1608804 \\
\hline $\begin{array}{l}\text { "Make sure my child knows I } \\
\text { appreciate what (he/she) tries } \\
\text { to accomplish." }\end{array}$ & $1-5$ & $\begin{array}{c}0.09 \\
(0.05)^{* *}\end{array}$ & $\begin{array}{c}0.13 \\
(0.07)^{* *}\end{array}$ & 1 & 0.03 & 7048 & -1118307 \\
\hline $\begin{array}{l}\text { "I encourage my child to be } \\
\text { independent of me." }\end{array}$ & $1-5$ & $\begin{array}{c}0.05 \\
(0.04)\end{array}$ & $\begin{array}{c}0.07 \\
(0.06)\end{array}$ & 1 & -0.03 & 7012 & -1778338 \\
\hline $\begin{array}{l}\text { "Once I decide how to deal } \\
\text { with misbehavior of child, I } \\
\text { follow through" }\end{array}$ & $1-5$ & $\begin{array}{c}0.08 \\
(0.04)^{* *}\end{array}$ & $\begin{array}{c}0.12 \\
(0.06)^{* * *}\end{array}$ & 1 & -0.02 & 7040 & -1970608 \\
\hline $\begin{array}{l}\text { "My child and I have warm } \\
\text { intimate moments together" }\end{array}$ & $1-5$ & $\begin{array}{c}0.02 \\
(0.05)\end{array}$ & $\begin{array}{c}0.03 \\
(0.07)\end{array}$ & 1 & -0.08 & 7056 & -2227240 \\
\hline $\begin{array}{l}\text { "There are times I don't have } \\
\text { the energy to make my child } \\
\text { behave as (he/she) should" }\end{array}$ & $1-5$ & $\begin{array}{c}0.02 \\
(0.04)\end{array}$ & $\begin{array}{c}0.03 \\
(0.06)\end{array}$ & 1 & -0.06 & 7045 & -1471852 \\
\hline $\begin{array}{l}\text { "Teach child that misbehavior } \\
\text { or breaking the rules will } \\
\text { always be punished" }\end{array}$ & $1-5$ & $\begin{array}{c}0.09 \\
(0.03)^{* *}\end{array}$ & $\begin{array}{c}0.13 \\
(0.04)^{* *}\end{array}$ & 0.872 & 0.00 & 7050 & -1883477 \\
\hline \multicolumn{8}{|l|}{ Medical } \\
\hline $\begin{array}{l}\text { Has [CHILD] been seen by a } \\
\text { dentist since September }\end{array}$ & Binary & $\begin{array}{c}0.07 \\
(0.04)^{*}\end{array}$ & $\begin{array}{c}0.10 \\
(0.06)^{*}\end{array}$ & 1 & -0.01 & 7064 & -963867 \\
\hline $\begin{array}{l}\text { Do you have a place where } \\
\text { you usually take [CHILD] for } \\
\text { routine medical care }\end{array}$ & Binary & $\begin{array}{c}0.08 \\
(0.07)\end{array}$ & $\begin{array}{c}0.12 \\
(0.10)\end{array}$ & 1 & 0.04 & 7075 & -204697 \\
\hline $\begin{array}{l}\text { Has a professional tested } \\
\text { [CHILD's] hearing }\end{array}$ & Binary & $\begin{array}{c}0.04 \\
(0.04)\end{array}$ & $\begin{array}{c}0.06 \\
(0.06)\end{array}$ & 1 & -0.02 & 6821 & -857457 \\
\hline $\begin{array}{l}\text { Has a professional tested } \\
\text { [CHILD's] vision }\end{array}$ & Binary & $\begin{array}{c}0.04 \\
(0.04)\end{array}$ & $\begin{array}{c}0.06 \\
(0.06)\end{array}$ & 1 & -0.01 & 6811 & -842408 \\
\hline
\end{tabular}


Appendix Table 2B (continued). Effect of treatment on parent involvement after the experiment

\begin{tabular}{|c|c|c|c|c|c|c|c|}
\hline (1) Dependent Variable & $\begin{array}{l}(2) \\
\text { Scale }\end{array}$ & $\begin{array}{l}\text { (3) } \\
\text { Reduced } \\
\text { form }\end{array}$ & $\begin{array}{l}(4) \\
\text { IV }\end{array}$ & $\begin{array}{l}(5) \\
\text { Holm } \\
\text { adjust- } \\
\text { ment (p- } \\
\text { value) }\end{array}$ & $\begin{array}{c}\text { (6) } \\
\text { Lee } \\
\text { lower } \\
\text { bound }\end{array}$ & $\begin{array}{l}(7) \\
N\end{array}$ & $\begin{array}{c}(8) \\
\text { R-sq./ } \\
\text { log- } \\
\text { likeli- } \\
\text { hood }\end{array}$ \\
\hline \multicolumn{8}{|l|}{ Father inputs } \\
\hline $\begin{array}{l}\text { In the past month, on about } \\
\text { how many days has [CHILD] } \\
\text { seen (his/her) father }\end{array}$ & $\begin{array}{l}\text { Contin- } \\
\text { uous }\end{array}$ & $\begin{array}{c}0.94 \\
(0.47)^{* *}\end{array}$ & $\begin{array}{c}1.38 \\
(0.69)^{* *}\end{array}$ & 1 & -1.83 & 3336 & 0.00 \\
\hline $\begin{array}{l}\text { Has your family received any } \\
\text { child support payments from } \\
\text { (his/her) father }\end{array}$ & Binary & $\begin{array}{l}-0.05 \\
(0.07)\end{array}$ & $\begin{array}{l}-0.07 \\
(0.10)\end{array}$ & 1 & -0.28 & 3357 & -515918 \\
\hline \multicolumn{8}{|l|}{ Rules or routines in the home } \\
\hline $\begin{array}{l}\text { Rules or routines about } \\
\text { bedtime }\end{array}$ & Binary & $\begin{array}{c}0.05 \\
(0.08)\end{array}$ & $\begin{array}{c}0.07 \\
(0.12)\end{array}$ & 1 & 0.00 & 7065 & -328548 \\
\hline $\begin{array}{l}\text { Rule or routines about TV } \\
\text { programs allowed to watch }\end{array}$ & Binary & $\begin{array}{c}0.21 \\
(0.05)^{* * * *}\end{array}$ & $\begin{array}{c}0.31 \\
(0.07) * * *\end{array}$ & 0.00 & 0.17 & 7034 & -521752 \\
\hline $\begin{array}{l}\text { Rules or routines about how } \\
\text { many hours of TV allowed to } \\
\text { watch }\end{array}$ & Binary & $\begin{array}{c}0.13 \\
(0.04)^{* * *}\end{array}$ & $\begin{array}{c}0.19 \\
(0.06)^{* * *}\end{array}$ & 0.07 & 0.06 & 7036 & -889820 \\
\hline $\begin{array}{l}\text { Rules or routines about what } \\
\text { kinds of food child eats }\end{array}$ & Binary & $\begin{array}{c}0.06 \\
(0.05)\end{array}$ & $\begin{array}{c}0.09 \\
(0.07)\end{array}$ & 1 & -0.02 & 7062 & -1028372 \\
\hline $\begin{array}{l}\text { Rules or routines about what } \\
\text { chores child does }\end{array}$ & Binary & $\begin{array}{l}0.06 \\
(0.05)\end{array}$ & $\begin{array}{c}0.09 \\
(0.07)\end{array}$ & 1 & 0.00 & 7061 & -789969 \\
\hline Parent Involvement in School & & & & 1 & & & \\
\hline $\begin{array}{l}\text { How often work with } \\
\text { [CHILD] on things he/she } \\
\text { learned in school }\end{array}$ & $1-6$ & $\begin{array}{c}0.02 \\
(0.05)\end{array}$ & $\begin{array}{c}0.03 \\
(0.07)\end{array}$ & 1 & -0.07 & 7054 & -1806621 \\
\hline $\begin{array}{l}\text { Mother attended general } \\
\text { school meeting }\end{array}$ & $1-6$ & $\begin{array}{l}-0.03 \\
(0.05)\end{array}$ & $\begin{array}{c}0.04 \\
(0.07)\end{array}$ & 1 & -0.09 & 6983 & -724537 \\
\hline $\begin{array}{l}\text { Mother gone to parent teacher } \\
\text { conference }\end{array}$ & $1-6$ & $\begin{array}{c}0.05 \\
(0.05)\end{array}$ & $\begin{array}{c}0.07 \\
(0.07)\end{array}$ & 1 & -0.01 & 6979 & -686689 \\
\hline $\begin{array}{l}\text { Mother attended a class event, } \\
\text { such as a play or sport event }\end{array}$ & $1-6$ & $\begin{array}{l}-0.05 \\
(0.04)\end{array}$ & $\begin{array}{l}-0.07 \\
(0.06)\end{array}$ & 1 & -0.14 & 6972 & -1007060 \\
\hline Mother volunteer at the school & & $\begin{array}{l}0.10 \\
(0.05)^{* * *}\end{array}$ & $\begin{array}{c}0.15 \\
(0.07)^{* *}\end{array}$ & 1 & -0.06 & 6962 & -1023060 \\
\hline $\begin{array}{l}\text { Father attended general school } \\
\text { meeting }\end{array}$ & $1-6$ & $\begin{array}{l}-0.03 \\
(0.05)\end{array}$ & $\begin{array}{l}-0.04 \\
(0.07)\end{array}$ & 1 & -0.19 & 6856 & -998523 \\
\hline $\begin{array}{l}\text { Father gone to parent teacher } \\
\text { conference }\end{array}$ & $1-6$ & $\begin{array}{l}-0.02 \\
(0.05)\end{array}$ & $\begin{array}{l}-0.03 \\
(0.07)\end{array}$ & 1 & -0.19 & 6860 & -972092 \\
\hline $\begin{array}{l}\text { Father attended a class event, } \\
\text { such as a play or sport event }\end{array}$ & $1-6$ & $\begin{array}{l}-0.03 \\
(0.05)\end{array}$ & $\begin{array}{l}-0.04 \\
(0.07)\end{array}$ & 1 & -0.21 & 6851 & -947169 \\
\hline Father volunteer at the school & $1-6$ & $\begin{array}{c}0.06 \\
(0.07)\end{array}$ & $\begin{array}{c}0.09 \\
(0.10)\end{array}$ & 1 & -0.76 & 6839 & -461697 \\
\hline
\end{tabular}


Appendix Table 2B (continued). Effect of treatment on parent involvement after the experiment

\begin{tabular}{|c|c|c|c|c|c|c|c|}
\hline (1) Dependent Variable & $\begin{array}{l}(2) \\
\text { Scale }\end{array}$ & $\begin{array}{c}(3) \\
\text { Reduced } \\
\text { form }\end{array}$ & $\begin{array}{l}\text { (4) } \\
\text { IV }\end{array}$ & $\begin{array}{l}\text { (5) } \\
\text { Holm }(\mathrm{p}- \\
\text { value })\end{array}$ & $\begin{array}{l}\text { (6) } \\
\text { Lee } \\
\text { lower } \\
\text { bound }\end{array}$ & $\begin{array}{l}(7) \\
\mathrm{N}\end{array}$ & $\begin{array}{c}(8) \\
\text { R-sq./ } \\
\text { loglikeli- } \\
\text { hood }\end{array}$ \\
\hline \multicolumn{8}{|c|}{ Teacher-and Interviewer-Reported Parent Involvement } \\
\hline Parent attend open house & Binary & $\begin{array}{l}-0.05 \\
(0.07)\end{array}$ & $\begin{array}{l}-0.07 \\
(0.10)\end{array}$ & 1 & -0.09 & 5360 & -639928 \\
\hline Have parents volunteered & Binary & $\begin{array}{c}0.00 \\
(0.05)\end{array}$ & $\begin{array}{c}0.00 \\
(0.07)\end{array}$ & 0.959 & -0.12 & 5353 & -980784 \\
\hline $\begin{array}{l}\text { Have parents met with teacher } \\
\text { and special needs team for } \\
\text { special needs children }\end{array}$ & Binary & $\begin{array}{c}0.32 \\
(0.15)^{* *}\end{array}$ & $\begin{array}{c}0.47 \\
(0.22)^{* *}\end{array}$ & 1 & 0.12 & 609 & -114614 \\
\hline $\begin{array}{l}\text { A variety of learning materials } \\
\text { are available }\end{array}$ & $1-7$ & $\begin{array}{c}0.06 \\
(0.04)\end{array}$ & $\begin{array}{c}0.09 \\
(0.06)\end{array}$ & 1 & -0.04 & 5908 & -10212 \\
\hline
\end{tabular}

Notes: Appendix Table 2 shows the coefficients and standard errors on the treatment dummy from OLS, probit, ordered probit, and two-stage least squares regressions of parent inputs on the treatment dummy. Column 1 shows the dependent variable in question. Column 2 shows the scale that the dependent variable takes. "Continuous" refers to dependent variables that can take on any value; otherwise, the range that the dependent variable can take is shown. A scale of "X$Y$ " means that the dependent variable can take on any integer value between the integers $\mathrm{X}$ and $Y$, inclusive. Column 3 shows the estimated coefficients and standard errors on the treatment dummy from the reduced form regression (3) without control variables. For continuous variables, we run OLS; for binary variables, we run probits; and for variables with multiple ordered outcomes, we run ordered probits. The probit and ordered probit results report coefficients on the treatment dummy (not marginal effects). Column 4 shows the estimated coefficients and standard errors on the treatment dummy from the IV estimates. For the continuous variables, we run twostage least squares as in regressions (1) and (2) without control variables. For the categorical outcomes, we take the coefficient estimates from the probit and ordered probit regressions in Column 3 and calculate the Wald estimate by multiplying the estimated coefficients by $1.47=1 / 0.68$, where 0.68 is the first-stage coefficient from the regression of the HS enrollment dummy on the HS access dummy (with no controls). Column 5 shows the estimated p-value associated with the coefficient estimate after performing the Holm adjustment to account for multiple comparisons. We do not perform a Holm adjustment for the variable measuring time spent reading because we construct this variable using the variables included in the basic data; the results are very similar after performing this adjustment, as well (and the coefficient on treatment remains significantly different from 0 at the 5\% level). Column 6 shows the lower bound on the estimated reduced form treatment effect in Column 3, after performing the trimming procedure of Lee (2009) to address missing data. Column 7 shows the number of observations in the regressions. Column 8 reports the R-squared for OLS regressions and the log-likelihood for probit and ordered probit regressions. Standard errors are clustered at the level of the program. All observations are weighted by the final parent weights, except the teacher-reported variables, which are weighted by teacher interview weights. *** denotes significance at the $1 \%$ level; ** at the $5 \%$ level; * at the $10 \%$ level. 
Appendix Table 3. Factor Analysis

\begin{tabular}{|c|c|c|c|c|c|}
\hline $\begin{array}{l}\text { (1) Dependent } \\
\text { variable }\end{array}$ & $\begin{array}{l}\text { (2) Treatment } \\
\text { Effect }\end{array}$ & $\begin{array}{c}\text { (3) Holm } \\
\text { adjustment (p- } \\
\text { value) }\end{array}$ & $\begin{array}{l}\text { (4) Lee lower } \\
\text { bound }\end{array}$ & $(5) \mathrm{N}$ & (6) R-squared \\
\hline \multicolumn{6}{|c|}{ Panel A: Fall 2002} \\
\hline Factor 1 & $\begin{array}{c}0.28 \\
(0.06)^{* * *}\end{array}$ & 0.00 & 0.00 & 3441 & 0.01 \\
\hline Factor 2 & $\begin{array}{c}0.02 \\
(0.04) \\
\end{array}$ & 0.51 & -0.15 & 3441 & 0.00 \\
\hline \multicolumn{6}{|c|}{ Panel B: Spring 2003} \\
\hline Factor 1 & $\begin{array}{c}0.36 \\
(0.07)^{* * *}\end{array}$ & 0.00 & 0.11 & 3367 & 0.02 \\
\hline Factor 2 & $\begin{array}{c}0.12 \\
(0.05)^{* *}\end{array}$ & 0.06 & -0.03 & 3367 & 0.00 \\
\hline Factor 3 & $\begin{array}{c}0.10 \\
(0.06) \\
\end{array}$ & 0.21 & -0.08 & 3367 & 0.00 \\
\hline \multicolumn{6}{|c|}{ Panel C: Spring 2004-5 } \\
\hline Factor 1 & $\begin{array}{c}0.15 \\
(0.06)^{* *}\end{array}$ & 0.17 & -0.03 & 3087 & 0.00 \\
\hline Factor 2 & $\begin{array}{c}0.00 \\
(0.06)\end{array}$ & 0.88 & -0.16 & 3087 & 0.00 \\
\hline Factor 3 & $\begin{array}{c}0.11 \\
(0.05)^{* * *}\end{array}$ & 0.19 & -0.04 & 3087 & 0.00 \\
\hline Factor 4 & $\begin{array}{c}0.07 \\
(0.06)\end{array}$ & 0.66 & -0.09 & 3087 & 0.00 \\
\hline Factor 5 & $\begin{array}{c}0.08 \\
(0.05)^{*}\end{array}$ & 0.46 & -0.03 & 3087 & 0.00 \\
\hline \multicolumn{6}{|c|}{ Panel D: Spring 2005-6 } \\
\hline Factor 1 & $\begin{array}{c}0.10 \\
(0.07)\end{array}$ & 0.62 & -0.02 & 3212 & 0.00 \\
\hline Factor 2 & $\begin{array}{l}-0.07 \\
(0.07)\end{array}$ & 0.69 & -0.14 & 3212 & 0.00 \\
\hline Factor 3 & $\begin{array}{c}0.13 \\
(0.06)^{* *}\end{array}$ & 0.33 & 0.00 & 3212 & 0.00 \\
\hline Factor 4 & $\begin{array}{c}0.09 \\
(0.04)^{*}\end{array}$ & 0.35 & -0.01 & 3212 & 0.00 \\
\hline
\end{tabular}

Notes: Appendix Table 3 shows the results of a factor analysis of the depenent variable. To perform this analysis, we first pool all of the dependent variables together and extract the principal components, and then we use the Kaiser criterion to keep factors whose eigenvalues are greater than 1 . We do so separately for each of the periods during which the dependent variables are observed. This yields two factors in Fall 2002; four factors in Spring 2003; six factors in Spring 2004-5; and five factors in Spring 2005-6. We then regress each of the factors on the Head Start dummy, instrumenting for Head Start enrollment with HS access. Column 2 shows the coefficients and standard errors on the treatment dummy from this regression. Standard errors are clustered at the level of the program. All observations are weighted by the final parent weights. Column 3 shows the p-values after performing the Holm adjustment. Column 4 shows the lower bound on the estimated treatment effect after performing the trimming procedure of Lee (2009) to address missing data. Column 5 shows the number of observations in the regressions. Column 6 reports the R-squared. *** denotes significance at the $1 \%$ level; *** at the $5 \%$ level; * at the $10 \%$ level. 
Appendix Table 4. Effect of HS on other outcomes. The table shows coefficients and standard errors on the treatment dummy from IV regressions of parent involvement on HS enrollment. Dependent variables are listed in column headings

\begin{tabular}{lcccc}
\hline & $\begin{array}{c}(1) \\
\text { Cog. } \\
\text { scores }\end{array}$ & $\begin{array}{c}(2) \\
\text { Non- } \\
\text { cog. } \\
\text { scores }\end{array}$ & $\begin{array}{c}\text { Father } \\
\text { lives in } \\
\text { home }\end{array}$ & $\begin{array}{c}\text { Special } \\
\text { needs } \\
\text { child }\end{array}$ \\
\hline $\begin{array}{l}\text { Panel A: During } \\
\text { HS }\end{array}$ & $\begin{array}{cccc}(22 \\
\text { enrollment }\end{array}$ & $\begin{array}{c}0.09 \\
(.06)^{* * *}\end{array}$ & $\begin{array}{c}-.04 \\
(0.05)^{*}\end{array}$ & -- \\
\hline $\mathrm{N}$ & $40,04)$ & 32,002 & 7273 & -- \\
\hline $\begin{array}{l}\text { Panel B: After } \\
\text { HS }\end{array}$ & 0.02 & 0.01 & -0.02 & 0.007 \\
enrollment & $(.05)$ & $(.03)$ & $(.03)$ & $(0.016)$ \\
\hline $\mathrm{N}$ & 64,506 & 137,280 & 7,090 & 5,364 \\
\hline \hline
\end{tabular}

Notes: The table shows the results of regressions in which additional outcomes of interest are related to HS enrollment through the two-stage least squares regressions (1) and (2). The dependent variable in question is listed in each column heading. Panel A shows results for the During period, and Panel B shows results for the After period. Standard errors are clustered at the level of the program. All observations are weighted by the final parent weights. In Column 1, the dependent variable is child cognitive scores. In Column 2, the dependent variable is child non-cognitive scores. Cognitive and non-cognitive scores have been normalized to have mean zero and standard deviation 1 (as described in the Appendix) and stacked in these regressions. In Column 3, the dependent variable is a dummy that equals 1 if the father lives in the home and 0 otherwise. In Column 4, the dependent variable is "In the past month, on about how many days has [CHILD] seen (his/her) father." The results are extremely similar when controlling for the covariates included in Columns 2 and 5 of Table 2. *** denotes significance at the $1 \%$ level; ** at the $5 \%$ level; and $*$ at the $10 \%$ level. 
Appendix Table 5. Correlation of program effects on cognitive scores and parent involvement. Table shows coefficients and standard errors from OLS (regression (9)) or two-stage least squares regressions (regressions (10) and (11)). The dependent variable in Columns 1-6 is formed by pooling measures of parent involvement and is formed in Column 7 by pooling cognitive score measures

\begin{tabular}{|c|c|c|c|c|c|c|c|}
\hline & (1) RF & (2) RF & (3) RF & (4) $2 \mathrm{SLS}$ & (5) 2 SLS & (6) 2 SLS & (7) $\mathrm{RF}$ \\
\hline \multicolumn{8}{|l|}{ Panel A: During } \\
\hline Coeff. on Program & 0.25 & -- & 0.23 & 0.21 & 0.16 & 0.16 & -- \\
\hline Quality (Cog.) & $(0.09) * * *$ & & $(0.09)^{* *}$ & $(0.10)^{* *}$ & $(0.04) * * *$ & $(0.04) * * *$ & \\
\hline Coefficient on & -- & -- & -- & -- & -- & -- & 0.38 \\
\hline Parent Inputs & & & & & & & $(0.12)^{* * *}$ \\
\hline Coeff. on Prog. & -- & 0.13 & 0.06 & 0.07 & 0.05 & 0.04 & -- \\
\hline Quality (Non-cog.) & & $(0.09)$ & $(0.09)$ & $(0.10)$ & $(0.05)$ & $(0.05)$ & \\
\hline $\begin{array}{l}\text { IV for parent- } \\
\text { reported measures }\end{array}$ & & & & & $\mathrm{X}$ & $\mathrm{X}$ & \\
\hline Control for labor & & & & & & $\mathrm{X}$ & \\
\hline force participation & & & & & & & \\
\hline $\begin{array}{l}\text { Avg. effect of center } \\
\text { measures }\end{array}$ & -- & -- & -- & -- & $\begin{array}{c}0.01 \\
(0.01)\end{array}$ & $\begin{array}{c}0.01 \\
(0.01)\end{array}$ & -- \\
\hline $\begin{array}{l}\text { F-statistic on reports } \\
\text { (p-value) }\end{array}$ & -- & -- & -- & -- & $\begin{array}{c}0.91 \\
(0.51)\end{array}$ & $\begin{array}{c}0.93 \\
(0.50)\end{array}$ & -- \\
\hline \multicolumn{8}{|l|}{ Panel B: After } \\
\hline Coeff. on Prog. & 0.14 & -- & 0.11 & 0.08 & 0.09 & 0.11 & -- \\
\hline Quality (Cog.) & $(0.07)^{*}$ & & $(0.07)$ & $(0.05)$ & $(0.02) * * *$ & $(0.02)^{* * *}$ & \\
\hline Coefficient on & -- & -- & -- & -- & -- & -- & 0.22 \\
\hline Parent Inputs & & & & & & & $(0.09)^{* *}$ \\
\hline Coeff. on Prog. & -- & $0.13^{*}$ & 0.09 & 0.12 & 0.12 & 0.11 & -- \\
\hline Quality (Non-cog.) & & $(0.07)$ & $(0.07)$ & $(0.08)$ & $(0.03) * * *$ & $(0.03) * * *$ & \\
\hline $\begin{array}{l}\text { IV for parent- } \\
\text { reported measures }\end{array}$ & & & & & $\mathrm{X}$ & $\mathrm{X}$ & \\
\hline $\begin{array}{l}\text { Control for labor } \\
\text { force participation }\end{array}$ & & & & & & $\mathrm{X}$ & \\
\hline $\begin{array}{l}\text { Avg. effect of center } \\
\text { measures }\end{array}$ & -- & -- & -- & -- & $\begin{array}{c}0.001 \\
(0.011)\end{array}$ & $\begin{array}{c}0.005 \\
(0.012)\end{array}$ & -- \\
\hline $\begin{array}{l}\text { F-statistic on reports } \\
\text { (p-value) }\end{array}$ & -- & -- & -- & -- & $\begin{array}{l}1.06 \\
(0.36)\end{array}$ & $\begin{array}{l}1.07 \\
(0.39)\end{array}$ & -- \\
\hline
\end{tabular}

Notes: In Column 1, we run reduced-form regression (9) from Appendix C. In Column 2, we run this regression except that the measure of program quality is formed using child non-cognitive scores. Column 3 adds both cognitive and non-cognitive scores. Column 4 shows the results from two-stage least squares regressions (10) and (11). Column 5 additionally instruments for the eight measures of HS center-encouraged parent involvement reported by parents (listed in Appendix C), using the 58 measures of center parent-related activity reported by center directors. Column 6 additionally controls for measures of parents' labor force participation. In Columns 4-6, the first stage F-statistics corresponding to the endogenous variables are typically over 100. In Column 7 , we effectively run the regression in reverse: the dependent variable is formed by pooling cognitive score measures, and the independent variable of interest is a measure of program quality formed using measures of parent involvement. "RF" denotes reduced form. "Cognitive scores" refers to the mean for each child of all 11 normalized cognitive score measures, listed in Appendix A. All of these results are nearly identical when we control for the covariates included in some specifications in Table 2. Standard errors are clustered at the level of the program. All observations are weighted by the final parent weights. N=257,704 in Columns 1-6 and 39,268 in Column 7 in the During period; $N=300,063$ in Columns 1-6 and 36,949 in Column 7 in the After period. 3,688 unique individuals are included in the regressions in the During period, and 3,456 unique individuals are included in the regressions in the After period. The sample size is slightly smaller than in Tables 2 and 4 because cognitive scores are sometimes missing for fellow program designees. $* * *$ denotes significance at the $1 \%$ level; $* *$ at the $5 \%$ level; * at the $10 \%$ level. 


\begin{tabular}{|c|c|c|c|}
\hline (1) Dependent var. & $\begin{array}{l}\text { (2) Coeff. on HS } \\
\text { Enrollment Dummy }\end{array}$ & $\begin{array}{c}\text { (3) Mean of } \\
\text { dependent variable }\end{array}$ & (4) $\mathrm{N}$ \\
\hline \multicolumn{4}{|l|}{ Panel A: Parent variables } \\
\hline $\begin{array}{l}\text { (A) Monthly } \\
\text { childcare expenses (\$) }\end{array}$ & $\begin{array}{c}-28.31 \\
(8.27)^{* * *}\end{array}$ & 37.45 & 3,696 \\
\hline $\begin{array}{l}\text { (B) Mother LFP } \\
\text { during }\end{array}$ & $\begin{array}{l}-0.04 \\
(0.03)\end{array}$ & 0.52 & 3,445 \\
\hline $\begin{array}{l}\text { (C) Father LFP } \\
\text { during }\end{array}$ & $\begin{array}{c}0.05 \\
(0.03)^{*}\end{array}$ & 0.89 & 1,743 \\
\hline (D) Mother LFP after & $\begin{array}{l}-0.01 \\
(0.03)\end{array}$ & 0.57 & 6,471 \\
\hline (E) Father LFP after & $\begin{array}{c}0.02 \\
(0.02) \\
\end{array}$ & 0.94 & 3,192 \\
\hline \multicolumn{4}{|l|}{ Panel B: Child variables } \\
\hline $\begin{array}{l}\text { (F) Hrs. of non-parent } \\
\text { care (inc. HS) }\end{array}$ & $\begin{array}{c}11.71 \\
(1.12)^{* * *}\end{array}$ & 22.10 & 3,696 \\
\hline $\begin{array}{l}\text { (G) Hrs. of ctr-based } \\
\text { daycare (non-HS) }\end{array}$ & $\begin{array}{c}-6.08 \\
(0.86)^{* * *}\end{array}$ & 4.71 & 3,696 \\
\hline $\begin{array}{l}\text { (H) Hrs. at a day care } \\
\text { home }\end{array}$ & $\begin{array}{c}-2.81 \\
(0.56)^{* * *}\end{array}$ & 1.71 & 3,696 \\
\hline $\begin{array}{l}\text { (I) Hrs. with non- } \\
\text { parent relatives }\end{array}$ & $\begin{array}{c}-2.87 \\
(0.67)^{* * *}\end{array}$ & 2.59 & 3,696 \\
\hline
\end{tabular}

Notes: The dependent variable in each row is listed in Column 1. Column 2 shows coefficients and standard errors on the treatment dummy from a regression of the outcome variable in question on the treatment dummy. In Rows B through E, we run probits of the outcome on the Head Start access dummy, and we form the reported Wald estimate of the effect by dividing this reduced form estimate of the effect of HS access on the outcome by the first stage coefficient on the treatment dummy. In Rows B through E, we report marginal effects on the dependent variable (rather than coefficients). In other rows, we show two stage least squares estimates. The measures of children's time in Rows F-I are all in weekly terms. The sample sizes differ across dependent variables in part because the After period contains more observations than the During period (since the questions were usually asked in more time periods in the After period), and in part because the amount of missing data differs across variables. Standard errors are clustered at the level of the program. All observations for parents are weighted by the final parent weights, and observations for children are weighted by the final child weights. *** denotes significance at the $1 \%$ level; $* *$ at the $5 \%$ level; * at the $10 \%$ level. 